The Promises of Fibre-Optic Broadband in Tourism and Tea Sectors: A Pipeline for Economic Development in East Africa

Timothy Waema and Charles Katua School of Computing and Informatics University of Nairobi

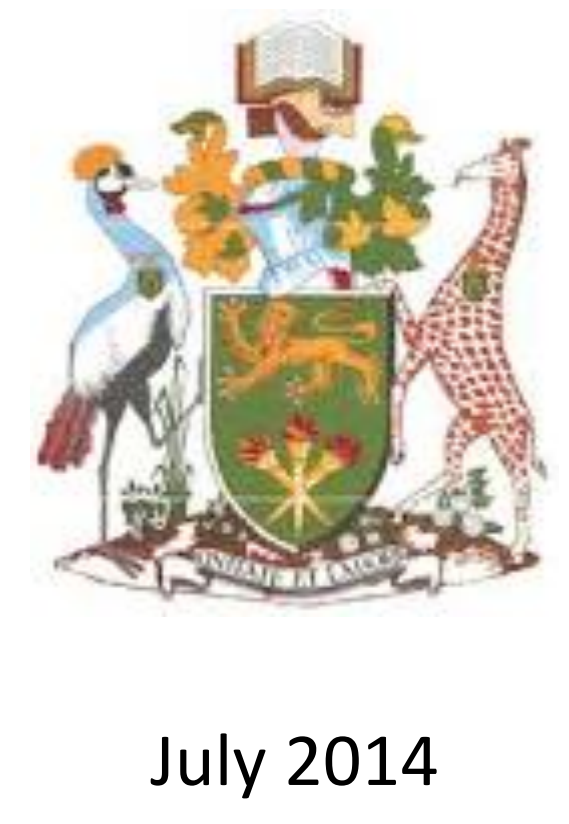




\section{Table of Contents}

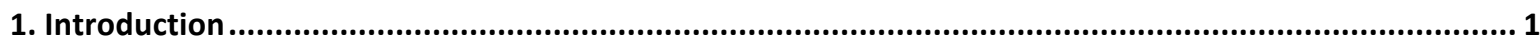

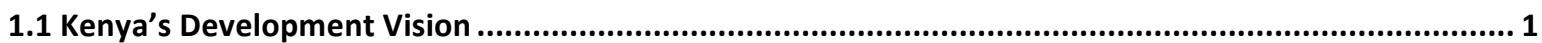

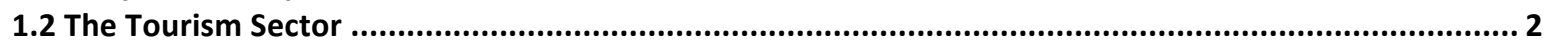

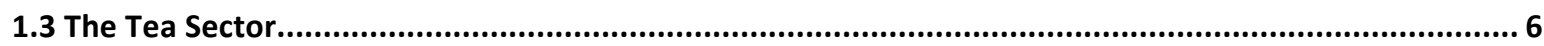

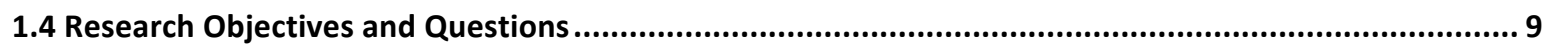

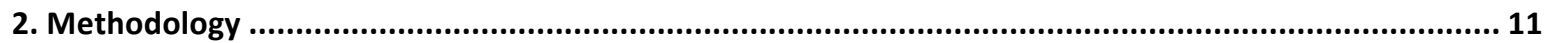

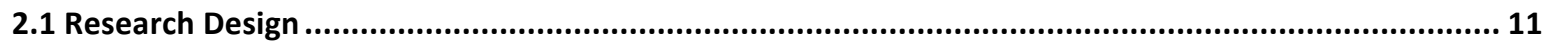

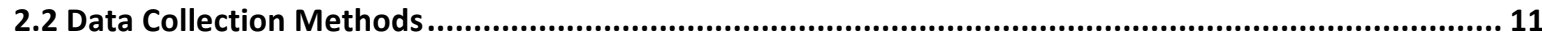

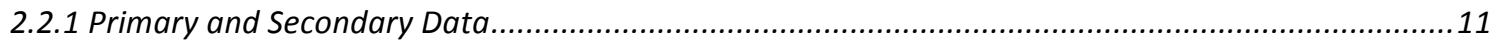

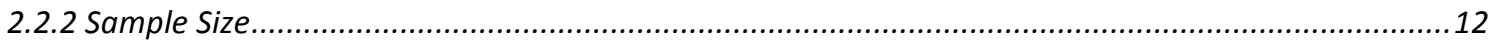

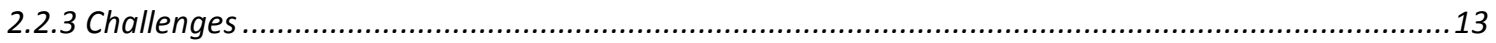

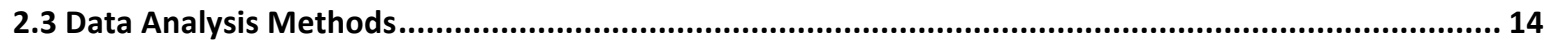

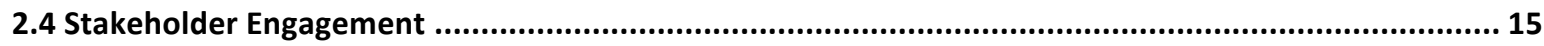

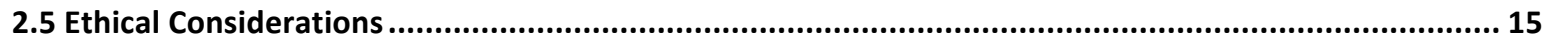

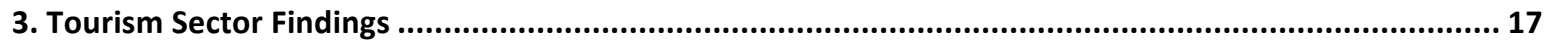

3.1 Anticipated Effects of Broadband as Represented in Political and Public Discourse (RQ1).................. 17

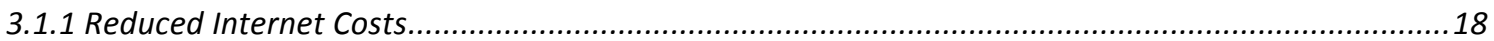

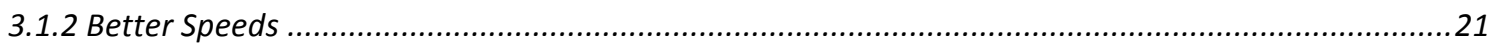

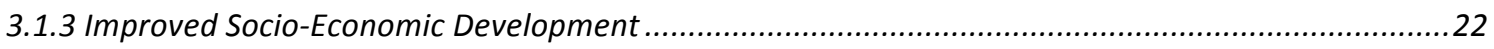

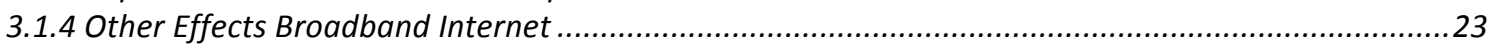

3.2 Integration of Broadband Internet and Related ICTs into Tourism Value Chains (RQ2)........................ 25

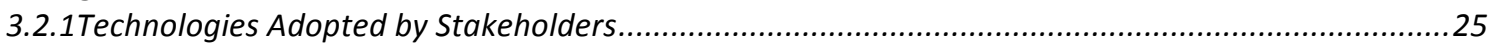

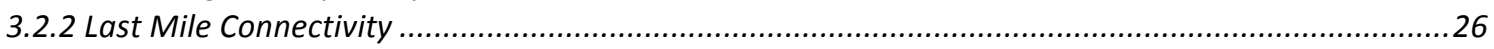

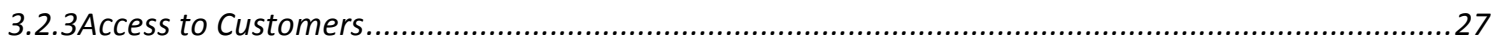

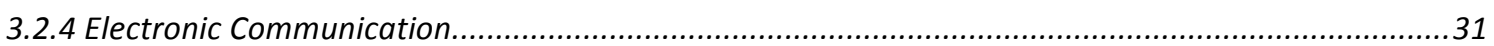

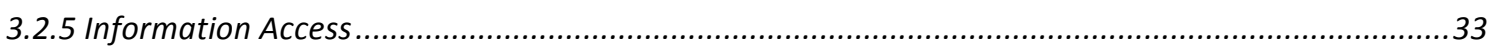

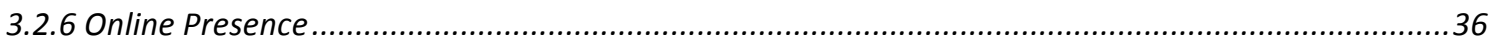

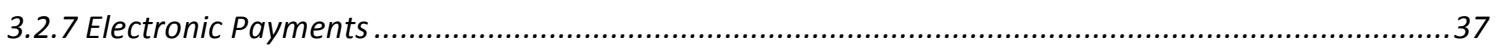

3.3 Unexpected Challenges to Broadband Use (RQ3)................................................................................. 39

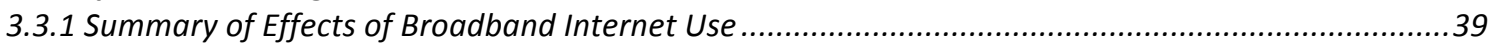

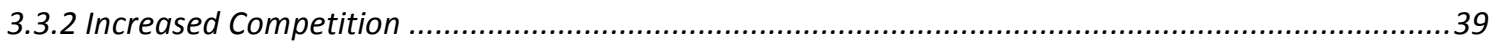

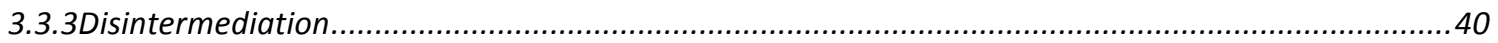

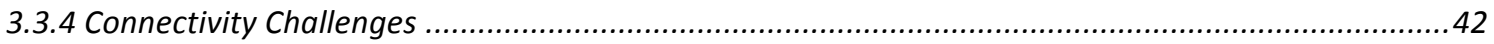

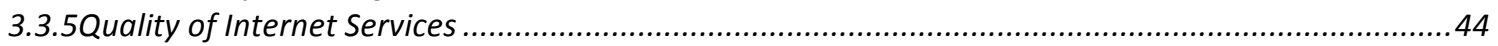

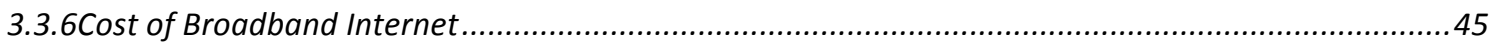

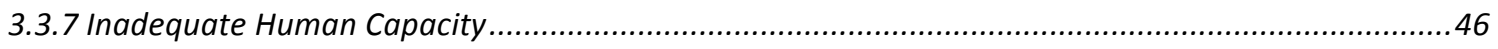

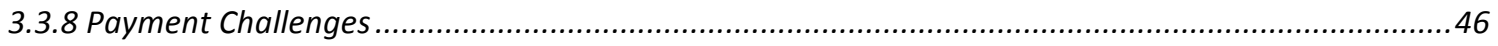

3.4 Socio-Economic Impacts on Economic Actors (RQ4) ............................................................................ 49

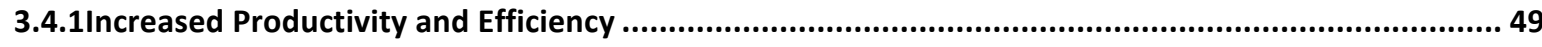

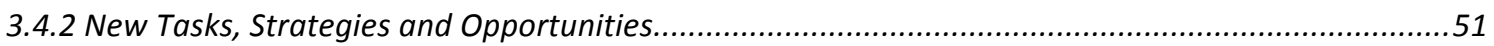

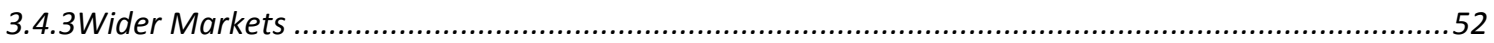

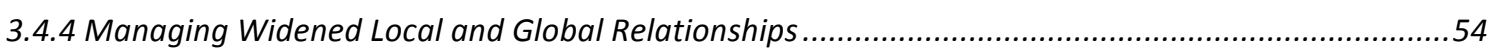

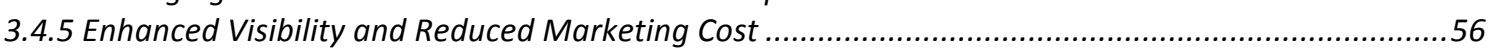

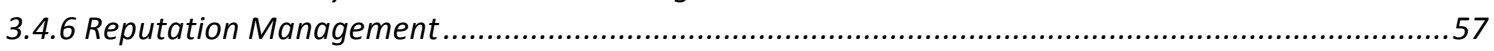

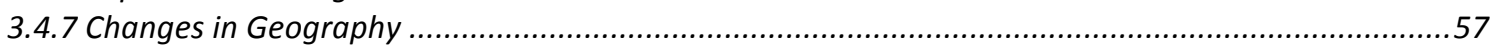

3.5 How Actual Changes Differ from Academic, Public and Political Discourses Surrounding Potential

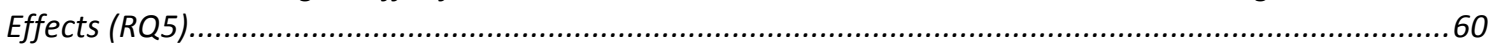

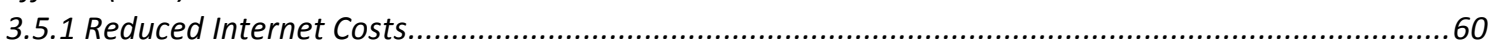

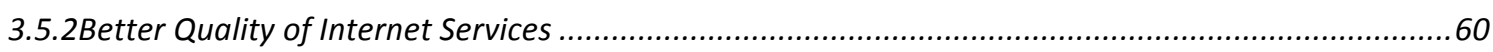

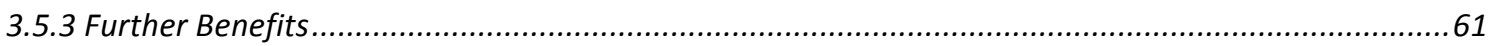




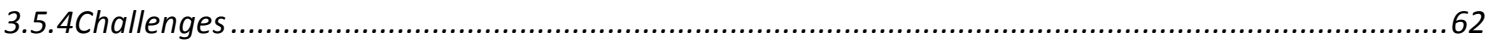

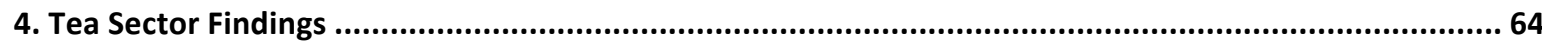

4.1 Integration of Broadband Internet and Related ICTs into Tea Value Chains (RQ2)............................6.6.

4.1.1 Last Mile Connectivity ....................................................................................................6

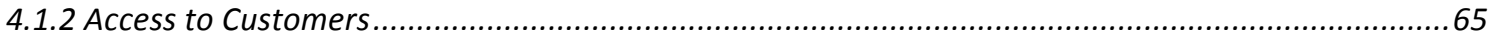

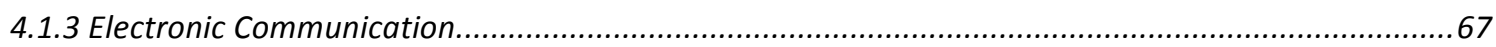

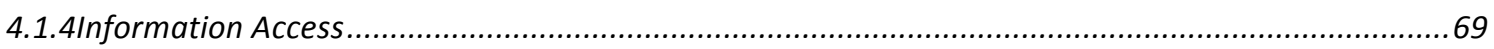

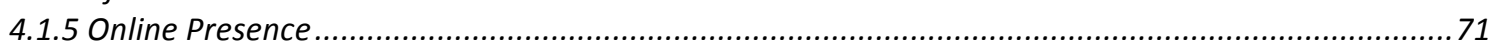

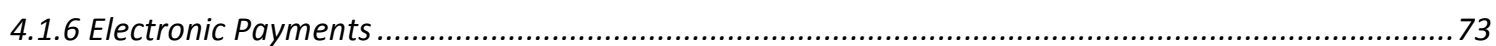

4.2 Unexpected Challenges to Broadband Use (RQ3).....................................................................75

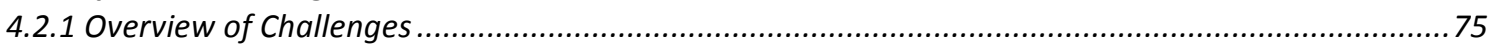

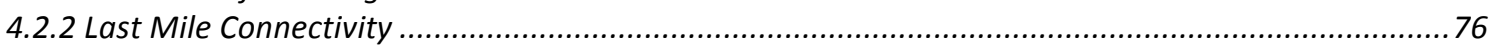

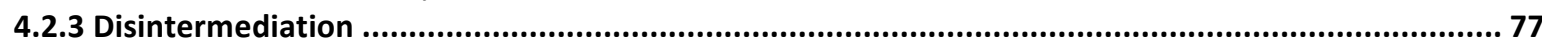

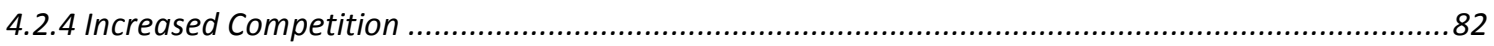

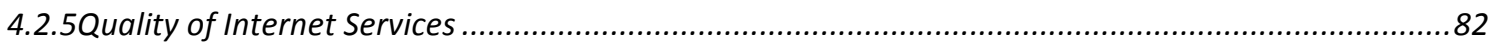

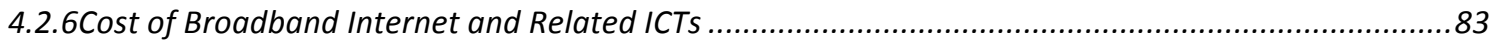

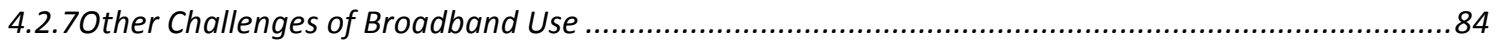

4.3 Socio-Economic Impacts on Economic Actors (RQ4) ......................................................... 86

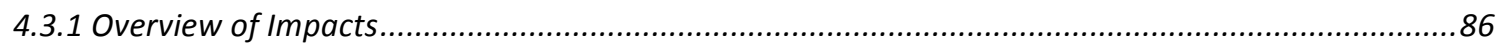

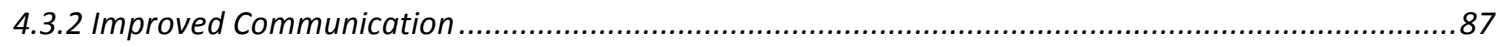

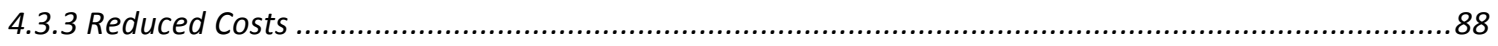

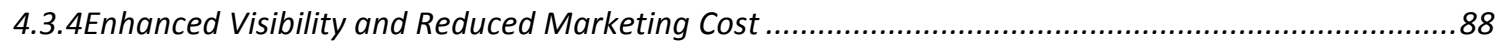

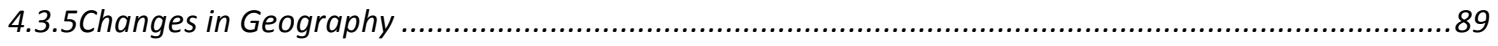

4.3.6 Further Impacts ...........................................................................................................99

4.4 How Actual Changes Differ from Academic, Public and Political Discourses Surrounding Potential

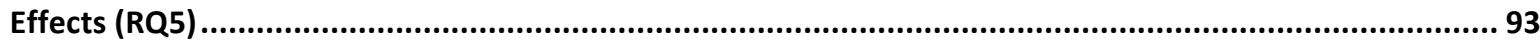

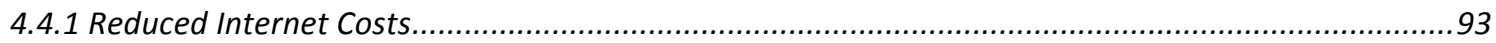

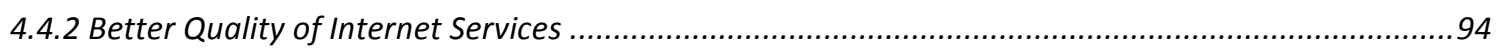

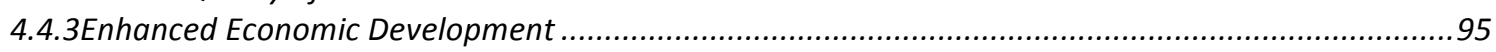

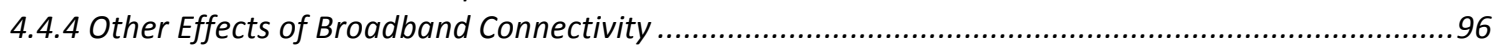

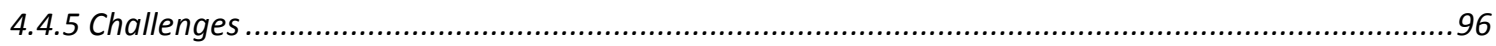

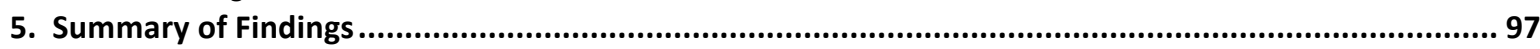

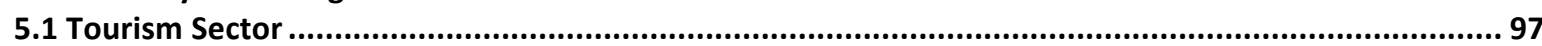

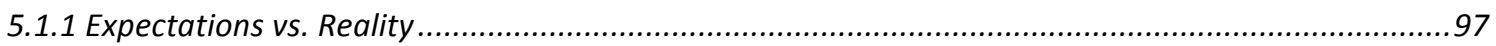

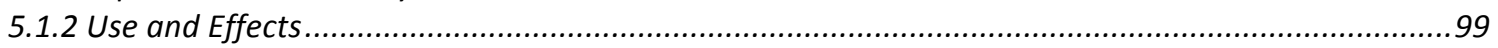

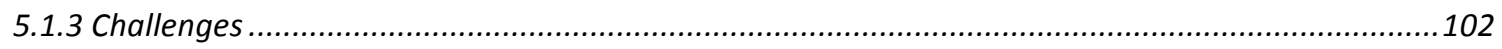

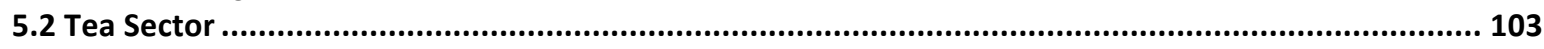

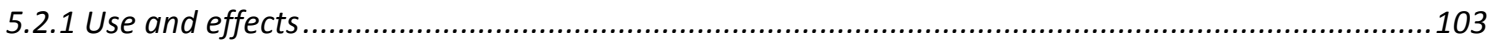

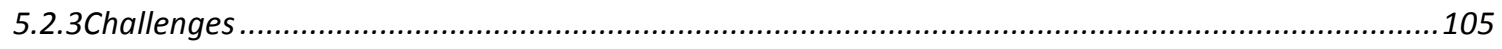

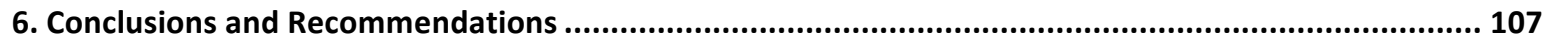

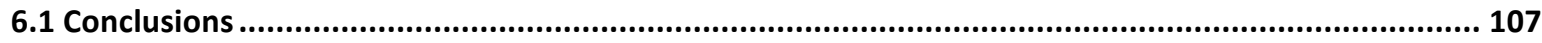

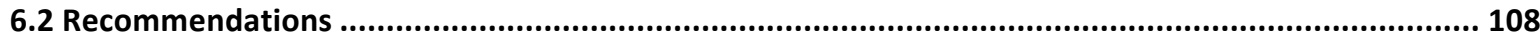

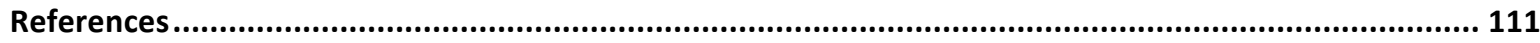




\section{Introduction}

\subsection{Kenya's Development Vision}

The Kenya Vision 2030 is the national long-term development blue-print that aims to transform the country into a modern, globally competitive, middle-income country offering a high quality of life for all citizens by 2030. The vision was planned to be implemented through a succession of five-year Medium Term Plans (MTPs). The first MTP (2008-2012) implemented the first five years of the vision. The vision comprises of three key pillars: economic, social, and political. The Economic Pillar aims to achieve an average economic growth rate of $10 \%$ per annum and sustaining the same until 2030 . The Social Pillar seeks to engender just, cohesive and equitable social development in a clean and secure environment while the Political Pillar aims to realize an issue-based, peoplecentred, result-oriented and accountable democratic system.

The theme of the second MTP, which coincides with the coming into power of a new government after the 2013 elections, is "Transforming Kenya: Pathway to Devolution, Socio-Economic Development, Equity and National Unity," running for the 2013-2017 period. The MTP gives priority to devolution as spelt out in the Kenya Constitution2010 and to more rapid socio-economic development with equity as a tool for building national unity. The second MTP also aims to build on the successes of the first MTP, particularly in increasing the scale and pace of economic transformation through infrastructure development, and strategic emphasis on priority sectors under the economic and social pillars of Vision 2030, as the second MTP explains (GoK, 2013):

Under this MTP, transformation of the economy is pegged on rapid economic growth on a stable macro-economic environment, modernization of infrastructure, diversification and commercialization of agriculture, food security, a higher contribution of manufacturing to our GDP, wider access to African and global markets, wider access for Kenyans to better quality education and health care, job creation targeting unemployed youth, provision of better housing and provision of improved water sources and sanitation to Kenyan households that presently lack these.

The overall aim of the plan is that by 2018 Kenyan families will have experienced a positive transformation in their earnings and quality of their livelihoods, and Kenya will be a more united, more prosperous society commanding respect in Africa and the world.

The Economic Pillar is the most relevant to this study. The vision of this pillar, which aims at increasing the annual GDP growth rates to an average of $10 \%$ over the vision horizon, is "adding value to our products and services." The vision prioritizes six key sectors as the key growth drivers for achievement of the economic vision: tourism, agriculture, 
wholesale and retail trade, manufacturing, business process outsourcing (BPO) and financial sectors. In tourism, the key goals in the first MTP (2008-2012) were (GoK, 2007):

- quadruple tourism's GDP contribution to more than KES 200 billion,

- raise international visitors from 1.6 million in 2006 to 3 million in 2012, while raising average spent per visitor from the present KES 40,000 to at least KES70,000, and

- increase hotel beds, combined with an emphasis on a high quality service, from 40,000 to at least 65,000 .

The thrust of the strategy in the agriculture sector was to add value to Kenyan agricultural products before they reach the market, and thus become more competitive. This was to be accomplished through an innovative, modern and commercially oriented agriculture, livestock and fisheries sector. These interventions were expected to generate an additional KES 80-90 billion increase in GDP, mainly through better yields in key crops, increased small-holder specialization in the cash crop sector (2-3 crops per plot), utilization of a million hectares of uncultivated land, and new cultivation of up to 1.2 million hectares of newly-opened lands (GoK, 2007).

\subsection{The Tourism Sector}

\section{Policy and Legal Framework}

Previously the tourism sector relied on outdated and fragmented policy and legal instruments. These include Sessional Paper No. 8 of 1969 on Development of Tourism in Kenya, Tourist Industry Licensing Act (TILA) Cap 381 of 1968, Hotels \& Restaurants Act (HRA) Cap 494 of 1972,KTDC Act 1967; Wildlife Act Cap 376. Some of the documents were not institutionalized by the ministry, but some recommendations were implemented piecemeal. Consequently, there was a need for harmonization of policies and legislation.

In 2003, the government came up with the Economic Recovery Strategy for Wealth \& Employment Creation Strategy (ERS). The ERS recognized that tourism can offer a good platform for encouraging local economic development. Once again, the tourism sector is identified as one of the key six growth sectors in the economic pillars of Vision 2030. A number of flagship projects are envisioned to facilitate the realization of these goals.

Various policy initiatives have been formulated in an effort aimed at actualizing the flagship projects identified under Vision 2030 such as the Sessional Paper No.1 of 2010 on Enhancing Sustainable Tourism in Kenya and the Tourism Act 2011. The Tourism Act 2011, which became operational in September 2012, provides for the development, management, marketing and regulation of sustainable tourism and tourism-related activities and services and allied purposes.

Among other things, the act provides for 
- a national tourism strategy,

- subsidiary Legislation,

- guidelines, rules and regulations,

- guidelines and measures for sustainable tourism,

- criteria for standardization and classification,

- hospitality and tourism curriculum for training industry professionals,

- code of practice for the tourism sector,

- tourism research,

- fiscal/tax incentives and disincentives, and

- prohibition and offences relating to pollution.

\section{Role of Information and Communication Technology (ICT)}

ICT has become an almost universal feature of the tourism industry. It allows information to be dispersed almost instantly to a wider audience that is spread globally. This has had an effect in the methods of operation in the tourism industry.

Information and communication technologies (ICTs) and related technologies have changed the way people communicate, search for information, make decisions, and, particularly, buy goods and services. The Internet enables buyers to shop for competitive prices and, thus, are less loyal to a specific supplier because of their ability to shift to a supplier who can meet their requirements. In the tourism sector, tourists and travellers are able to contact suppliers or travel agents directly-that is, without having to go through intermediaries. ICTs and related technologies allow both new and existing actors in the tourism industry to market their products and services to a wider audience at reduced costs.

ICTs can be powerful strategic and tactical tools for organizations which, if properly applied and used, can bring great benefits in promoting and strengthening competitiveness. In the tourism sector, we found that broadband Internet and related technologies have led to increased competition, thereby leading to price wars and increasing the bargaining power of buyers. At the same time, they have decreased the bargaining power of suppliers as they have reduced the need to buy from only a few suppliers.

\section{Existing Tourism Value Chain}

The tourism value chain is composed of tourism products, tourism suppliers and tourism consumers. As the tourism products pass through all activities of the chain in order, the product gains some value. Figure1.1 shows a typical tourism value chain with different levels of tourism enterprises and how value is added to a tourism product through its specific role differentiation and professional advantage. All these form part of the holiday 
product or package that is expected by tourists when they purchase holidays-whether or whether not a supplier of the components is directly contracted by a tourist.

The tourism value chain below covers all stakeholders involved in delivering a tourism experience: tourists, travel agents (domestic and international), tour operators (domestic and international), ancillary service providers (ASPs), and tourism destination and accommodation facilities.

\section{Figure 1.1: Existing Tourism Value Chain}

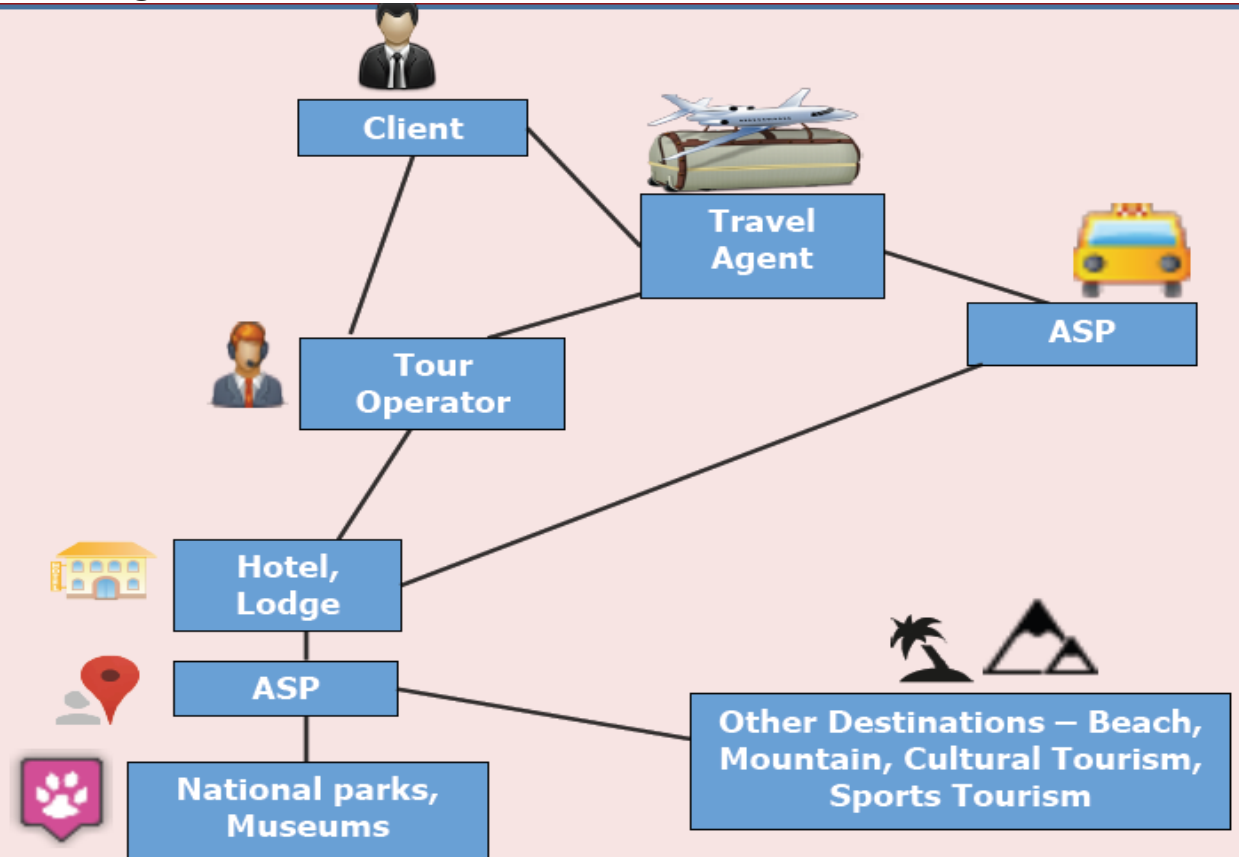

ASP -Ancillary Service Providers (Taxi, Car Hire, Beach Operators, Tour Guides, Arts and Crafts Operators)

Source: Authors

The tourism sector contains a fairly large number of actors in its value chain. As a crosscutting sector, tourism requires multi-stakeholder arrangements to be effective. The key actors in the vertical relationship involve everything from the suppliers to the customer (tourist). The key actors in the vertical relationship can be characterized as travel agents, tour operators, tourism destinations, accommodation services, transport providers and ASPs (see table 1.1). These actors, each of whom has own primary suppliers, produce a tourism service that is offered to customers. Table 1.1 shows actors, and their interrelationships, in the tourism sector. 
Table 1.1: Schematic Representation of Tourism Actors

\begin{tabular}{|c|c|c|}
\hline Actor Network & Actor & Description \\
\hline Tour Operators & $\begin{array}{l}\text { Inbound tour operators and } \\
\text { outbound tour operators }\end{array}$ & $\begin{array}{l}\text { - Combining different tourism-related services to a } \\
\text { sellable tourism product and distribution of the } \\
\text { product to other intermediaries or directly to } \\
\text { end consumer }\end{array}$ \\
\hline Travel Agent & $\begin{array}{l}\text { Local travel agents and } \\
\text { international travel agents }\end{array}$ & $\begin{array}{l}\text { - Link between tour operators and customers } \\
\text { - Provide customers with information, advice and } \\
\text { professional guidance on the choice of a holiday } \\
\text { or purchase product } \\
\text { - Sell holidays and associated products }\end{array}$ \\
\hline $\begin{array}{l}\text { Tourism } \\
\text { Destination }\end{array}$ & $\begin{array}{l}\text { Beach, cultural tourism, } \\
\text { sports tourism, national } \\
\text { parks and reserves, nature } \\
\text { parks, museums, wildlife } \\
\text { conservancies... }\end{array}$ & $\begin{array}{l}\text { - Service provision for tourism experience (nature, } \\
\text { culture, entertainment) }\end{array}$ \\
\hline $\begin{array}{l}\text { Accommodation } \\
\text { Facilities/ } \\
\text { Services }\end{array}$ & $\begin{array}{l}\text { Private villas, resorts, } \\
\text { hotels, lodges, camps, home } \\
\text { stays... }\end{array}$ & $\begin{array}{l}\text { - Service provision for tourist temporary stay in } \\
\text { destination }\end{array}$ \\
\hline $\begin{array}{l}\text { Transport } \\
\text { providers and } \\
\text { ASPs }\end{array}$ & $\begin{array}{l}\text { Airlines, ferry operators, car } \\
\text { hire companies, rail } \\
\text { companies, taxis, } \\
\text { professional guides... }\end{array}$ & $\begin{array}{l}\text { Provision of transport and logistics services to } \\
\text { tourists, they offer any form of transport to } \\
\text { tourists. } \\
\text { - Provision of tourist guiding services such as } \\
\text { guides and tour directors }\end{array}$ \\
\hline Customers & International/local tourists & $\begin{array}{l}\text { - They are the final customers of the tourist } \\
\text { services. They have expectations of good service, } \\
\text { quality products and services, and protection } \\
\text { from improper business practice. }\end{array}$ \\
\hline
\end{tabular}

Source: Authors 


\subsection{The Tea Sector}

\section{Policy and Legal Framework}

The tea industry operates under a legal framework dominated by the Tea Act (Cap. 343 of the Laws of Kenya) and the Agriculture Act (Cap. 318). The Tea Act establishes the Tea Board of Kenya and vests in it authority to oversee the sector through licensing, planting, cultivating, processing and exporting tea. The board is responsible for the promotion of Kenyan tea abroad and funding research.

The Agriculture Act gives the Kenya Tea Development Authority (KTDA) a legal monopoly and exclusive control over the provision of extension services, planting materials, fertilizers, green leaf collection, quality control, processing and marketing of smallholder tea.

The sector operates under the Ministry of Agriculture which provides technical and policy guidance. The Tea Board of Kenya as the regulatory body licenses all the producers, tea processing factories, the tea trade and blending and packing enterprises in the tea value chain.

Marketing of tea is independently carried out by tea trade members who include producers, buyers and brokers.

\section{Role of Information and Communication Technology (ICT)}

Today, ICT is used extensively as a "diffusion tool" to reach and share information, knowledge and resources efficiently and effectively in any field (Bouman et al., 2004; Warren, 2002). The tea industry is no exception to this.

The adoption of ICTs is a means to enable businesses to compete on a global scale with improved efficiency and closer customer and supplier relationship (Chong et al., 2007). In addition, ICTs play a major role in diffusing information to actors in the tea value chain. A respondent from a Tea Cooperative in Kericho supported this position by saying:

We make decisions through information, so it is the backbone. That information would give us the market value of the tea which would give us a better bargaining power with the processors. Actually we would say that information is what has grown our tea prices because first of all the quality of tea we are supplying now is not the quality of tea we used to supply then. There has been improvement in the quality. This is because there were channels to relay information to the particular farmers on good agricultural practices and their plucking systems and all that which produces good products which sell. Also the information about our products in the international market makes the international market want to buy from us which increases our sales in turn. 
Actors in the tea value chain can market their tea to a wider audience that is globally distributed through online marketing models, including e-markets and online auctions. Online marketing can have many benefits, including reduced transaction costs, disintermediation or the emergence of new types of Internet-based intermediaries, price transparency, and the possible re-distribution of earnings along the supply chain. In Kenya, we found that close to $95 \%$ of the tea produced is sold through the tea auction and therefore these benefits are far from being realized.

ICTs have made it possible for actors in the tea value chain to have access to agricultural information, allowing farmers to make informed decisions about how to price their products and where to sell their produce without having to meet their buyers. With market information available online, farmers are empowered to sell their produce at fairly rewarding prices, fetching more money to improve their living standards.

\section{Stakeholders in the Tea Value Chain}

Figure 1.2 shows the tea value chain from production to marketing, that is, from the farmer to the ultimate exporter, first domestic market operator, first international market operator and final consumer. The tea value chain is composed of a number of stakeholders who control and add value along the value chain.

Figure 1.2: Existing Tea Value Chain

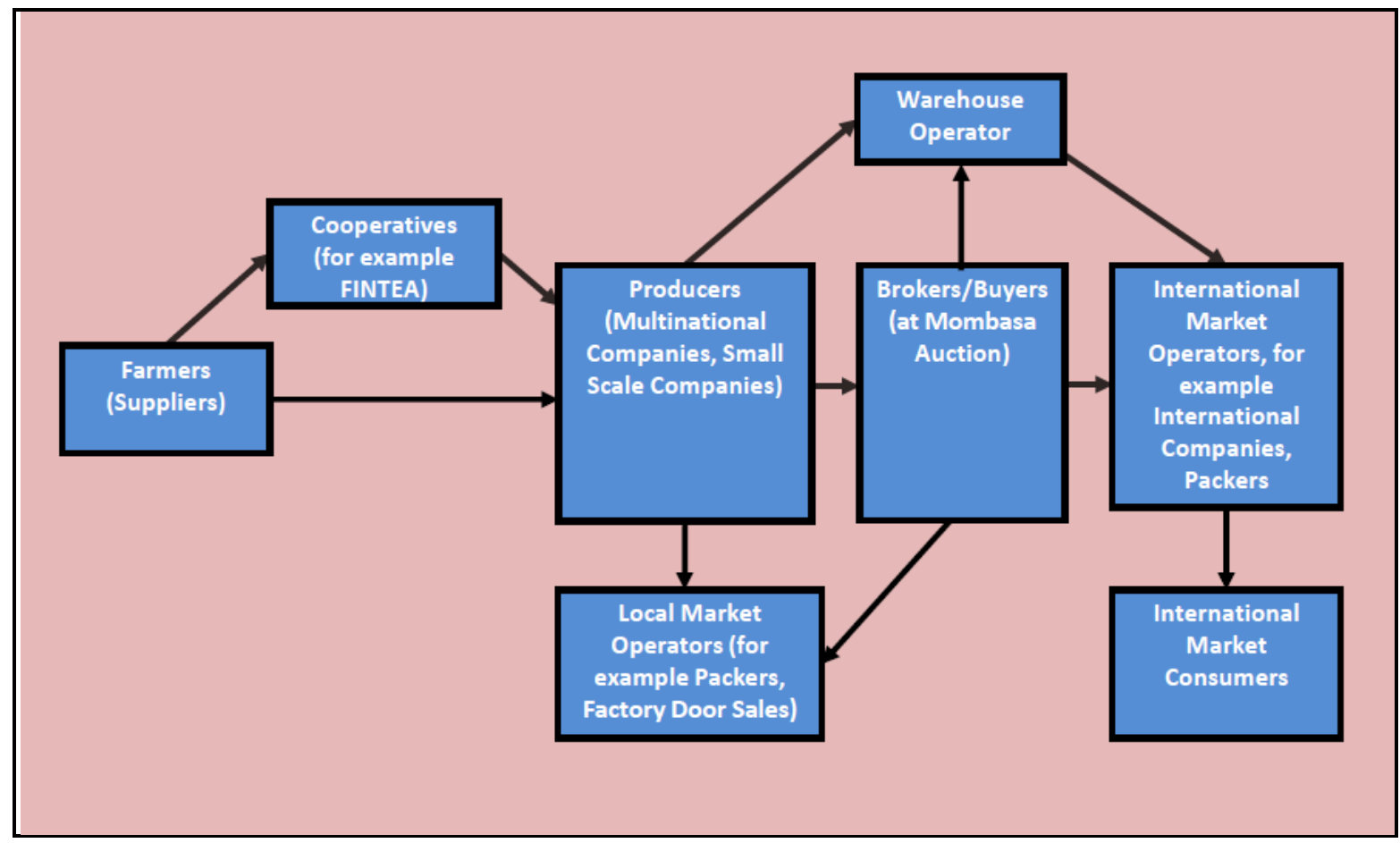

Source: Authors 
The tea sector in Kenya consists of a number of actors' networks: the farmers/suppliers, cooperatives, processors, packers, buyers, brokers, and consumers. The vertical relationship involves everything from the farm to the export. A brief description of each actor and enabler is presented in table 2.2.

Table 2.2: Schematic Representation of Tea Actors

\begin{tabular}{|c|c|c|}
\hline Actor Network & Actors & Description \\
\hline Farmers/growers/cooperatives/producers & $\begin{array}{l}\text { Plantations, } \\
\text { private estates, } \\
\text { small scale } \\
\text { growers }\end{array}$ & $\begin{array}{l}\text { - Cultivation and harvesting in } \\
\text { farms } \\
\text { - Field inspection and crop } \\
\text { maintenance } \\
\text { - Harvesting with standards } \\
\text { agreed with company } \\
\text { - Transportation of the harvest } \\
\text { to factory or closest collection } \\
\text { point } \\
\text { Quality control during } \\
\text { transportation and at the } \\
\text { weighing points }\end{array}$ \\
\hline Processors & $\begin{array}{l}\text { Small-, } \\
\text { medium- and } \\
\text { large-scale } \\
\text { processors }\end{array}$ & - Processing of green leaf tea \\
\hline Traders & $\begin{array}{l}\text { Auction (East } \\
\text { African Tea } \\
\text { Trade } \\
\text { Association), } \\
\text { warehouse } \\
\text { operators, and } \\
\text { brokers }\end{array}$ & 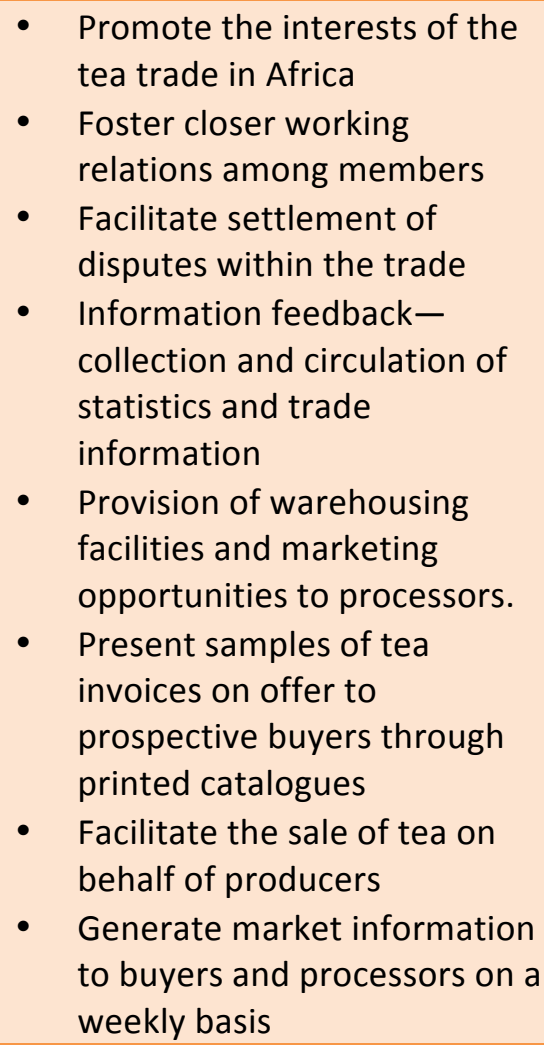 \\
\hline Wholesalers & Buyers & - Purchase bulk tea from \\
\hline
\end{tabular}




\begin{tabular}{|c|c|c|}
\hline & & $\begin{array}{l}\text { different processors at } \\
\text { the auction } \\
\text { - Shipment of tea worldwide } \\
\text { - Quality control and } \\
\text { monitoring }\end{array}$ \\
\hline Retailers & $\begin{array}{l}\text { Blenders, } \\
\text { packers }\end{array}$ & $\begin{array}{l}\text { - } \text { Blending of bulk teas into } \\
\text { branded tea } \\
\text { - } \quad \text { Packaging and value addition } \\
\text { - Marketing and advertising } \\
\text { products } \\
\text { - Quality control and } \\
\text { monitoring }\end{array}$ \\
\hline Consumers & $\begin{array}{l}\text { International } \\
\text { and domestic } \\
\text { consumers }\end{array}$ & - Purchasing tea from retailers \\
\hline
\end{tabular}

Source: Authors

\subsection{Research Objectives and Questions}

The research set out to examine how broadband Internet and related ICTs have impacted on tourism and tea value chains in Kenya. The study compared the period before and after the fibre optic broadband Internet arrived in Kenya in 2009-2010 to unravel how these technological infrastructures and related technologies transformed tourism and tea sectors.

The overall research objective was to expand our understanding of the social and economic impacts of ICTs in the context of development. The research sought to answer the following questions:

a) How are the potential effects of the East African fibre optic link represented in political and public discourse in Kenya and Rwanda?

b) How are ICTs, including mobile devices, old satellite and new broadband Internet connectivity, variably integrated into value chains and flows of knowledge, commodities and capital?

c) Are any sectors characterized by innovative uses of broadband connectivity or unexpected challenges to broadband use?

d) How are changes in the use of methods of communication and Internet access linked to altered socio-economic conditions of economic actors?

e) How do those changes differ from academic, public and political discourses surrounding potential effects?

This chapter has given a general context of the research carried out and introduced the report. The next chapter provides the methodology that was followed. It describes the 
research design, sampling, data collection and analysis methods and ethical considerations. Chapter three presents the findings for tourism and tea sectors. The findings are arranged according to the five research questions. Chapter four gives a summary of the findings and briefly discusses them in the context of findings by other researchers. The final chapter gives conclusions and implications for policy makers. 


\section{Methodology}

This chapter outlines the research methodology that was adopted for this study. The chapter describes the research design, the data collection methods, sampling, qualitative data analysis and ethical considerations.

\subsection{Research Design}

To answer the research questions, the study adopted a qualitative approach to collect primary data. Qualitative research is an unstructured and exploratory methodology used to provide insight and understanding of responses from qualitative interviews. The qualitative approach has been used in this study because of its ability to investigate in detail human subject motivation and actions within a research study, thus providing indepth understanding of the phenomena under study.

To answer the research questions, three stages of work were followed. Stage 1 entailed developing a policy map of ICT policies for the mobile and broadband sectors in Kenya. Stage 2 involved conducting content and discourse analysis of documents and websites pertaining to the effects of the East African fibre optic cables published by international agencies, government agencies, representatives of the tea and tourism industries, as well as local and international media. Stage 3 consisted of a detailed survey containing standardized and open-ended questions in about 78organizations in the two sectors. We interviewed 15 tourists using a simple interview guide. Drafts of the survey instruments had already been field-tested in preliminary fieldwork.

\subsection{Data Collection Methods}

\subsubsection{Primary and Secondary Data}

\section{Interviews}

The research project employed interviews as the main data-collection method, supplemented with secondary data. Semi-structured interviews were conducted in participants' places of work and an interview guide with a list of guiding questions was used with the intention of giving an interviewee a wide scope in which to respond. All respondents were asked the same questions. The order of asking these questions was determined by the flow of an interviewee's story.

\section{Secondary Data}

Data was collected by reviewing secondary data comprising the Tourism Act 2011 and the National Tourism Strategy 2013-2018 for the tourism sector, the Tea Act and the Agriculture Act for the tea sector, and the Kenya Vision 2030. Further secondary data 
sources include Google Scholar, online journals, and websites. The main purpose of collecting the secondary data was to discover existing work that may have already investigated how broadband Internet and related ICTs have impacted on the tourism and tea value chains.

\subsubsection{Sample Size}

\section{Sample of Tourism Actors}

The participants of the study included big and small economic actors, as well as foreign and local operators, in the industry so as to make our sample more representative of the tourism sector. They participants involved were tour operators, travel agents, tourism destinations (hotels chains, lodges, villas, and national parks), ASPs (taxi operators, tour guides, car hire companies and beach operators), and tourism associations.

Initial interviews were held with sector associations to give an overview of the sector and to assist in recruiting institutions to participate in the study. Once an in-depth understanding of the sector was secured through these initial interviews with key sector associations, the procedure of reaching individual respondents to make up the sample for the study was based on convenience sampling. Some of the interviews were facilitated by key senior managers in the industry.

In total, data was collected through an exploratory survey of 38 organizations in the tourism sector in Kenya. These comprised tour operators in Nairobi, travel agencies in Nairobi, hotels in Nairobi and Malindi, taxi operators in Nairobi and Malindi, beach operators in Malindi, national parks (the Tsavo West National Park and the Malindi Marine Park), tour guides in Nairobi and the national parks and ASPs in Nairobi and Malindi. In the sampled organizations, interviews were held with sales managers, directors, general managers or deputy general managers.

\section{Sample of Tea Actors}

The identification and the selection of research participants were done in consultation with the research teams from the University of Oxford, the National University of Rwanda and the University of Nairobi. Convenience sampling was used in selecting the final respondents who participated in the study after holding interviews with a number of individuals who understood the tea sector. A number of interviews were facilitated by some key senior managers in the tea sector. These are the actors who were the focus of this research:

- growers,

- cooperatives, associations, and small-, medium- and large-scale processors,

- buyers,

- brokers,

- warehouse operators, 
- transporters,

- blenders/packers,

- tea solution provider, and

- a value chain specialist.

In total, in-depth and open-ended interviews were held with 38 value chain agents. Care was taken to ensure that a representative sample participates in the research project. The specific people interviewed were:

- input suppliers/producers (factory unit managers, factory system administrators, marketing managers and production managers) in Nairobi and its environs, Mt Kenya region (Nyeri, Embu, and Meru) and west of the Rift Valley region (Kericho),

- warehouse operators (managing directors),

- buyers (operations directors),

- brokers (managing directors),

- heads of tea associations (heads of ICT, heads of marketing),

- transporter (ICT managers), and

- representatives of cooperatives.

Interviews and interactions were mainly focused on how faster Internet had impacted on the value chains of actors in the tea sector, whether faster Internet had enabled them get more clients directly, or whether the faster Internet had cut off or reduced the need for intermediaries in the sector. Interviews lasted between one hour and two hours. All interviews were recorded using voice recorders and supplemented by field notes.

\subsubsection{Challenges}

There were challenges with implications for the process of data collection although they did not compromise the quality of the findings of this study. It is possible that companies which were significantly impacted or were not impacted on by faster Internet did not participate in the study. The effect of this was reduced by focusing on both large and small actors in tourism and tea sectors. In addition, some respondents were less conversant with the area of study. In such cases, they were faced with challenges in answering questions or gave contradicting statements. We addressed this problem by asking respondents to recommend technical and business-oriented personnel before or after the interviews. This request was granted in most cases. Further, we faced a challenge in contacting actors in the two sectors - a challenge we addressed by obtaining letters of introduction from key informants in the respective sectors and we were allowed to conduct our study. 


\subsection{Data Analysis Methods}

The purpose of the interviews was to gather valid and reliable data that was relevant to the research questions. The authors began with an exploratory analysis. Once an interview was complete, the interview data was transcribed. For the exploratory analysis, the authors reviewed transcripts of interviews several times to summarize key points and identify themes.

All textual resources and interview transcripts were analysed using Atlas.ti, a computerbased tool used for code-based searching and reporting. This analysis started with open coding, a process of identifying, naming, categorizing and describing phenomena found in the dataset based on a general familiarity with the dataset. The final code tables developed for each sector are shown in annex 1.

To ensure data coding reliability, we used two coders (the research assistant and the principal investigator) open-coding the same dataset and checking the agreement between the two coders for all the categories identified. The process is detailed in annex 2. From this annex, it can be observed that for the first transcript, the Kappa measures for the codes was 0.37, indicating fair agreement between the two coders. The Kappa measure for the themes was higher at 0.42 , indicating moderate agreement.

The coding team discussed differences in coding. This resulted in new codes being introduced, some codes being merged, or codes being split, among others, with mutual agreement. The coders' understanding of the coding process was also expected to improve since they shared reasons they coded some transcript lines as they did, thus increasing chances of convergence in their coding.

When the process of coding was repeated with another transcript chosen at random, the annex shows there was an improvement in agreement from the first round of coding to the next one. In terms of how coding had been done among the two coders (codes), inter-coder agreement increased from 0.37 to 0.58 ; 0.58 indicates that the agreement had improved from fair to moderate. The agreement between the coders in identifying the themes manifesting in a particular line of transcript improved also from 0.42 to 0.80 . The new level of agreement of 0.80 indicates that the agreement had improved from moderate to good.

The two coders again discussed their coding. In cases of disagreement, each coder indicated why coding had been done the way it had been done. This led to a further refinement of the codes. The new set of codes is shown in annex 1 and was used to code the rest of the transcripts.

Established techniques of content analysis were employed to allow a qualitative and quantitative interpretation of relations between categories and emergent themes. The 
analysis of the coded datasets was therefore largely an inductive process in which we combined some elements of a deductive approach (Yin, 2003).

The analysis of the data was guided by the five research questions given in chapter 1 and went beyond the dataset obtained through field data collection. With the first research question, for example, the analysis focused on anticipated effects of the fibre broadband infrastructure as represented in the political and public discourse. With the fifth research question, the analysis allowed a comparison between written statements and ideas about possible effects of broadband Internet from the first research question with actual experiences by respondents interviewed from research questions 2 and 3.

\subsection{Stakeholder Engagement}

Given the significance of stakeholder engagement, two workshops were held in May ( 9 and 10 May 2013) and December (4 and 5 December 2013), where all the stakeholders in were invited to discuss the impact of broadband Internet. The first set of the tourism and the tea sectors meetings in May presented preliminary findings, and the second set of the tourism and the tea sectors meetings in December presented the full findings, conclusions and recommendations. These focus group meetings were characterized by lively discussions on the impact of broadband Internet and related technologies in the two sectors. The discussions focused on technology uses and its effects, current and expected value chains, intermediation and disintermediation, and increased competition.

\subsection{Ethical Considerations}

A number of ethical considerations were taken into account throughout the study. A letter of consent was sent by email to participants in the research. Once permission was granted, respondents received an overview on the nature and purpose of the research under study. The participants were assured of confidentially to make them more comfortable in sharing and explaining their personal views (Cobb \& Forbes, 2002). The participants had a right, and the freedom to decline at any time, to participate in the research.

The anonymity of participants was protected as individuals were not identified at any point during the study. Interview transcripts were assigned codes which were then used when presenting transcript quotations in the report of the findings.

The participants were informed via email about interview dates. The interviews were recorded with a digital voice recorder, with permission of an interviewee, and later transcribed verbatim. When transcribing the interviews, participants' names were replaced with code numbers. The interview transcripts were then analysed thematically and interrogated to identify and determine the most dominant concepts found in the 
dataset using ATLAS.ti. The data analysis process is described in more detail in the following section. 


\section{Tourism Sector Findings}

The findings presented in this chapter follow the five research questions of the study.

\subsection{Anticipated Effects of Broadband as Represented in Political and Public Discourse (RQ1)}

Until about second and third quarters of 2009, Kenya, like the rest of the East African countries, relied solely on satellite connections for Internet access and international communication. Two submarine cables, The East African Marine Systems (TEAMS) and SEACOM landed in Mombasa in mid-2009 and were operational before the end of that year. The Eastern African Submarine Cable System (EASSY) cable landed in mid-2010 (Waema etal., 2010). A fourth cable (LION) followed.

According Waema et al. (2010), the expected benefits of the fibre optic broadband cables were to

- link Kenya with business hubs in Europe, South Africa, and India,

- enable the transmission of massive data at high speed,

- decrease telecommunications costs,

- encourage intra-African and direct access to worldwide international cable networks,

- diminish reliance on expensive satellite communication,

- reduce data costs from US\$7,000 per megabit per second of bandwidth to below US\$500 per megabit per second,

- open up the entire East African region, in especially the business outsourcing industry, and

- $\quad$ significantly lower bandwidth costs and encourage the growth of small businesses while giving a competitive edge to big business in business communications.

Overall, results from a review of public discourse analysis shows that the dominant expectations of the arrival of undersea fibre optic connectivity were reduced Internet costs, improved speeds and economic growth as shown in figure 3.1. 
Figure 3.1: Results of Public Discourse Analysis

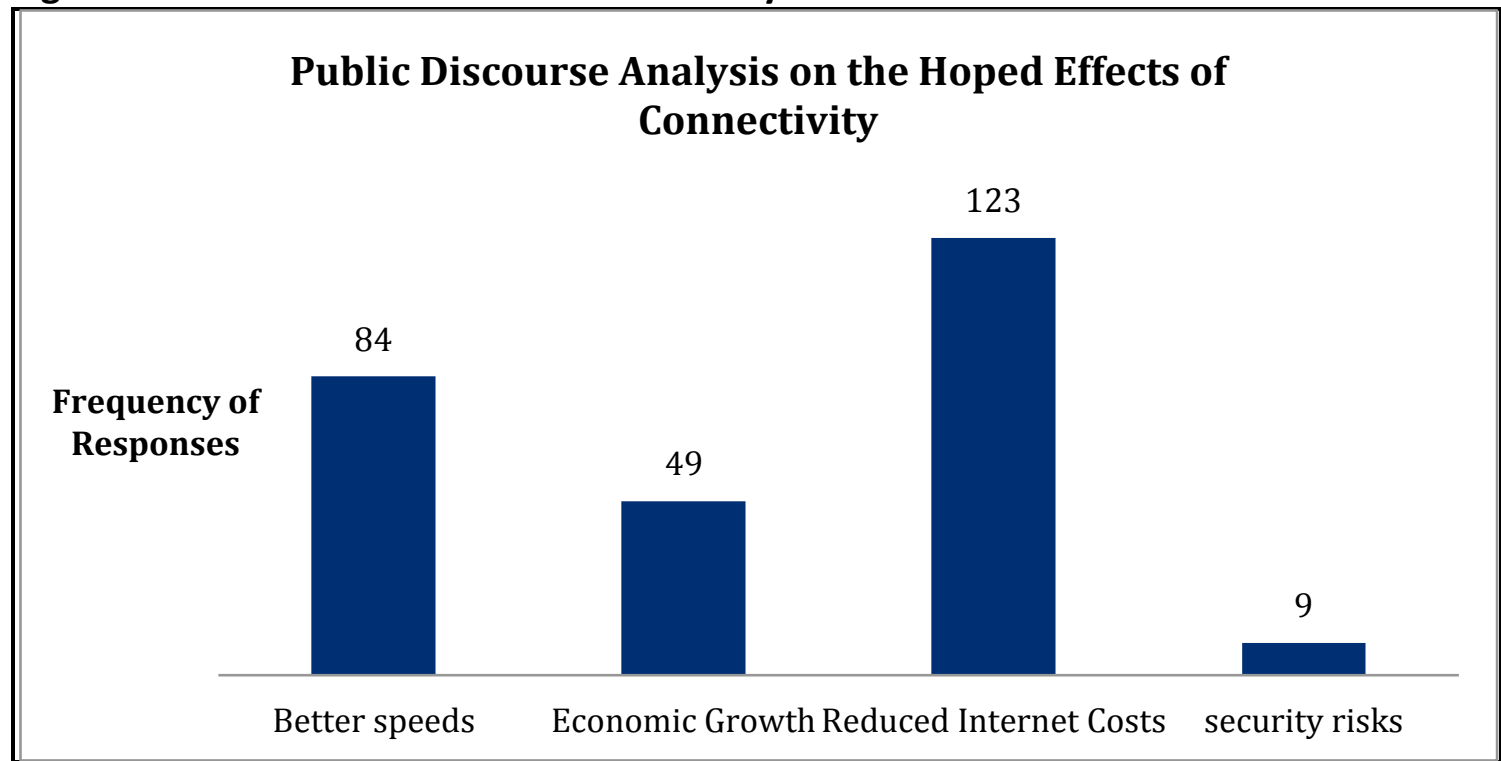

Source: Study

We now discuss each of these expectations.

\subsubsection{Reduced Internet Costs}

With respect to reduced Internet costs, these statements illustrate of the expectations of reduced Internet costs.

Teams will provide affordable international broadband connectivity to Kenya and the Great Lakes region. It will slash bandwidth costs to $\$ 400$ per megabyte, from between $\$ 6,500$ and $\$ 7,500$. (All Africa News, January 2008)

The overwhelming demand for increased bandwidth in East and South Africa grows greater each day. The Sea Cable System is making massive new bandwidth available, enabling prices to come down dramatically and opening up the possibility of developing new fields of economic activity in all the countries served. (All Africa News, January 2008)

We think it's feasible to bring the costs of bandwidth to $\$ 100$ to compare with other parts of the world. (All Africa News, March 2008).

Telecoms companies SEACOM and Cisco Systems said in a statement that Thursday's start of broadband services will make fast Internet cheaper and more accessible in places like Kenya. (Associated Press, July 2009) 
While for the past several years it has been possible to use the Internet to make long-distance telephone calls in Kenya, the costs and the speeds of connection have not met many people's expectations. Kenyan entrepreneurs like Sammy Macharia - who owns an Internet cafe in Nairobi-have high hopes that business-operating costs will come down once SEACOM is workingpotentially from $\$ 250$ ( $£ 170$ ) to $\$ 100$ ( $£ 68$ ) per month for an Internet service provider subscription. (BBC, April 2009)

We can expect prices to fall by between 20 and $25 \%$ by next year, and after that pricing will fall based on demand, as fibre operators try to get more users. (Managing Director, Swift Global, Business Daily, July 2009)

The extent of the expected reduction in the cost of Internet varied, as table 3.1shows.

Table 3.1: A Sample of Expectations in Reduction of Internet

\begin{tabular}{|l|l|l|}
\hline $\begin{array}{l}\text { Satellite Cost before } \\
\text { Undersea Cables }\end{array}$ & $\begin{array}{l}\text { Expected Undersea } \\
\text { Fibre Cable Cost }\end{array}$ & Source \\
\hline US\$6,500 per Mbps & US\$500 per Mbps & $\begin{array}{l}\text { Kenya BPO and Contact Centre } \\
\text { Society Chairman, All Africa News, } \\
\text { March 2008 }\end{array}$ \\
\hline US\$3,000 per Mbps & US\$600 per Mbps & BBC, July 2009 \\
\hline US\$3,000 per Mbps & US\$400 per Mbps & Daily Nation, June 2009 \\
\hline $\begin{array}{l}\text { US\$5,000-6,500 per } \\
\text { Mbps }\end{array}$ & US\$400 per Mbps & Business Daily, January 2010 \\
\hline $\begin{array}{l}\text { US\$3,000-4,500 per } \\
\text { Mbps }\end{array}$ & $\begin{array}{l}\text { US\$500 - 1,000 per } \\
\text { Mbps }\end{array}$ & $\begin{array}{l}\text { "Undersea Cables to Drive an } \\
\text { African Broadband Boom," Light } \\
\text { Reading, March 2010 }\end{array}$ \\
\hline
\end{tabular}

Source: Study

Key: Mbps-megabit per second

The variations echo Waema et al. (2010) when they show that operators gave conflicting information on the expected reduction in broadband tariffs after the operationalization of the undersea fibre cable. There however were disappointments because the prices did not come down as expected, as these statements illustrate:

Telecommunication operators had warned that prices will not drop drastically as expected. (Business Daily, July 2009)

You may not understand why people are bitter about the providers yet Michael Joseph, the Chair of TEAMS, has already indicated that the costs are not coming down soon. But that is not the story we were hearing for the last two years; they were all saying how bandwidth will come down to US\$400 per Mbps. (Computer World, August 2009) 
But despite the much hyped arrival of international links last year, consumers are yet to experience the up to ten times price reduction promised by Internet providers prior to fibre arriving on our shores... Internet consumers widely expected that the highly anticipated arrival of the fibre cables would lead to [a] drop in the price of communication by up to 10 times, but have since had to come to terms with the reality of market forces which have seen prices for end-users drop by just fraction, and in some cases, remain the same. (Business Daily, March 2010)

The reality for the wholesale cost of Internet is reflected in table 3.2.

Table 3.2: Actual Wholesale Cost of Internet

\begin{tabular}{|l|l|l|}
\hline \multicolumn{1}{|c|}{ Actual Cost } & \multicolumn{1}{c|}{ Time } & \multicolumn{1}{c|}{ Source } \\
\hline $\begin{array}{l}\text { The go-to-market launch prices } \\
\text { on SEACOM US\$500 per } \\
\text { Mbps-a reduction of } 83 \%\end{array}$ & 2009 & BiztechAfrica \\
\hline $\begin{array}{l}\text { 90\% to 95\% cheaper than the } \\
\text { equivalent unit price of } \\
\text { satellite }\end{array}$ & February 2009 & $\begin{array}{l}\text { All Africa News, } \\
\text { February 2009 }\end{array}$ \\
\hline US\$600 per Mbps & September 2009 & Waema et al., 2010 \\
\hline
\end{tabular}

Wholesale - this means the cost of internet by the Internet Service Providers

Source: Study

The Kenya Government gave a four-month deadline (ended March 2010) for Internet service providers (ISPs) to cut down the charges or face an official price cap, but nothing seems to have happened to the dithering ISPs. Some reasons given for the prices not coming down were

- operators had to recover their investment costs (Waema et al. [2010]; Business Daily, July 2009),

- low bandwidth consumption-6-8\% of supply,

- lack of competitive pressure that would yield better pricing (Daily Nation, January 2010),

- government-controlled regulation: "The market is regulated by the 'invisible hand' of the government. The prices might go down, but the industry is regulated by the government, which can easily determine the market prices" (BBC, April 2009),

- the relatively high cost of the local loop,

- lack of competition in the industry (Business Daily, January 2010), and

- false expectations: "Some of the industry actors had fed the market with false expectations. They were not realistic, mostly because they did not factor in the cost of local infrastructure, the maintenance and other logistics that resulted in prices remaining relatively high" (CEO, Access Kenya, February 2012). 


\subsubsection{Better Speeds}

An expectation of fibre optic cables was an access to better speeds for Internet connectivity or high capacity bandwidth. This is linked to a better quality of service and to the other expectations of cost reduction and socio-economic development. These statements illustrate this expectation.

It has come ashore in South Africa, Mozambique, Tanzania and Kenya-and Internet service providers are just beginning to hook up customers who should now benefit from much speedier connections. (BBC, September 2009).

Once hooked into the optic cable, Ms Kerubo's employer and the country at large are expected to get connection to the rest of the world via higher speed and adequate broadband. Currently, Kenyans use satellite connection, which is expensive and hence offers a limited broadband capacity. (Daily Nation, June 2009)

For many Kenyans, the news was expected to herald a fall in Internet charges and faster connectivity as operators who had bought capacity into the cable can now offer the services to end users. (Business Daily, July 2009)

The growth of undersea fibre optic cables boosted access to high capacity bandwidth, linking businesses and communities in Africa with Europe and South Asia. Africa has up to now failed to attract international business because of reliance on high-cost satellite systems to transmit voice and data services. (All Africa News, December 2009)

SEACOM's Brian Herhily says the launch marks the "dawn of a new era for communications between the continent and the rest of the world." The 17,000kilometer (10,625-mile) cable allows information to be sent at speeds of 1.28 terabytes per second, fast enough to stream high-definition video. It connects Djibouti, Madagascar, Mozambique, Kenya, South Africa and Tanzania to India and Europe. Southern and Western Africa already have broadband services. (Associated Press, July 2009)

When the fibre optic cable goes live this means the speeds will be fantastic, we'll have a higher turnover of clients and that translates to increased income. (BBC, July 2009) 


\subsubsection{Improved Socio-Economic Development}

The undersea fibre optic cable connectivity was also expected to spur socio-economic development in all development sectors, especially in BPO and IT enabled services (ITES). This was supposed to happen through a tremendous growth in the ICT sector in line with the World Bank's Information and Communication for Development Report 2009 that "every $10 \%$ increase in high speed Internet connections in developing countries (results) in an increase of $1.3 \%$ in economic growth" (BiztechAfrica, July 2011). All this assumes that there would be commensurate affordability of ICT for more people to use it to accrue social as well as economic benefits. These statements illustrate the strength of this expectation.

Kenya's information communication technology (ICT) sector is expected to grow tremendously once the fibre optic cables are up and running. The cables will stop reliance on the more expensive satellite technologies, bringing down costs and attracting new actors especially in the Business Process Outsourcing, call centres, segment. (All Africa News, March 2008)

Brian Herlihy, president of SEACOM, the company constructing the cable, told All Africa how the cable will "fundamentally change" the region by reducing costs, increasing investment and, ultimately, alleviating poverty... Business is only one sphere where low-cost, high-speed connectivity is anticipated to have a substantial impact. High-speed links are also expected to improve access to health information from abroad and between healthcare providers on the continent. Better access can lead to more cost-effective healthcare systems and even outsourcing opportunities, such as telemedicine, said Herlihy. (AllAfrica News, September 2008)

These days, all the excitement in the optical business is around new undersea cables being laid (or planned), bridging previously unconnected parts of the world. These cables are, in fact, the early warning signs of a coming economic boom. (Bloomerg, August 2008)

Juma said the effect of cheap, fast connectivity on business in the region would be "phenomenal". But the biggest potential gains will be had in education, especially if schools and universities are given subsidised bandwidth. (The Guardian, August 2008)

Kikwete [Tanzania's President] said his government plans to extend the existing fibre optic cable network in the country to reach about 10,680 kilometres $(6,600$ miles) within a year so that a Tanzanian will, for example, be able to apply online for a passport, get an acknowledgment and receive the passport in the post in a matter of days. Broadband "will reduce the need for someone travelling. It will reduce the people-to-people contact. And above all, the highest benefit of all, it 
will reduce corruption. It is really a great moment for Tanzania," said Kikwete. (Associated Press, July 2009)

Through appropriate awareness, this will open up avenues for economic development in the rural areas, especially those that mainly rely on agricultural activities. They could benefit from online training on agricultural practices, exchange of information as well as creating new markets for their products. (Daily Nation, June 2009)

The cable has simultaneously launched in Kenya, Tanzania, Mozambique, South Africa and Uganda. It is widely seen to be opening up opportunities for governments and business to use the network as a platform to compete globally and drive economic growth. (Computerworld Zambia, July 2009)

On a wider spectrum, the cable is expected to spur unrivalled growth in the ecommerce and e-learning sectors. It is also expected that this would provide a platform for local content generation. This is expected to go down well with the government project of digital villages currently underway. Additionally, the government has set up a one million computers campaign aimed at improving both literacy and Internet penetration across the country. (Daily Nation, July 2009)

Mr. Magambo said that the over-arching goal of the EASSY project is to promote economic development and reinforce regional and inter-regional integration, by providing cost effective and improved alternative international connectivity to the global optic fibre system. (AllAfrica News, March 2010)

Mr. Musyoka [Kenya's Vice President] said the entry of optic fibre in Kenya will enhance business process outsourcing and software development. He noted that Kenya is at the threshold of becoming a digital economy which will be instrumental in building and broadening the investment base in the country and neighbours who are benefiting from the submarine connectivity. Mr. Musyoka said the government has in the past few years, undertaken a series of policy, regulatory and structural reform initiatives to enhance the ICT sector and increase its contribution to the economy. (KBC, March 2010)

\subsubsection{Other Effects Broadband Internet}

One significant negative effect associated with the adoption and use of the undersea fibre optic broadband connectivity is increased cyber-attacks. These two statements predict this possible outcome:

"Increased bandwidth due to cheaper and faster connections could result in Internet attacks," Mr. Raiu said. (East African, December 2009) 
Broadband Internet access will allow Africa's virus and malware problems to go global. With more users able to access the Internet (and faster), larger amounts of data can be transferred both out and inward. More spam messages in your inbox from Africa's email fraudsters will be only the beginning. (Foreign Policy, March 2010)

Given the impact of high speed connectivity on information, some people for example this Guardian reporter on July 2009 , saw changes in the political landscape:

With the arrival of mobile phone and now broadband Internet, we are leaping from the medieval age connectivity-wise into the 21st century in a very short period of time. This represents an enormous economic boost and a political game changer given how information is now going to be spread.

There were expectations of challenges in the legal framework too, indicating that some laws needed to be changed to cope with an increasingly online community as evident in this report:

Those who have ventured into the brave new world of business made possible by faster Internet, however, say challenges abound, including on the regulatory front. "Digital laws are a big issue, our constitution is really old, it doesn't have a lot of the stuff you require to enable people to do a lot of digital activities," says Wachira. "Parliament needs to do something to change these laws because my generation is going to be online." (Reuters [Nairobi], June 2010)

\section{Summary}

Results from a review of public discourse show that there were expectations of the arrival of the undersea fibre optic cable such as reduced internet costs, better speeds, economic growth and security risks. In sum, the dominant expectation of the arrival of the undersea cable was reduced internet costs and better speeds. 


\subsection{Integration of Broadband Internet and Related ICTs into Tourism Value Chains (RQ2)}

\subsubsection{Technologies Adopted by Stakeholders}

Most respondents used different technologies to enhance their daily operations. The findings from this study identified the types of online technologies and platforms different stakeholders used while interacting with suppliers and clients in their value chain (see table 3.3). The six most popular online technologies used by most respondents are websites, mobile phones, social media, emails, search engines, and online payment platforms.

Table 3.3: Technologies Adopted by Stakeholders

\begin{tabular}{|c|c|c|c|c|c|c|}
\hline Technologies & $\begin{array}{c}\text { Tour } \\
\text { Operators }\end{array}$ & $\begin{array}{l}\text { Travel } \\
\text { Agents }\end{array}$ & $\begin{array}{c}\text { Destinations } \\
\text { (Hotels, KWS } \\
\text { Parks...) }\end{array}$ & ASPs & $\begin{array}{c}\text { Tourist } \\
\text { Associations }\end{array}$ & Tourists \\
\hline $\begin{array}{l}\text { Computerized } \\
\text { Reservation } \\
\text { Systems }\end{array}$ & $\checkmark$ & $\checkmark$ & $\checkmark$ & $x$ & $x$ & $\checkmark$ \\
\hline Websites & $\checkmark$ & $\checkmark$ & $\checkmark$ & $\checkmark$ & $\checkmark$ & $\checkmark$ \\
\hline Personal Blogs & $\checkmark$ & $\checkmark$ & $x$ & $x$ & $\checkmark$ & $\checkmark$ \\
\hline $\begin{array}{l}\text { Mobile Devices/ } \\
\text { Mobile Phones }\end{array}$ & $\checkmark$ & $\checkmark$ & $\checkmark$ & $\checkmark$ & $\checkmark$ & $\checkmark$ \\
\hline $\begin{array}{l}\text { Social Media } \\
\text { Platforms } \\
\text { (Facebook, } \\
\text { Linkedln, Twitter, } \\
\text { YouTube) }\end{array}$ & $\checkmark$ & $\checkmark$ & $\checkmark$ & $\checkmark$ & $\checkmark$ & $\checkmark$ \\
\hline $\begin{array}{l}\text { Video Conferencing } \\
\text { and } \\
\text { Teleconferencing }\end{array}$ & $\checkmark$ & $x$ & $\checkmark$ & $x$ & $\checkmark$ & $x$ \\
\hline $\begin{array}{l}\text { Virtual } \\
\text { Communities }\end{array}$ & $\checkmark$ & $x$ & $x$ & $\checkmark$ & $x$ & $\checkmark$ \\
\hline VolP & $\checkmark$ & $x$ & $\checkmark$ & $x$ & $x$ & $x$ \\
\hline Emails & $\checkmark$ & $\checkmark$ & $\checkmark$ & $\checkmark$ & $\checkmark$ & $\checkmark$ \\
\hline $\begin{array}{l}\text { Online Payment } \\
\text { Methods (M-PESA, } \\
\text { PayPal, PesaPal, } \\
\text { Funds Transfer, } \\
\text { Credit Cards) }\end{array}$ & $\checkmark$ & $\checkmark$ & $\checkmark$ & $\checkmark$ & $\checkmark$ & $\checkmark$ \\
\hline Third Party & $\checkmark$ & $\checkmark$ & $\checkmark$ & $\checkmark$ & $\checkmark$ & $\checkmark$ \\
\hline
\end{tabular}




\begin{tabular}{|c|c|c|c|c|c|c|}
\hline $\begin{array}{l}\text { Websites (Expedia, } \\
\text { Lonely Travel, } \\
\text { TripAdvisor, } \\
\text { Lastminute.com) }\end{array}$ & & & & & & \\
\hline Digital Signatures & $\checkmark$ & $\checkmark$ & $\checkmark$ & $x$ & $x$ & $x$ \\
\hline $\begin{array}{l}\text { Virtual Tours/ } \\
\text { Virtual Visits }\end{array}$ & $x$ & $x$ & $\checkmark$ & $x$ & $x$ & $\checkmark$ \\
\hline Skype & $\checkmark$ & $\checkmark$ & $\checkmark$ & $x$ & $\checkmark$ & $\checkmark$ \\
\hline $\begin{array}{l}\text { Online } \\
\text { Advertisements }\end{array}$ & $\checkmark$ & $\checkmark$ & $\checkmark$ & $\checkmark$ & $x$ & $x$ \\
\hline $\begin{array}{l}\text { Business Insights, } \\
\text { Analytics and } \\
\text { Search Engines }\end{array}$ & $\checkmark$ & $\checkmark$ & $\checkmark$ & $\checkmark$ & $\checkmark$ & $\checkmark$ \\
\hline
\end{tabular}

KWS-Kenya Wildlife Service

Source: Study

The technologies used by the various stakeholders in the value chain have been divided into six categories which we discuss in the next sections: last mile connectivity, access to customers, electronic communication, information access, online presence, and electronic payments.

\subsubsection{Last Mile Connectivity}

Most respondents were using broadband Internet connections in their work places. Last mile connectivity are the media used by Internet operators or service providers to deliver Internet to an actor's premises. Table 3.4 shows that most actors used modems, WiMax, and fibre connections in their premises-which is not surprising since broadband companies have invested heavily on this infrastructure, hence its popularity with respondents.

Broadband is becoming more affordable due to the growing competition between telecommunication service providers like Safaricom, Airtel, Orange Kenya, and Access Kenya. Table 3.4 shows only few actors in the tourism value chain are connected via satellite links because of the very high cost of satellite connectivity. It further shows that no actor is connected through a digital subscriber line because of the unpopularity of fixed line connections compared to either fibre cables or broadband modems. 
Table 3.4: Types of Last Mile Connectivity

\begin{tabular}{|c|c|c|c|c|c|}
\hline & $\begin{array}{l}\text { Digital Subscriber } \\
\text { Lines }\end{array}$ & $\begin{array}{l}\text { Fibre } \\
\text { Cable }\end{array}$ & $\begin{array}{l}\text { Broadband } \\
\text { Modems }\end{array}$ & Satellite & Wimax \\
\hline Associations & 0 & 0 & 2 & 0 & 1 \\
\hline Beach Operators & 0 & 0 & 2 & 0 & 0 \\
\hline Hotels & 0 & 2 & 1 & 2 & 5 \\
\hline KWS & 0 & 0 & 1 & 1 & 1 \\
\hline Travel Agents & 0 & 2 & 5 & 0 & 0 \\
\hline Tour Operators & 0 & 6 & 5 & 0 & 0 \\
\hline Total & 0 & 10 & 16 & 3 & 7 \\
\hline
\end{tabular}

Source: Study

\subsubsection{Access to Customers}

When respondents spoke of online access to customers, they focused on online platforms and tools that enabled them to access customers. Regardless of the industry or size of the company, they all agreed that online tools had made access to customers easier, faster and cheaper. All respondents spoke of the network effect-being interconnected to their suppliers and customers via the Internet. The Internet thus allows companies to communicate and share information across the tourism value chain, as a beach operator stated:"99\% get their clients through email. If you go to TripAdvisor, you will see Picasso and whoever, those are beach boys. You can find them online." At the same time, online tools help companies to access markets, or as a respondent said:

I think it has enabled even that local person to market their small products. I will give an example of Twitter and an example of one of our local communities, Kaya Kinondo. They already have a Twitter account and they are able to say the things that they see every day and communicate that, and with that you see they are already reaching out to someone who would be interested in visiting Kayas ${ }^{1}$ in the coastal region. (Tourism Association)

Further, as respondents show, the technologies had enabled companies to access customers they could not reach before:

The camel derby in Maralal ${ }^{2}$ that has grown because of ICT largely that these guys ... people are booking directly and because of channels like YouTube. This guy was speaking at some conference and was saying two years ago someone recorded the camel derby and he put it on YouTube and they started getting inquiries. It is not even them who had put it on YouTube, it is one of the clients who put it and they started getting inquiries and they realized that they can actually use this

\footnotetext{
${ }^{1}$ Kayas are holy shrines for local communities at the Kenyan coast.

2 Maralal is a small town in Samburu, northern Kenya.
} 
thing to generate interest. Please not they are not in Nairobi, they are all the way in Maralal. So for them ICT has been phenomenal. There is a place in Laikipia called Ilingwesi, it is in the bush and it is a community conservancy. They were also saying for them ICT has really helped them, yes to communicate directly with clients, to talk about the community projects that they have. We are seeing a lot of people being able to access markets that they could never have accessed because you had to go through the developed intermediary channels. (Tourism Association)

Some of the beach operators have emails. They have their emails which of course they can talk to a visitor even from Italy up to when he checks in a hotel. Then the next day they are going to meet on the same beach. So they are using the Internet to communicate with a guest; I will be waiting for you at this kind of a place. This is a person possibly you have never met. (Destination Service Provider)

Video conferencing is growing also because of ICT. We are seeing a lot of nontraditional operators growing because they are able to use ICT to reach markets which traditionally they would not have been able to access. (Tourism Association)

Broadband internet and related ICTs had also enabled informal operators to enter the tourism business and start looking for customers as exemplified by this comment from a beach operator:

For us freelancers, it becomes very difficult, especially for me, when I am at the beach. The only exception is recently we joined the youth and opened our own office. It would have been very difficult without Internet. (Beach Operator)

Figures 3.2 to 3.4 show methods that respondents used to access customers. The methods were identified in the empirical data and were used in the coding of all the interviews. Respondents were grouped as associations, intermediaries, and destinations. Below is a representation of the online access method used per category.

\section{Associations}

Figure 3.2 shows the methods used by associations to access customers. The figure indicates that most associations depend on email as the primary mode of communication with their membership who are their immediate customers. The figure also shows other popular platforms used by associations to access customers include online recommendations and referrals, social networks, personal blogs and websites.

The least used platform is TripAdvisor because of the nature of the business. Given that associations are not directly involved in the provision of tourism service, TripAdvisor does not really feature in their business operations. As one representative of the associations noted, however, questions and comments do arise on the TripAdvisor platform. Associations thus use it as a channel to respond to client inquiries. 
Figure3.2: Online Access to Customers by Associations

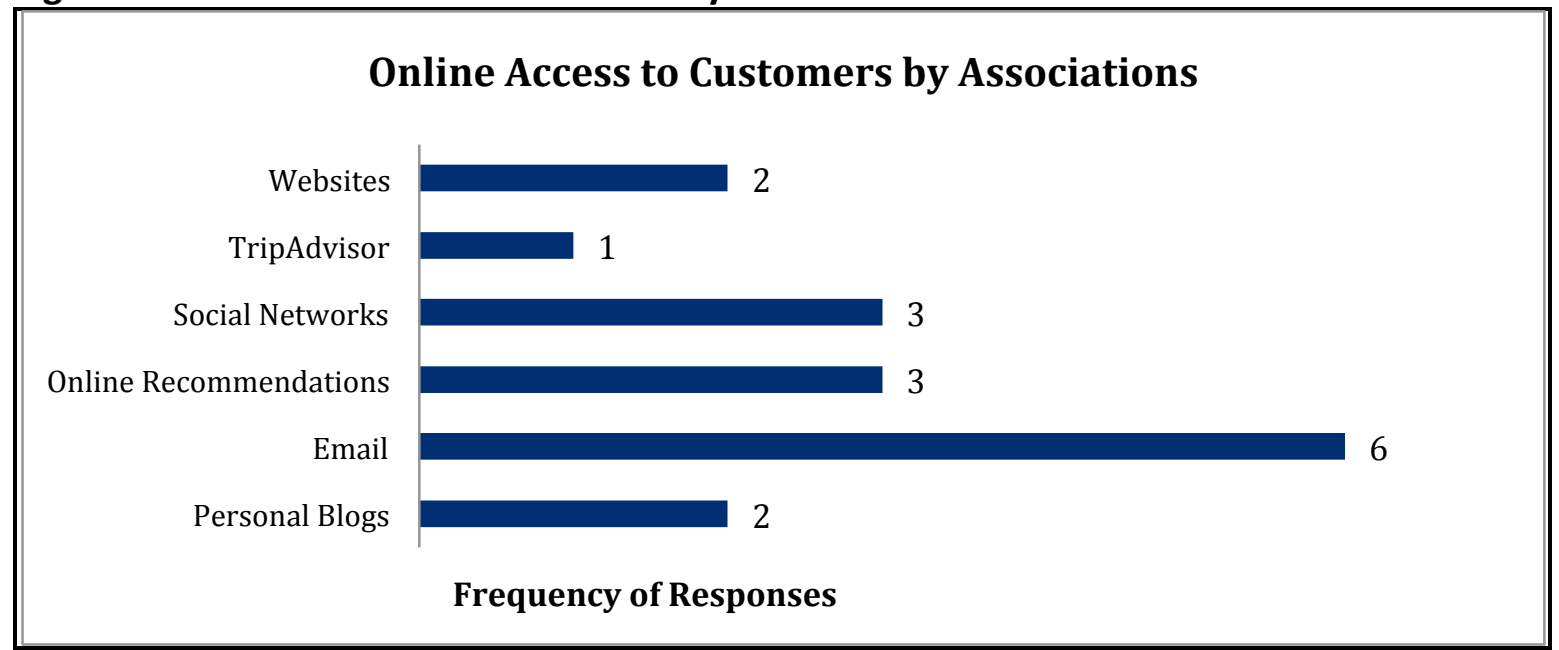

Source: Study

\section{Intermediaries}

Figure 3.3 shows that most intermediaries used websites, online recommendations and referrals, and social networks as their main customer access tools. TripAdvisor as a platform was used by a number of respondents but it had not been fully adopted by beach operators and travel agents, largely because of the cost implications. Different stakeholders are required to pay an annual fee so as to have their businesses listed on this platform, which is a challenge to operators who cannot afford the annual fee.

At the same time, some of the actors preferred to market themselves in other ways (websites, social networks, and offline and online referrals) since they are not guaranteed continuous business once they register through TripAdvisor. This platform was mostly used by customers to vet individual tourist service providers.

Personal blogs were the least used tools to access customers apparently because of the time needed to keep the blogs up to date as well as the need to have control over information posted. 
Figure 3.3: Online Access to Customers by Intermediaries

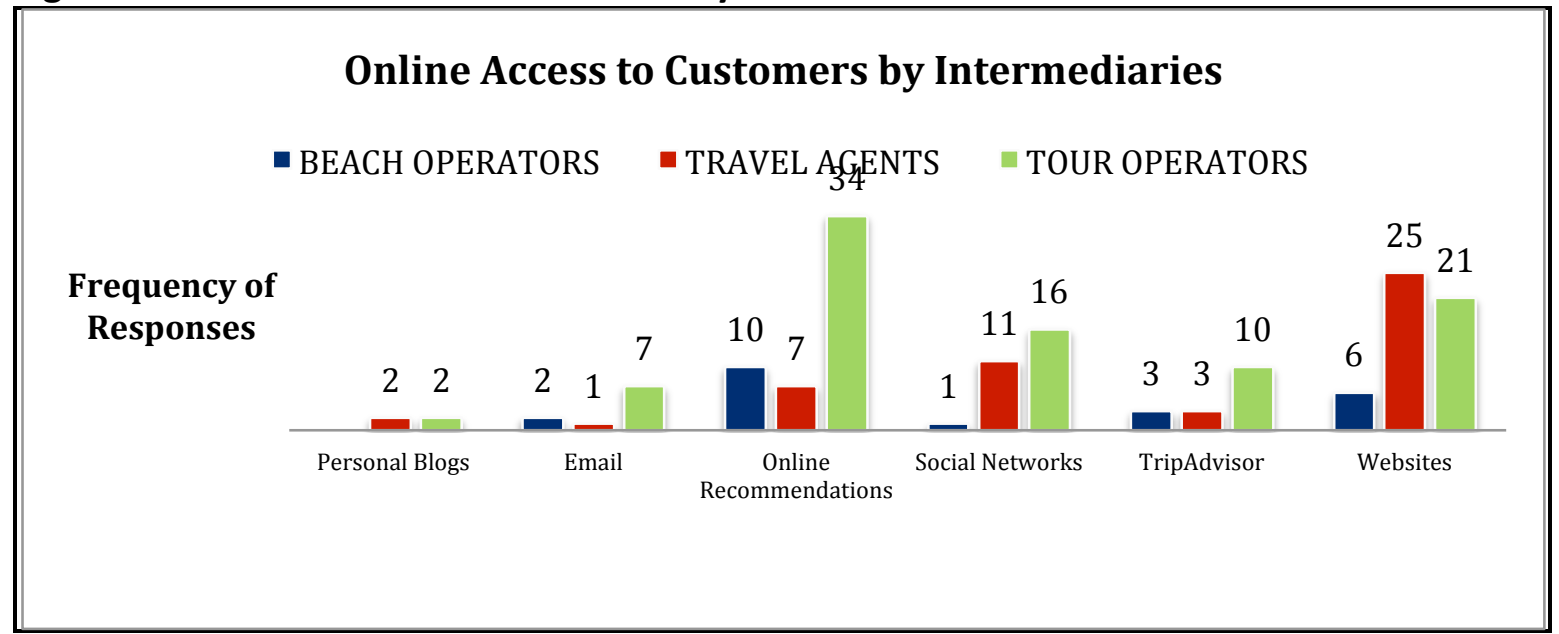

Source: Study

\section{Destination Service Providers}

Figure 3.4 shows that destination service providers used all the tools to target customers: websites, TripAdvisor, online recommendations, emails, and social networks.KWS did not use social networks or TripAdvisor to access clients because these platforms were yet to be adopted at the time when we did the study and they were to be used to target specific clientele. In the past, KWS had used these platforms to respond to comments and questions raised by its customers but not as a marketing tool for its services.

\section{Figure 3.4: Online Access to Customers by Destinations}

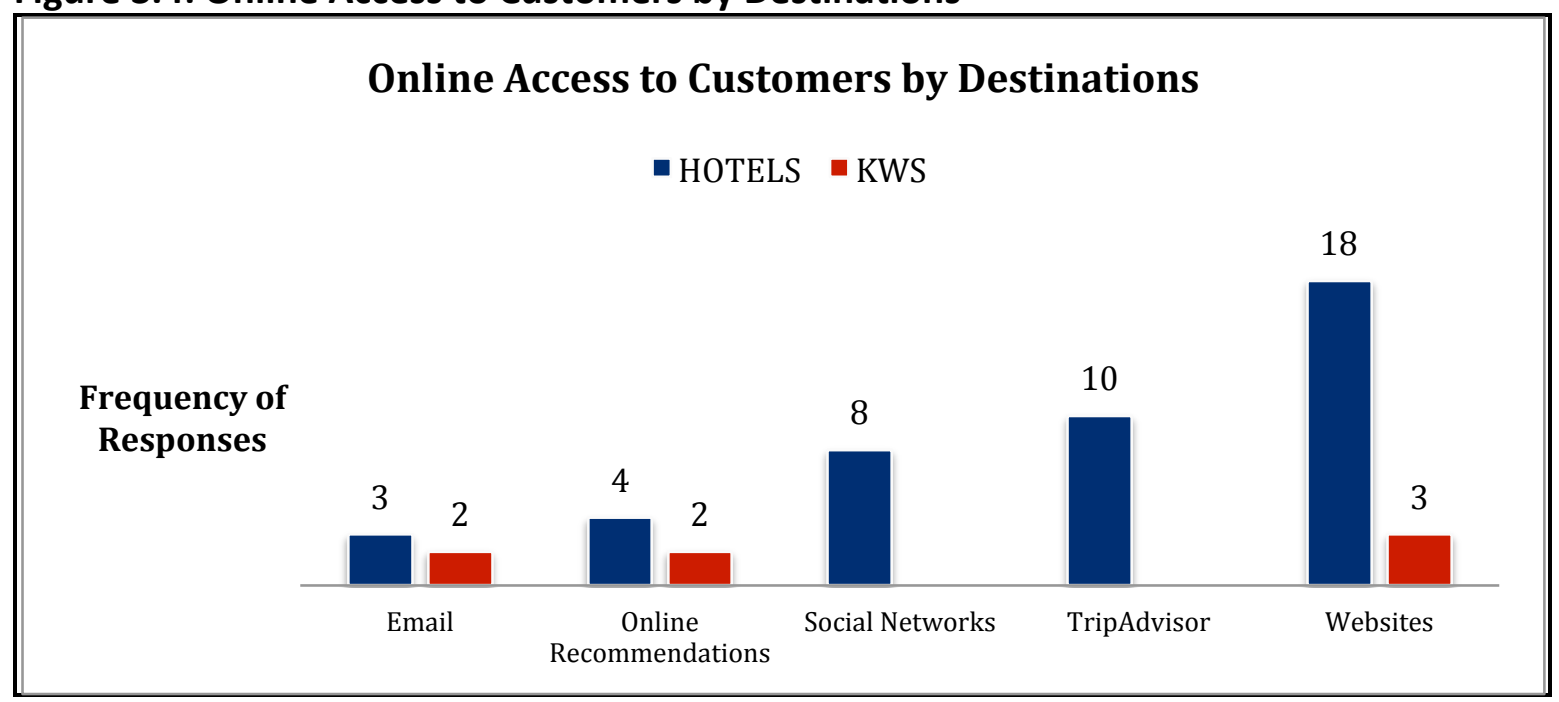

Source: Study 


\subsubsection{Electronic Communication}

Broadband Internet and related ICTs have introduced major improvements in the internal organization of actors in the tourism value chain and quality tools for communicating with customers and suppliers. Most respondents, indicating that they used the Internet for communication, focused mainly on the forms of electronic communication-as this sample of the responses from a cross-section of actors illustrates:

We have a lot of communication between us and the clients, also other agents, the proprietors of the property and the industry as a whole because like Kenya Tourist Board communicates to the tour operators through emails, they have bulletins. They have weekly snapshots that they send to us. (Tour Operator)

For example I don't have to keep on travelling around the world everywhere. I can communicate with somebody in Australia and we agree on things. We can Skype and agree on what they need to do for them so as to get the business. It is cutting costs, travelling costs, marketing costs are going down. (Tour Operator)

Mainly is for communication of email, we are not only a publishing company, we support a lot of companies but we do the online business for them. So we work with companies, we are working with one major company I won't mention the name but it is in Europe, yeah we do their online work, in terms of their newsletters, in terms of their website. (Travel Agent)

One of the communication tools we have is the Internet, Facebook, Twitter and Linkedln and one of the ways it has helped us is to market our members to the whole world. (Tourism Association)

I will just let you know of the ways we use to cut costs. We have all our units all around and every unit does their finances and in the morning the Group Finance Manager might just decide I need to question why Mara got such revenues yesterday. They don't have to lift up a phone or call them, we have a link in our system, let's say Skype, something like a chat. You just pick up your camera, headphones call them, you are able to interact with them, have a meeting with them talk about the figures, you can share your desktop with them, ask them where they got these and that has saved a lot. (Hotel)

\section{Associations and Intermediaries}

Figures 3.5and3.6 show that emails, phones, Skype, and social networks were the most popularly used forms of electronic communication by associations and intermediaries. Teleconferencing, videoconferencing and Voice over Internet Protocol (VoIP) were the least adopted technologies because these technologies are expensive to adopt and maintain, and thus only big companies had adopted them. 
Figure 3.5: Forms of Electronic Communication by Associations

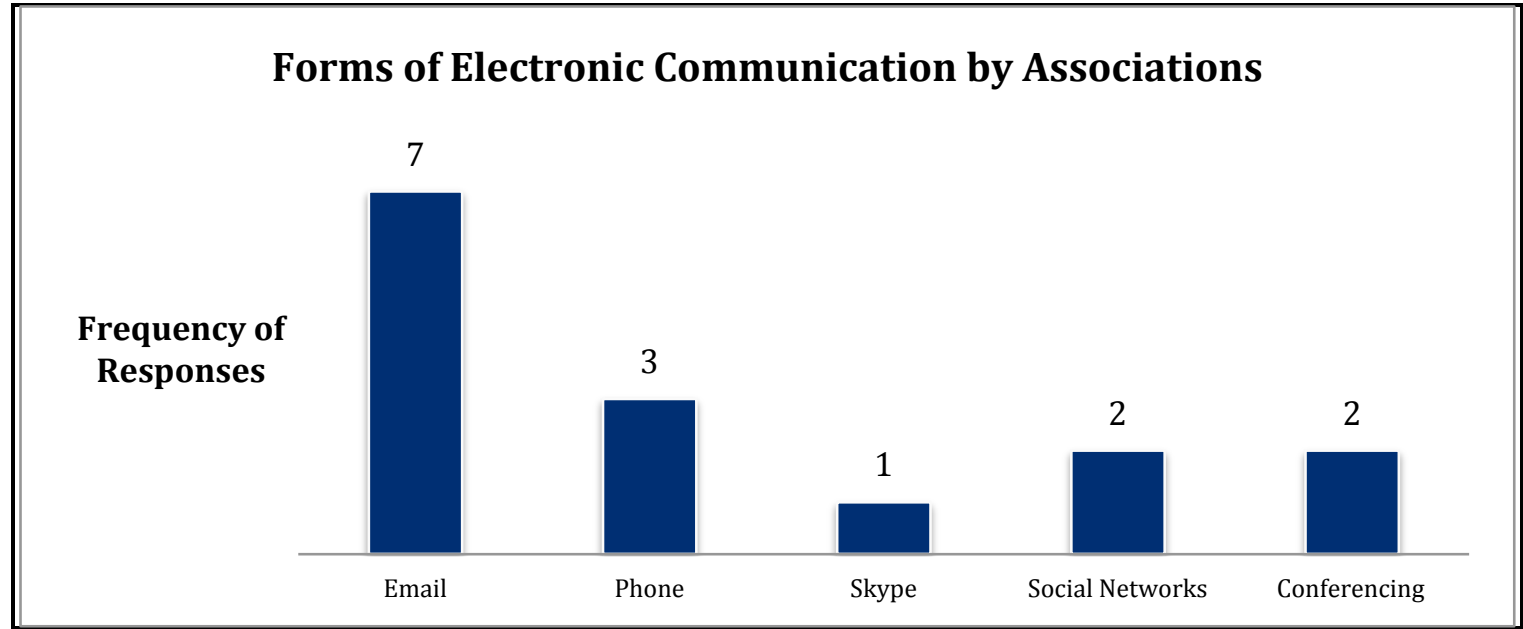

Source: Study

Figure3.6: Forms of Electronic Communication by Intermediaries

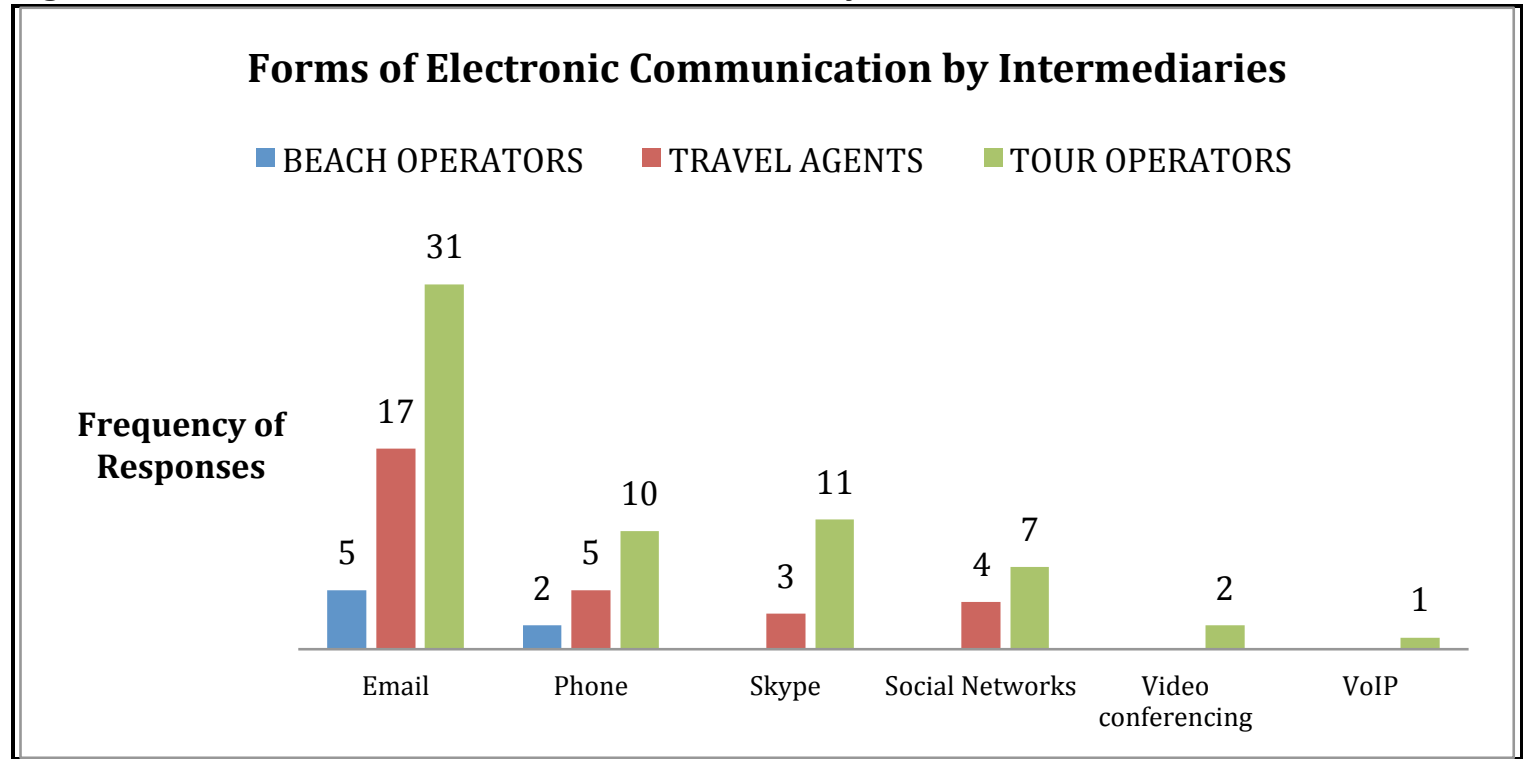

Source: Study

\section{Destination Service Providers}

Figure 3.7 shows that emails and phones were the most used forms of electronic communication by destination service providers. The email and the phone are the most dominant modes of communication. 
Figure 3.7: Forms of Electronic Communication by Destinations

\section{Forms of Electronic Communication by Destinations}

-HOTELS $\square$ KWS

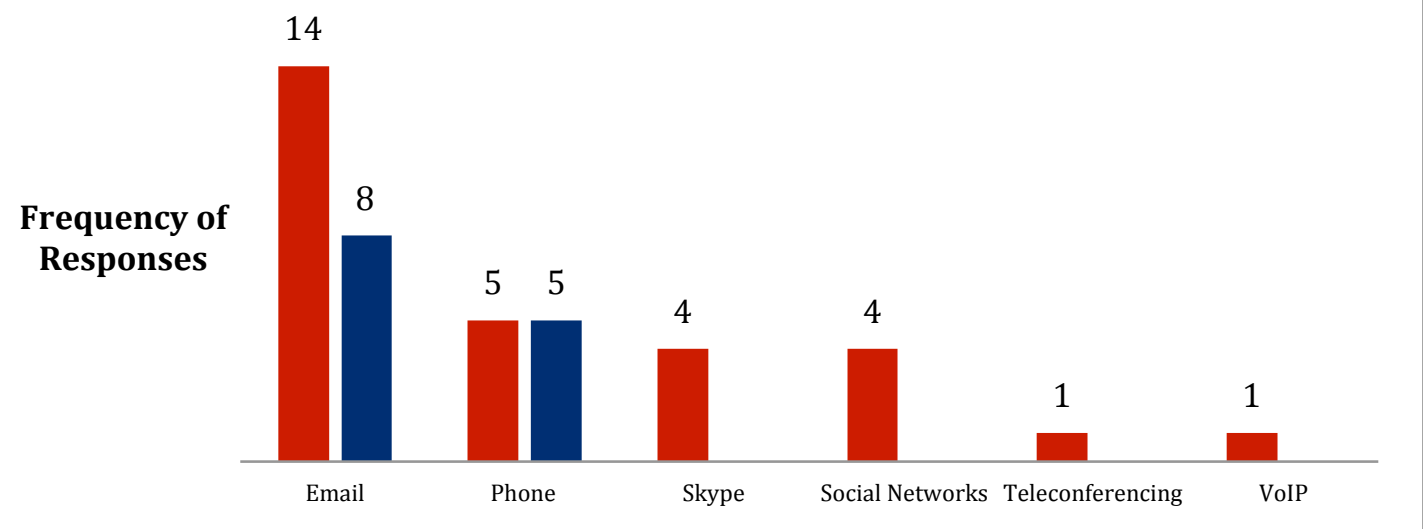

Source: Study

\subsubsection{Information Access}

Table 3.5 shows a summary of the common technological platforms adopted by various stakeholders in the tourism value chain for online access to customers. The three most popular online access strategies used by most respondents were websites, social networks, and TripAdvisor. Use of personal blogs and YouTube as online presence strategies was very low presumably because of human skills required in developing blogs and good videos and the relatively high cost of creating videos as will be discussed in section 3.3.

Table 3.5: Technologies Used for Online Access to Customers

\begin{tabular}{|l|r|r|r|r|r|r|r|}
\hline & $\begin{array}{l}\text { Personal } \\
\text { Blogs }\end{array}$ & $\begin{array}{l}\text { Social } \\
\text { Networks }\end{array}$ & $\begin{array}{l}\text { Trip- } \\
\text { Advisor }\end{array}$ & Websites & $\begin{array}{l}\text { You- } \\
\text { Tube }\end{array}$ & $\begin{array}{l}\text { Third- } \\
\text { party } \\
\text { Websites }\end{array}$ & $\begin{array}{l}\text { Online } \\
\text { Advertise } \\
\text { ments }\end{array}$ \\
\hline Associations & 2 & 8 & 2 & 8 & 1 & 1 & 0 \\
\hline Hotels & 2 & 25 & 20 & 45 & 0 & 7 & 4 \\
\hline KWS & 0 & 7 & 0 & 15 & 0 & 1 & 0 \\
\hline Travel Agents & 2 & 36 & 6 & 74 & 0 & 5 & 4 \\
\hline Tour Operators & 2 & 49 & 21 & 75 & 6 & 29 & 4 \\
\hline Beach Operators & 0 & 7 & 6 & 23 & 0 & 9 & 2 \\
\hline $\begin{array}{l}\text { Total Frequency of } \\
\text { Utilization of Online }\end{array}$ & $\mathbf{8}$ & $\mathbf{1 3 2}$ & $\mathbf{5 5}$ & $\mathbf{2 4 0}$ & $\mathbf{7}$ & $\mathbf{5 2}$ & $\mathbf{1 4}$ \\
\hline Tools & & & & & & & \\
\hline
\end{tabular}

Source: Study 


\section{Associations}

Associations also used print media to access information.

\section{Intermediaries}

As these statements indicate, tour operators emphasized the importance of using social media and websites for customers to have access to information:

Well, those are tools that give you more presence. They allow you at a very low cost to have presence in very many different places. So of course it is a very important selling tool that you need to use and actually is not something future, it is already happening. You read the news this week I think Thomas Cook... increased the sales of a package by $30 \%$ by only doing a Facebook campaign. (Tour Operator)

You would rather not have a business card but have a website. In two weeks' time, I am to attend a trade show in South Africa, and we don't need to carry brochures. Sometime back we used to carry CDs, etc. the most prominent thing is the website, it contains who you are, what you do and your contacts. (Tour Operator)

Tour operators also emphasized the use of the TripAdvisor is illustrated below:

This has happened recently on TripAdvisor when someone posted something nasty about another hotel online. This is all business rivalry, xxx Hotel [name withheld] had its competition do that to them, and it was on TripAdvisor for a long while. Another company purported to be a client and went out and posted a nasty message on how bad their stay was at the hotel. (Tour Operator)

They are important because they could be both positive and negative and that could actually mess you up and that is why it is critical to ensure that before your clients actually leave here you have actually seen them. If there are any areas where something went wrong you are able to sort it out. Yeah it is critical because that can mess you up because TripAdvisor is basically...Anybody can access it and once you are there negatively I think as a professional tour operator you would work very, very hard to resolve that issue. Yeah it can build you and it can kill you. (Tour Operator)

People really read the comments on TripAdvisor and sometimes we have had clients saying no we don't want to go to this hotel because the rating is very low or because they have heard some complaints or the other way round this hotel. They ask about a specific hotel just because of the comments on TripAdvisor (Tour Operator) 
An access to information can also lead to information overload, however, as both customers and suppliers can have access to more information than they are accustomed to managing, potentially resulting in confusion and additional uncertainty in the connected environment. These accounts show the problem of information overload:

I know there are sites which have so much but as a company, we have not taken that approach because when you have too much information on your site sometimes you may lose the client. (Travel Agent)

We are embracing the technology and losing the critical part of what the website should be. There is the problem of too much information being presented online or on the website. Most websites are overly complicated; we need to get straight to the point. (Tour Operator)

\section{Destination Service Providers}

These comments illustrate how Internet technologies had enabled customers to have access on destination service providers:

There are some people who really did not know about Sarova and most of the time you will find that these people will always go to sites like TripAdvisor. They will probably go to Google and type Sarova. So if our website is not listed among the first, sorry we are not there. And that has also been our focus as well as making sure that we are present on the Internet so that we are seen as market actors; we are seen as the leading organization so by doing that people have created a lot of trust in us outside there. You will find that any person who is booking at Sarova will not think twice about it because they have seen the comments that are there. They have seen the offers and they can see what we can do for their clients. So it is about putting the information out there and people reading for themselves, people making decisions with a lot of knowledge. So I believe that is what the Internet has done for the industry and as well for Panafric. (Hotel)

There is more information out there. Because if you can find somebody coming to Kenya, hiring a vehicle in Nairobi and coming all the way here, you know that is something which was unheard of in the past. How does he know his way around? It is because of the Internet. He goes online and he zeros in on this Tsavo Westwhat does it have? How many kilometres is it from Nairobi? He tries to do his research; he makes a phone call; he also inquires with a receptionist or something. After he gets some information, he actually comes. (National Park)

A number of respondents also described how access to negative information posted online had led to increased negative publicity faced by destination service providers. This statement clarifies this issue: 
I know it really counts because of the ratings on TripAdvisor. Right now and the world seems to be for it, the TripAdvisor thing, they have embraced technology. So in equal measure somebody may post a negative rating and you may be judged by postings, that is how you will be judged. So whether there is some truth in it or not that may be a challenge to some extent. (Hotel)

\subsubsection{Online Presence}

According to most respondents, the main online presence technologies or strategies were websites, social networks, and presence on third party websites-as indicated in Figures3.8to 3.10. It is presumed that the popularity of these online presence platforms is due to the fact they are free. The third party websites charge commissions based on the number of clients who confirm their bookings to an establishment. Online advertisements were least used, largely because of the cost of advertising.

Figure 3.8: Online Presence-Associations

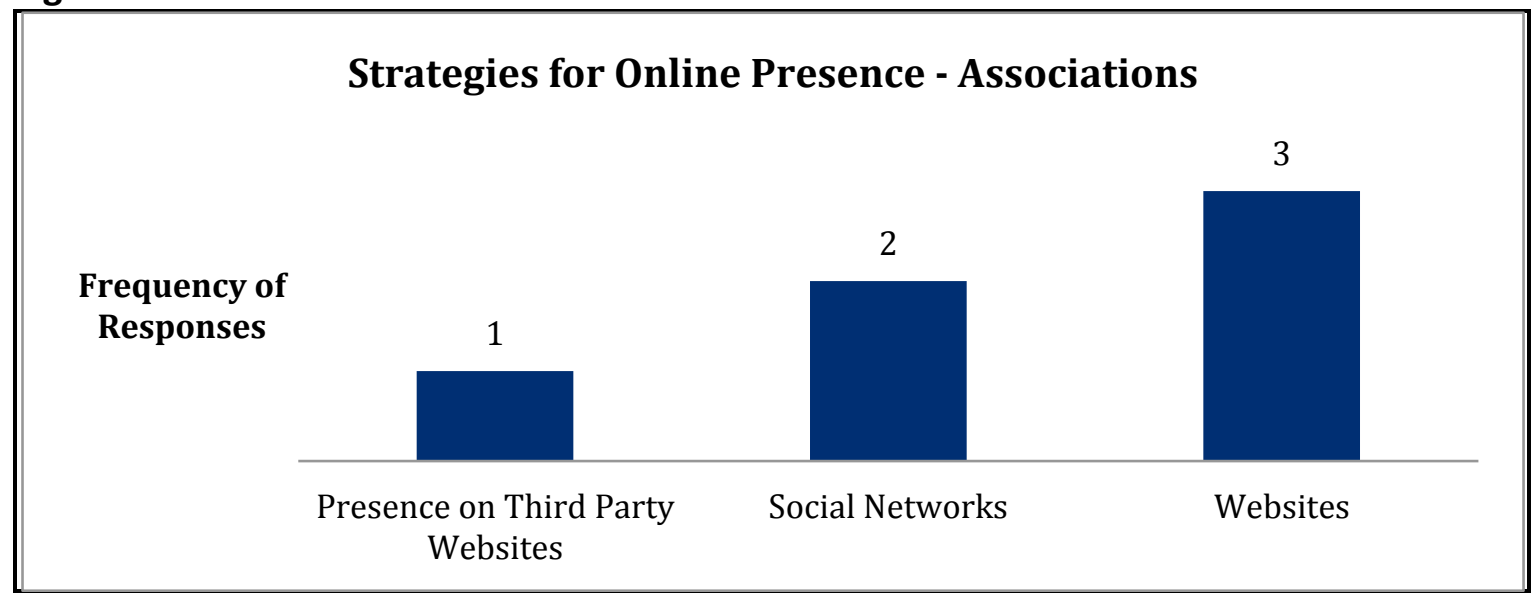

Source: Study

As figure 3.9 shows, most intermediaries utilized websites, social networks, and third party websites (Expedia and Alibaba) as platforms for online presence. There were however other intermediaries who did not adopt these platforms because, as discussed in section 3.3, they faced challenges both of technological skills to utilize online platforms and of affordability of the technologies. 
Figure 3.9: Online Presence-Intermediaries

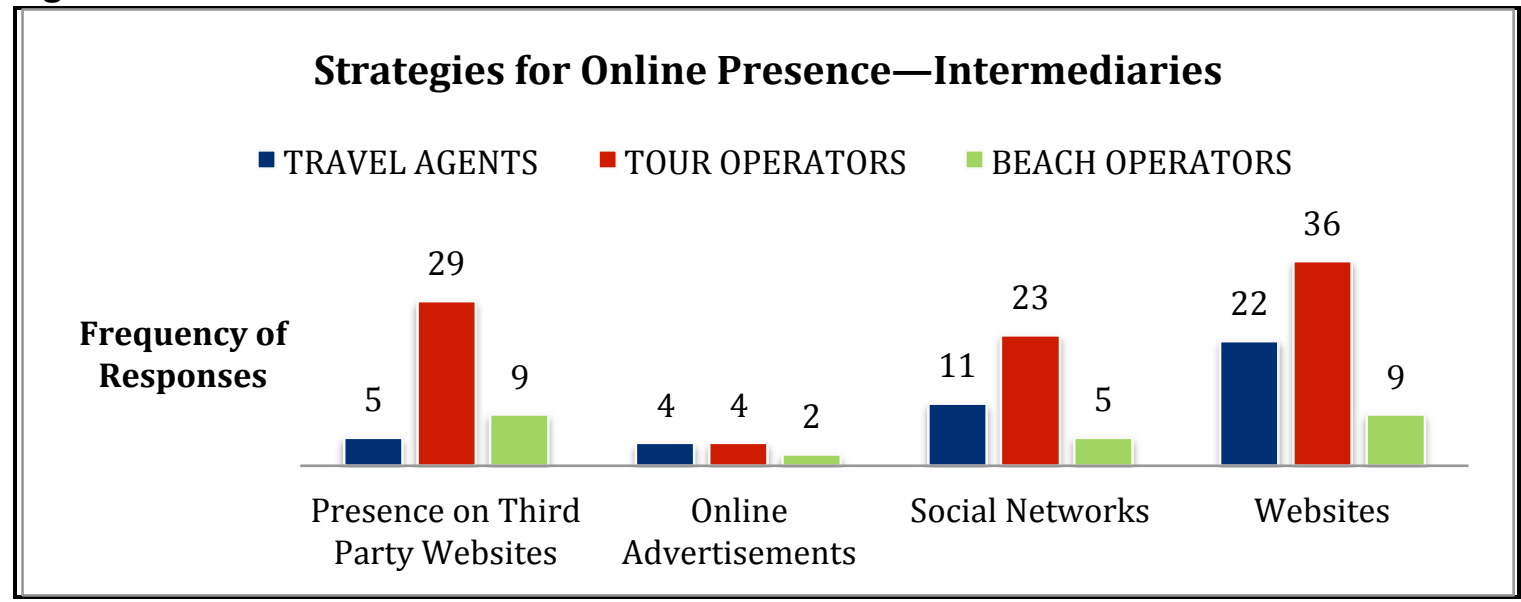

Source: Study

Figure 3.10: Online Presence - Destination Service Providers

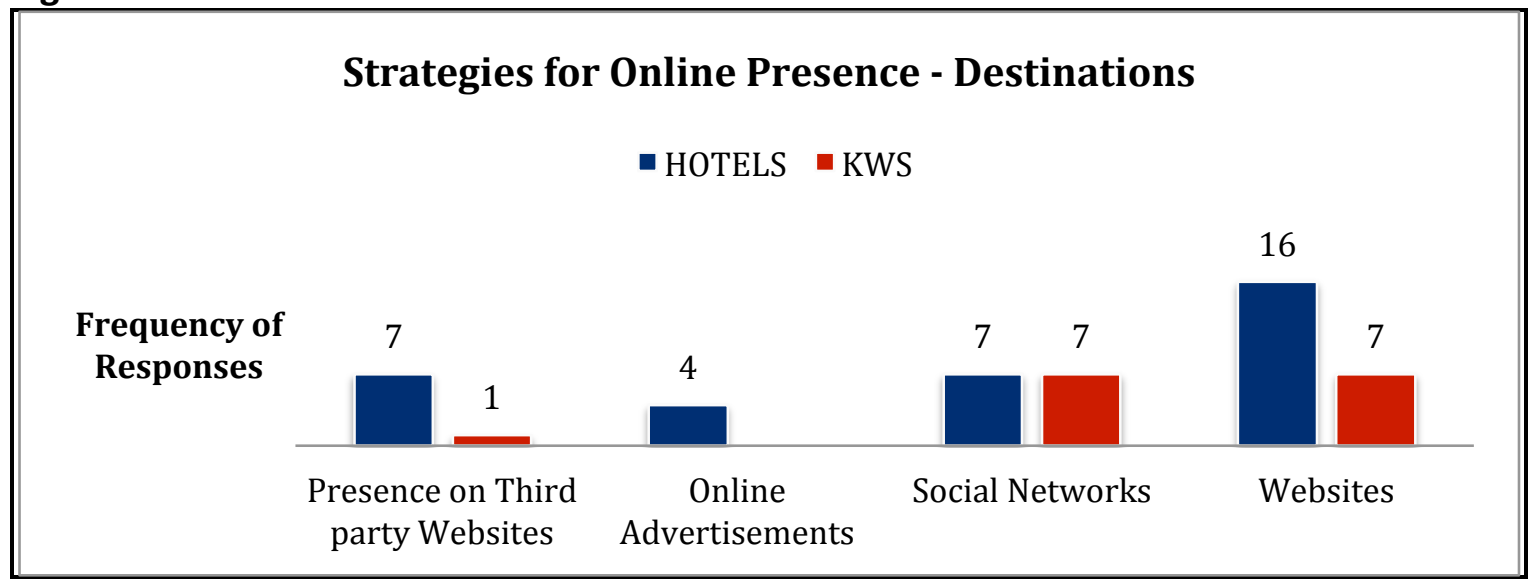

Source: Study

\subsubsection{Electronic Payments}

There was generally a positive attitude towards ICT use among those interviewed. Most respondents had adopted different payment methods such as bank transfers, electronic funds transfers, credit cards, M-PESA, PayPal, and PesaPal. Few companies had taken full advantage of the opportunities presented by broadband Internet and related technologies. Many smaller actors in the value chain were yet to benefit from these technological advancements. A number of respondents complained that:

The banks were sceptical but they have slowly been accepting it and we have got KCB and Imperial Bank who are doing online payments together with hotels so I think it is a good move. (Tourism Association) 
There is this service called PesaPal. It is a Kenyan company that is offering services. It is expensive. If you don't have any other option, you will have to use it because you have to get your thing from wherever it's coming from and you need it that bad but you will not use it again. (Tourism Association)

I think it is still a trust issue. I had used an online payment system to subscribe for something overseas and I tested it and it worked. I got debited correctly and two months down the road I got billed for the same thing again. So I ran to the bank and explained this to them at the same time question as to why the payment was made and they said the visa guys called in they said they need to be paid. So I got charged twice, so I lost that money, cancelled that card. (Tour Operator)

If you look at you know in the West their websites have got...you know you can book a safari and pay online. Payment online is still yet to come for us. That is one big problem though we have tried to set up. Recently there are people who have come up with such arrangements but they are very expensive. (Tour Operator)

\section{Summary}

The results of the study explain how broadband internet and related technologies have been integrated in the tourism value chain. Different technologies have been adopted by different actors along the value chain. A majority of the actors used websites, mobile devices, social media platforms, online payment methods, third party websites and search engines to communicate, interact and transact with their partners, suppliers and customers both locally and internationally. 


\subsection{Unexpected Challenges to Broadband Use (RQ3)}

This section discusses the impacts of broadband connectivity. Nearly all the respondents spoke of for example networking and widened market access as one of the positive impacts of broadband Internet and related ICTs. Broadband connectivity and related technologies however have some negative effects on the tourism sector. Consequently, this section focuses mainly on the negative impacts of broadband Internet and related technologies in the tourism industry.

\subsubsection{Summary of Effects of Broadband Internet Use}

Most respondents agreed that faster Internet and related ICTs had brought interesting opportunities to enhance productivity, optimize distribution and reduce process costs because the new technologies are used as a work tool and had allowed them to speed up their work. Respondents were asked, "What are the threats to your business in relation to the changing Internet infrastructure?"Probed further, they were asked, "Are you worried the Internet is cutting you out in any way? Do you think the Internet has enabled other firms to take business away from you?"Figure 3.11 shows the effects of the broadband Internet on actors in the tourism sector.

Figure 3.11: Effects of Broadband Internet on Actors in the Tourism Value Chain

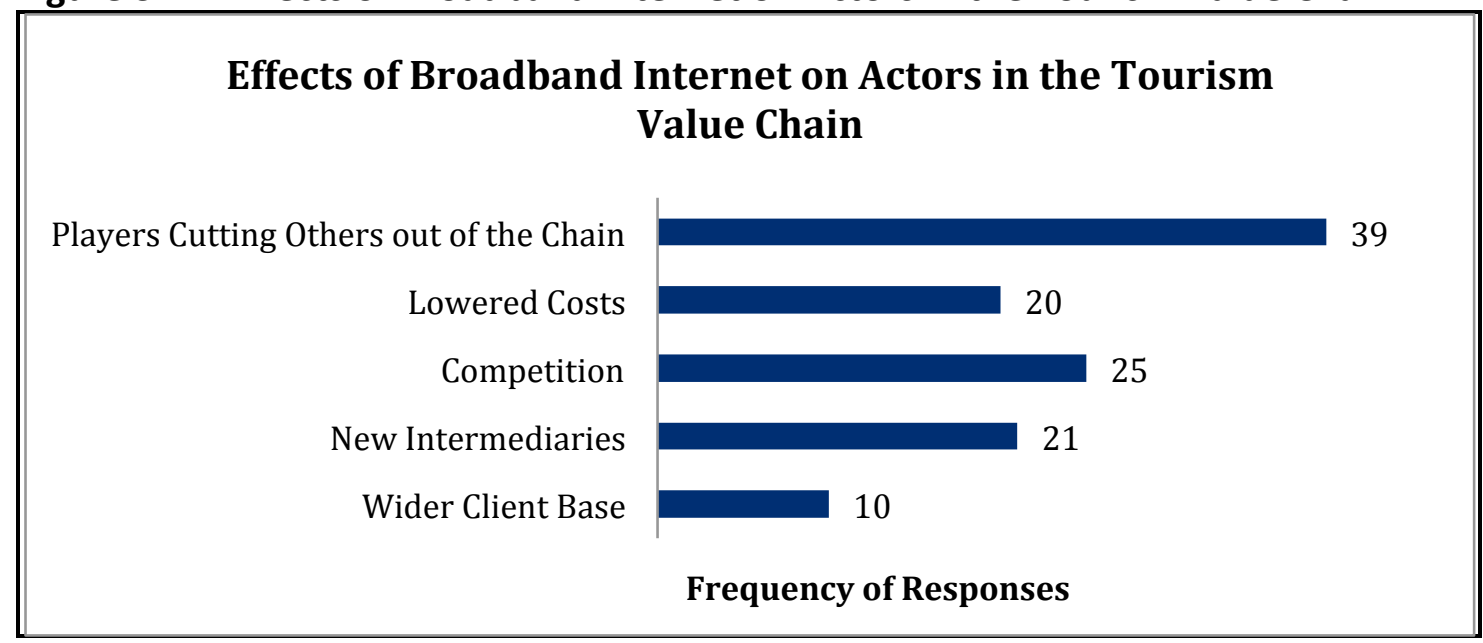

Source: Study

\subsubsection{Increased Competition}

Respondents revealed that competition had intensified after the emergence of the broadband Internet due to lowered barriers to entry. That in turn had led to an increase in the number of competitors. New entrants had the ability to be represented in equal 
terms with the existing rivals and maximize their market share. Interviewees suggested that the emergence of the broadband connectivity reduced organizational costs.

\subsubsection{Disintermediation}

With regard to disintermediation, some of the respondents pointed out that at the same time, faster Internet and related ICTs had become a threat for traditional intermediaries who did not provide value addition to services because the customers can use the new technologies as well. This was aptly captured by one respondent, when he remarked: "If what you are offering is exactly the same as what I can get on my own through the Internet, what is the value-add? Look at your package and add value to the package" (Tourism Association).

When requested to draw the desired tourism value chain during the first focus group discussion, one of the participants came up with the drawing shown in Figure 3.12. After some discussion, the other participants agreed with it. The figure shows that customers access services directly from destination service providers as well as from intermediaries.

\section{Figure 3.12: Desired Tourism Sector Value Chain with New Technology}

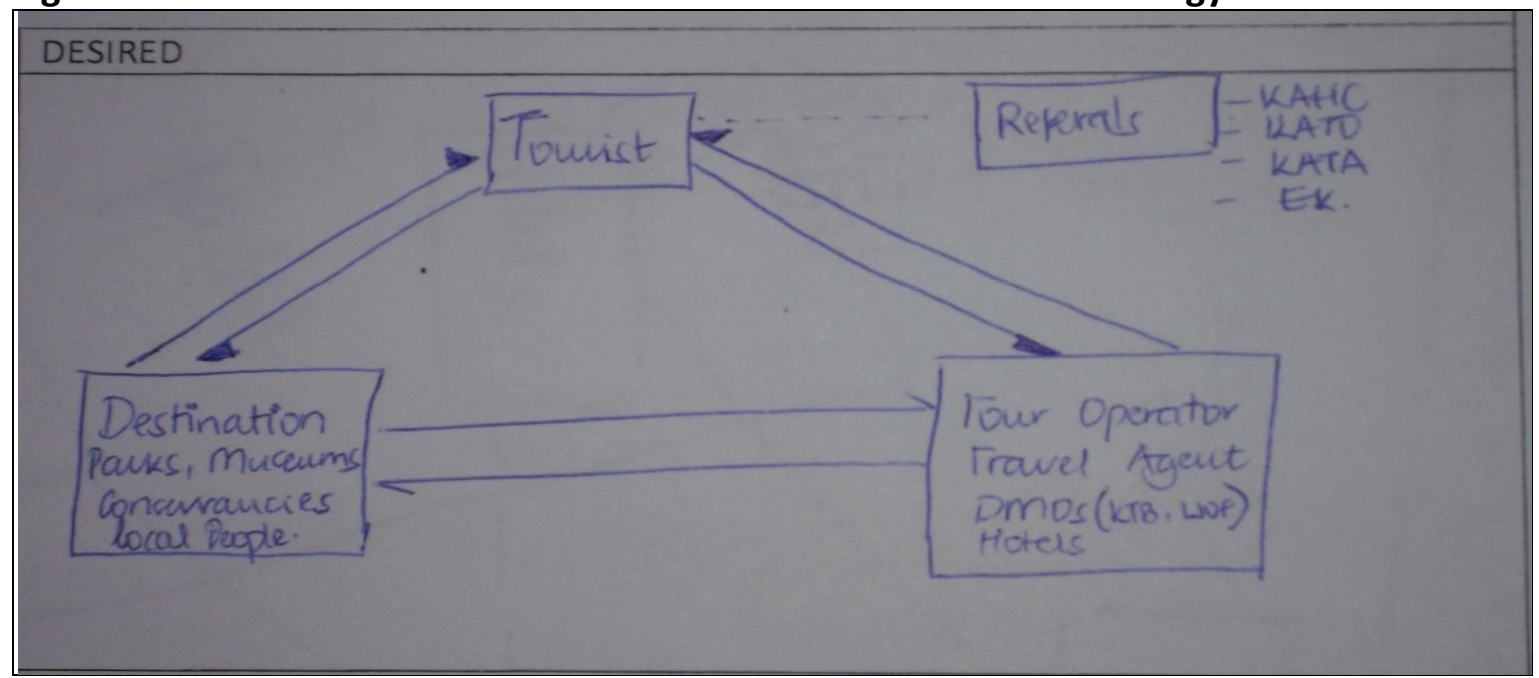

Source: Study

As this figure shows, broadband Internet and related ICTs do not eliminate traditional intermediaries that offered high levels of service and expertise or add value. There was evidence that several travel agents had closed their businesses, perhaps not necessarily because of the effects of disintermediation, though a number of respondents argued that tour operators were changing their strategy and embracing the Internet as a survival strategy.

The key conclusion during the focus group discussion was that in the near future, virtual and traditional intermediaries will continue to coexist, with each focusing on one's type 
of business and attending to one's market segments. These accounts indicate that a number of respondents seemed to support this position:

I think when you look at where we are placed in the international tourism business the role of intermediaries will still be there for a very long, long time. This is because we are a long-haul destination. The main role that the tour operator plays is assurance, I am there to take care of you, I am an expert in these things I am taking you to Africa and I will hold your hand. Right now you can get a lot of information on the net but you want assurance that there is someone who knows what is happening and will take care of that. So I see the role of the intermediary being more than informational but more emotional sort of a security. So the power of the intermediary is reducing but I don't think it will be obliterated soon. (Tourism Association)

There is still room for a travel agent, there is still room for a tour operator. Like I remember during that volcanic ash over Scotland, you will find people who had booked with the travel agents were able to get rerouted very easily. So you will always find people who are seasoned travellers, people who are well aware would still go through a tour operator because for example you want to come here, you want to visit different parts of the country. So the tour operator will still exist, same with the travel agents. (Tour Operator)

Kenya is still very dependent on tour operators because of course the knowledge you need to have to move around is quite big. (Tour Operator)

They book through a travel agency. For them, they still want to have that security of having someone to talk to. Some people don't feel confident to leave credit card details for a trip to Africa and then come here and expect somebody will be waiting for them at the airport. I still feel that in our markets maybe in other countries it is different. In the countries that we operate, people still have this need for having a person to talk to not an online system-at least for trips to Africa they need more advise, they need more information, they need more confidence to go for it. (Tour Operator)

Figure 3.13 shows a fundamental shift on the tourism value chain brought about by broadband Internet and related ICTs. Tourists are now able to contact individual stakeholders from any location on the globe without having to go through intermediaries. 
Figure 3.13: Tourism Value Chain after Technology

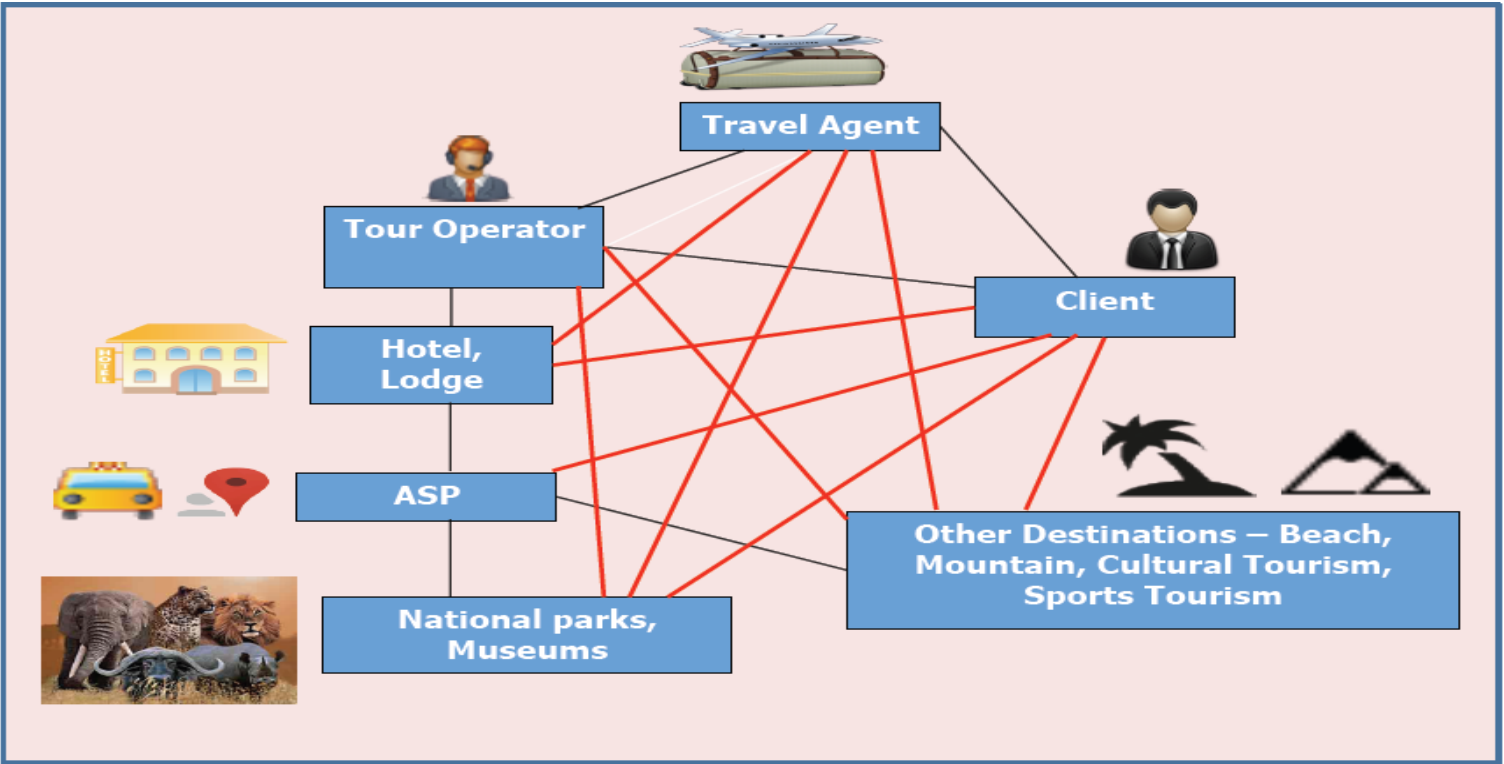

Source: Study

Legend: Red lines -new relationships enabled by broadband Internet and related technologies

As can be seen from this figure, broadband Internet and related technologies had transformed the value chain from a hierarchical to a matrix value chain.

\subsubsection{Connectivity Challenges}

Tourists and travel agents alike turn to the Web as their first source of information on a potential destination for themselves or their clients. They also use email and other online applications for fast, efficient and inexpensive communication to have their questions answered.

Respondents were asked, "Are there any remaining barriers to communication that you face either in terms of Internet access, access to software/hardware or any other technological access?" Most respondents cited a number of challenges as a result of the improved connectivity. Figure 3.14shows that the major challenges perceived by actors in the tourism sector are increased competition, technical barriers, cybercrime, cable breaks, and virtual companies. The statements on respondents' experiences illustrate of some key connectivity challenges:

Of course we have had our bad times with the Internet when TEAMS or what happens in the high seas (cable cuts) and we are not able to give our clients...services they need or if there is a problem countrywide and we are not able to provide our clients. We are not able to receive mails, we are not able to respond to our clients' needs. (Travel Agent) 
I can say sometimes it is very hard to predict the credibility because sometimes there are some crooks and dishonest bookings. So sometimes we have a challenge there. We cannot exactly know which is true and which one is a false booking. You see mostly there are such things in the Internet, more so on PayPal and the credit card. So that has been the challenge. (Travel Agent)

Very many people have a website nowadays. You have to go a step further by trying to see the kind of testimonials they have, how many people are writing that they have dealt with them. For example, you go from social media to the website. You can have a feel of how serious a company is. Because nowadays, the con artists can also do a website or even masquerade as the ones running a certain website, yet they are not the ones running that. Yet you end up thinking that they are the ones running the website. So it is a very big challenge with the briefcase companies and the ones that offer dubious services to the clients. So the companies that are there really need to do a lot. (Tour Operator)

\section{Figure 3.14: Connectivity Challenges}

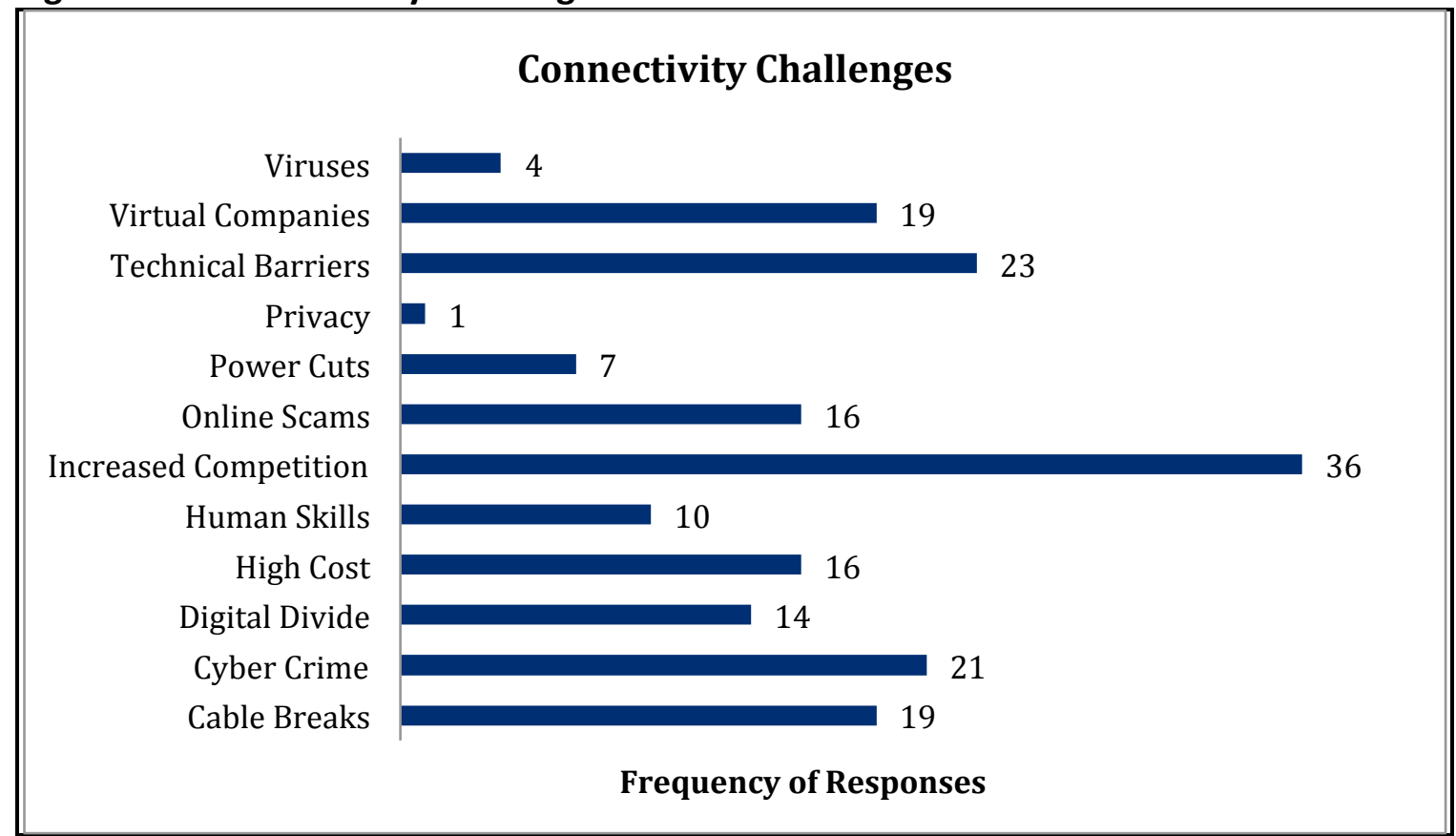

Source: Study

Faster Internet and related ICTs had enabled actors to create business linkages across different regions, cultures and business sectors. A number of actors within the value chain however did not have access to these technologies. Below are statements by some respondents who expressed concerns over the digital divide: 
The other one is PayPal; we receive money through PayPal but we cannot access that money. Kenya is still one of the countries where you cannot access your money. (Travel Agent)

For example other lodges are using Safaricom. Like Safaricom have their boosters somewhere. For example they are using either WiMax or microwave, but here you cannot get (the signal). We are only on Airtel. We have a limitation, we are only on Airtel for voice communication. So maybe that is partly a reason because others are connected to Safaricom and their speeds are actually higher. (Hotel)

It could be much better if we were able to do that SEO (search engine optimization). You see you need some people who are continually updated in their knowledge because me and the staff that I have here, whoever it is we don't have that much, we are not specialists. The Internet is changing so much, I don't know how to use Facebook and Twitter. Some of my staff do it, but I have not taken advantage of that for marketing. (Tour Operator)

\subsubsection{Quality of Internet Services}

When respondents spoke of the quality of service, they focused on three components: the speed of the Internet, the availability of the Internet and the Internet reliability. Respondents discussed the quality of services rendered to them by several ISPs. As an example, a travel agent commented: "Downtime; that is why I was talking of consistency. Sometimes you are online, then the Internet goes down, that is a common occurrence, not just here, but this affects many other people. This happens at least once a week."A tour operator echoed similar sentiments with the remark:

It is only that sometimes it is not quite steady. There are some periods you will have to keep on refreshing and whatever but all in all I would say it is working remarkably well. I don't know if those are factors beyond the service provider but there are times it is a bit unstable. That is why we have all these backups.

In contrast, there are actors who felt that their speeds had improved and were satisfied with their connections:

Because of the high speeds now, we are able to use the Internet much better in terms of posting photos, posting videos, posting virtual tours of our properties that we advertise. So because of the high speed we can do all that previously you could not do it. (Travel Agent)

Generally, I can say acquiring this big capacity Internet has helped our business tremendously because, one, we don't have any issues with downtime affecting our systems and applications. Fibre has really helped us because there are no 
more delays; there are no breakdowns so it has improved our business a great deal. (Travel Agent)

Having migrated from dial-up connection and all that we can actually say it is reliable, the speeds are better. I think I read somewhere that LIONS is now live. So I believe we should be getting faster connection that is what we looking forward to. (Tour Operator)

\subsubsection{Cost of Broadband Internet}

Concerning the adoption of broadband Internet in tourism enterprises along the value chain, the cost associated with adopting and using broadband Internet was cited as an obstacle by a majority of the respondents. The use of broadband Internet is clearly linked to the size of tourism enterprises. For example, Internet connection costs were prohibitively high for the smaller actors in the value chain. These actors were therefore not taking full advantage of the benefits brought about by broadband Internet. One can argue that some actors, especially the smaller ones, can be locked out of the business opportunities because they cannot not afford such technologies, as these sentiments suggest:

In tourism there are very many opportunities, one is marketing. Today if you are able to post some nice clips, like you went to Mara and posted a small video, you saw this and that, you post it. But now that bandwidth for posting those things is very expensive, I cannot afford[it]. The bandwidth required to operate those virtual tours is still quite high, the cost is still very high. (Tourism Association)

I will also say that fibre has come but I am sorry it is not as we had expected, it is still not cheap. (Tour Operator)

Let me say there is still not so much change in cost, because it [is]almost the same amount I was paying then is what I am paying currently despite only $2 \mathrm{MB}$ increase on the bandwidth, which I feel is very negligible. (Hotel)

The bandwidth required to operate those virtual tours is still quite high. And what is being offered right now is not enough and if you get the high one you will pay through the nose. The cost is still very high. (Tourism Association Representative)

The other thing that I find difficult... the Internet is good marketing on the Internet but optimizing. Search optimization is still expensive. (Tour Operator) 


\subsubsection{Inadequate Human Capacity}

While there is a need for tourism enterprises to keep pace with technological advancements so as to be competitive in the industry, there was a general consensus that there was an inadequate capacity to develop useful websites to take advantage of broadband Internet, as these views illustrate:

The other one is awareness. I think people are not savvy of what they can do with the Internet. In fact we are having a training seminar; we are planning this week on Internet presence. And if you look at most of the websites we have, they are just static brochures; they have no interaction. Then you look at it and then you say I have looked at it and like it and then?(Tourism Association)

I don't know how to use Facebook and Twitter, some of my staff do it, but I have not taken advantage of that for marketing, I have gone into the Internet and I have produced a manual form there to read about how deal with Facebook which I cannot understand. (Tour Operator)

It is expensive; the reason we outsourced is that we didn't have enough or competent resource to do that internally, we don't have in-house expertise to maintain the site. I know that is possible but we are not using it to its full potential because of lack of expertise, this is one of the reasons...this is not being captured through the Internet. (Travel Agent)

A lack of skills to sustain the ever-changing technology was another challenge. A respondent mentioned that for example his firm was not able to use social media because of a lack of skills and ability to create a social media profile for the business. In this connection, some respondents said:

Some of course lack that knowledge, how to create that website. Someone can create that website for them but now they need also to be using it. So due to[a] lack of that knowledge and that education it becomes a challenge to them on using the website. (Destination Service Provider)

We need people who are continually updated in their knowledge because me and the staff that I have here we don't have that much, we are not specialists. The Internet is changing so much, I don't know how to use Facebook and Twitter. (Tour Operator)

\subsubsection{Payment Challenges}

Ability to use online payment platforms was a key challenge; thus, according to a respondent: 
They [customers] can correspond online but they are not booking online because the infrastructure is not there particularly for passing value. Money transfers are not there, that is one hindrance. In fact if we can get one...if that can be made available it would make life very easy.

There are a plethora of online payment platforms available, however, which this respondent was possibly not aware of. Respondents aware of such platforms claim that they are too expensive. For example, one respondent claimed that PesaPal, one of the payment platforms, charged a very high proportion of the transaction value. Another responded cited an additional challenge as the lack of adequate trust and security of online transactions.

Figure 3.15shows challenges of using e-payment platforms by tourism enterprises in Kenya. Most respondents felt that trust issues had not been addressed and, as a result, the respondents had not adopted electronic payment methods. Some respondents described a lack of infrastructure, high transaction costs and lack of electronic payment skills as barriers too to the adopting electronic payment methods. These views capture these challenges:

This is something that is picking up, but security issues prevent any company from adapting that. So we are still going through the main banking system. (Tour Operator)

I think it is still a trust issue. I had used an online payment system to subscribe for something overseas and I tested it and it worked. I got debited correctly and 2 months down the road I got billed for the same thing again. So I ran to the bank and explained this to them at the same time question as to why the payment was made. And they said the visa guys called in they said they need to be paid. So I got charged twice, so I lost that money, cancelled that card. (Tour Operator)

That has been one of the major challenges we have been facing as an industry because you find most clients do not want to transfer money. They want to pay using their credit cards, one, for security, two, they get loyalty points wherever it is so. It is secure and that actually is the mode of payment they prefer. (Tour Operator) 
Figure 3.15: Payment Challenges

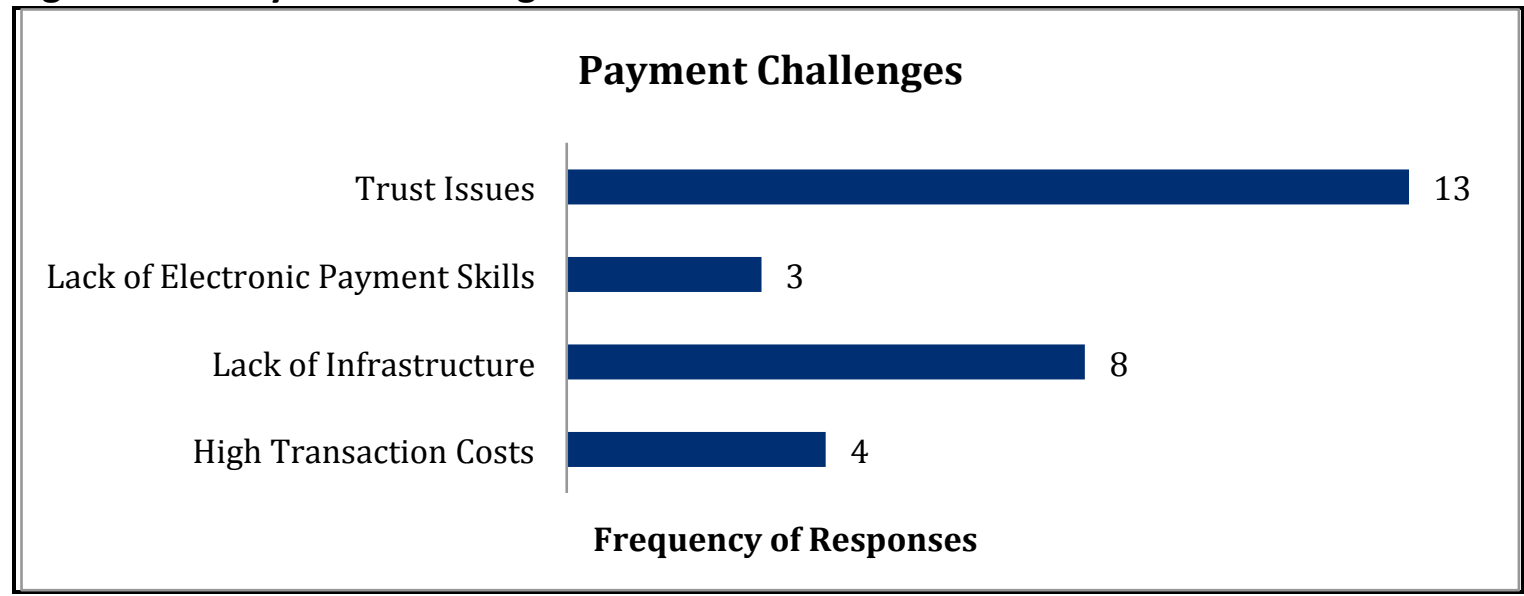

Source: Study

With respect to the trust issue, one respondent mentioned that a main barrier to adopting electronic payment methods is security of online payments because of fraud. Here are related views:

It is a new area in Kenya as I said before; many banks were not willing to take it up because of that issue of fraud. That issue of online payments has been an area where people are not positive, they have been sceptical about it. In addition banks are not willing to take the risk to handle this process. So as we start eliminating those small gaps I believe many people will come on board and do online payments. (Association)

The way we receive payments online is ridiculous, but we don't have one way whichever works for the clients. There are clients who can only pay you by credit cards, so physically somebody has to be there to run it, if they went there physically for you to run it. The other option is called mail order...it is very open to fraud. (Travel Agent)

Whereas trust and security issues was a barrier to the adoption of electronic payment systems, the case was different for respondents who tried to find a way around this problem by using bank transfers or by resorting to other means of payment such as PayPal.

\section{Summary}

Results on the unexpected challenges of broadband internet and related technologies indicate multiple challenges. A major challenge is that the tourism value chain had changed with the adoption of these technologies. In particular, actors had been cut off the value chain with customers opting to go directly to both destination service providers and intermediaries to look for better deals. Their role as intermediaries in the value chain 
was at risk if they do not provide value added services. This is because customers can use these technologies as well to purchase products and services directly.

Secondly, connectivity poses as a negative challenge to most operators. These include increased competition, technical barriers, cyber crime and cable breaks as some of the major threats resulting from the adoption of broadband internet and related technologies. Other challenges include quality of internet services, cost of broadband internet, inadequate human capacity and payment challenges.

\subsection{Socio-Economic Impacts on Economic Actors (RQ4)}

In summary, we found that broadband Internet and related ICTs had brought about positive socio-economic benefits to economic actors, the key ones being

- enhanced productivity and increased efficiency in businesses,

- new tasks, strategies and opportunities to firms,

- new customers, and

- enhanced visibility and reduced marketing costs.

\subsubsection{Increased Productivity and Efficiency}

Figures3.16 to3.18show that all actual impacts listed in the interviews received some affirmative responses. All surveyed tourism enterprises that adopted broadband Internet and related ICTs believed that there were benefits in employing the technologies. The most commonly cited impacts of broadband Internet and related ICTs were enhanced productivity and increased efficiency. Enhanced productivity means the ability to perform more activities and tasks with broadband Internet and related ICTs. Increased efficiency means the ability to accomplish tasks with minimum time and effort such as faster access to information. Respondents identified reduced costs and reduced fraud as additional impacts. 
Figure 3.16: Positive Business Benefits/Impacts of Connectivity on Associations

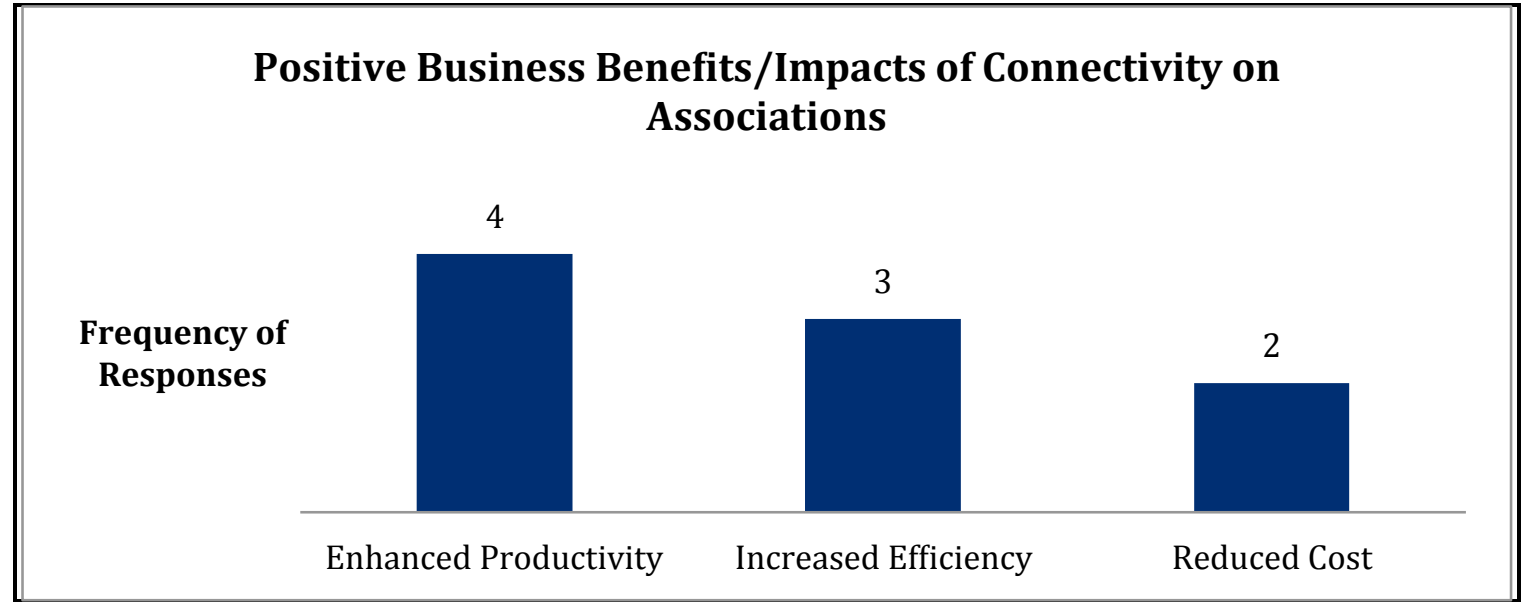

Source: Study

Figure 3.17: Positive Business Benefits/Impacts of Connectivity on Intermediaries

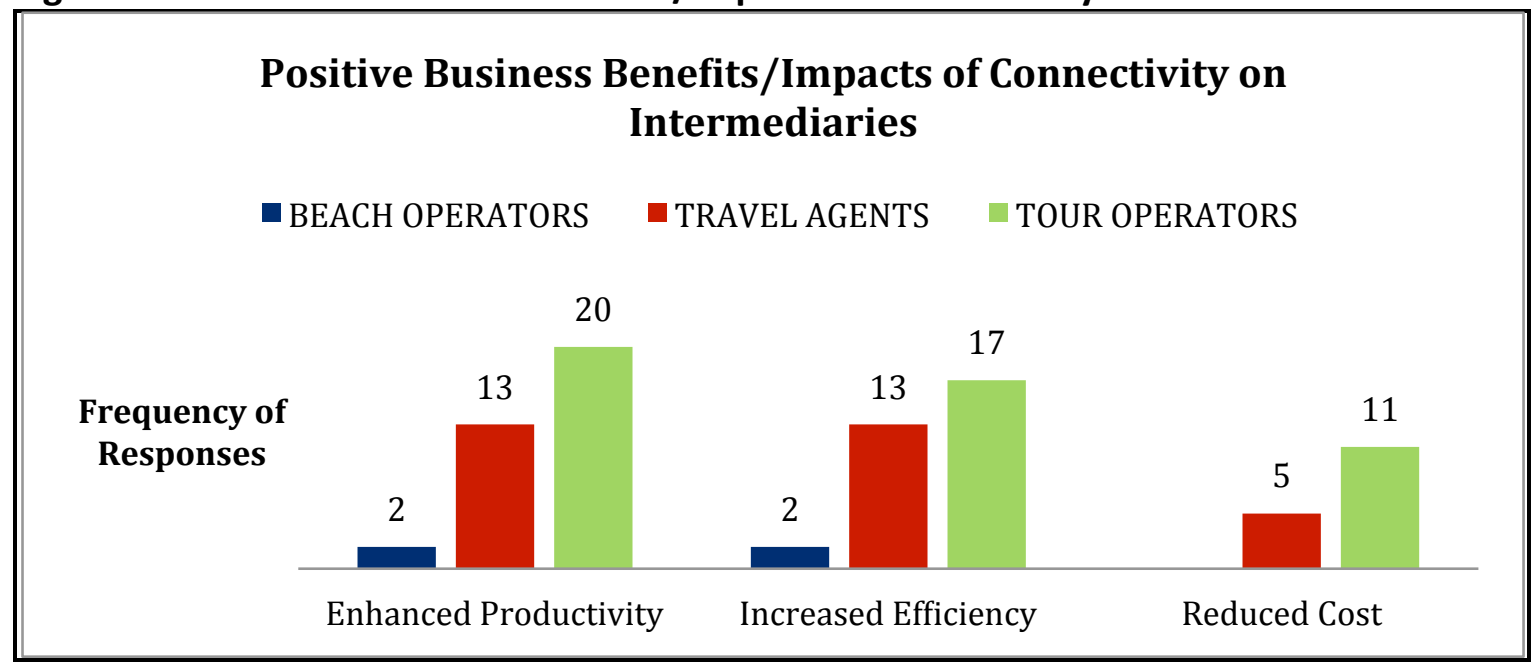

Source: Study

Figure 3.18 Positive Business Benefits/Impacts of Connectivity on Destinations

\begin{tabular}{|cccccccc|}
\hline \multicolumn{7}{|c||}{ Positive Business Benefits/Impacts of Connectivity on } \\
Destinations \\
- HOTELS
\end{tabular}

Source: Study 
Most respondents who had employed broadband Internet and related ICTs believed their productivity had increased as a result of using them. A representative from a tourism organization for example said:

Of course people will mention how things have changed. The Internet is better, we are able to do online payments and we are able to do various things that we were not able to do before like when it comes to communication with the guest.

A travel agent added:

There has been a major change for the better because now instead of reaching out to 30,000 people we can reach out to much more in terms of through our website, so yes it has made a tremendous difference especially in the tourism sector.

A tour operator summarized how broadband Internet had transformed business:

Business has changed over time in the past we used to rely very much on walk in clients, you know, that is off the streets. But times have changed. Most people want to make their holidays before they arrive here and so the Internet has come handy so that a lot of arrangements are made prior to the clients arriving, including most of the payments although not through the Internet as such but through bank transfers at the moment.

\subsubsection{New Tasks, Strategies and Opportunities}

Figure 3.19shows the changing tasks, strategies and opportunities resulting from the adoption of broadband Internet and related ICTs along the tourism value chain.

Figure 3.19: Changing Tasks, Strategies and Opportunities

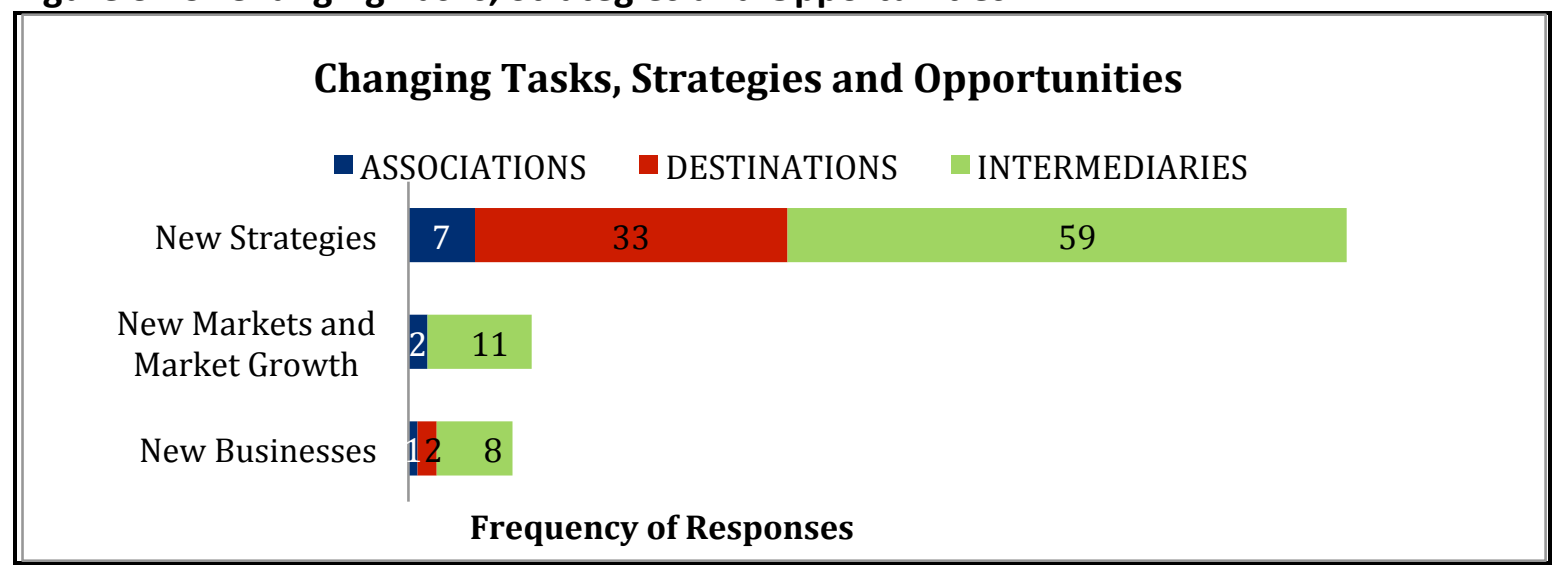

Source: Study 
The general opinion of the respondents was that broadband Internet and related ICTS played an important role in their daily operations and offered to them new opportunities and strategies not available before broadband Internet. A representative from a hotel for example said:

As opposed to what we used to do some years back, we used to do our reservations via the telephone and fax machine. Now it's not there anymore. Therefore it has a number of impacts on the good side of it. Whenever the Internet is on, guests send email and we reply to them. It has simplified a lot of things.

A tour operator echoed similar sentiments:

Actually it does help a lot, because you find that other upcoming companies or even companies of the same age [with] or older than us, you find that when they are looking for an agent in a certain country like in Kenya, most probably they turn to the Internet. They have to do their due diligence on the Internet to learn more about you.

In the sections that follow, we present effects of specific technologies.

\subsubsection{Wider Markets}

The pace of technological change has brought considerable opportunities for all involved in the tourism value chain. Most respondents regarded broadband Internet and related ICTs as positive to their businesses. Figure 3.20shows that most respondents were of the opinion that their adoption of different forms of electronic communication had led to improved market audience, to reductions in costs and to faster speed of reply. Most respondents cited improved market audience, which is really new customers, as the biggest effect of electronic communication. For tourism service providers, this is largely due to broadband Internet enabling disintermediation, and hence consumers being able to book directly with service providers. This study however found that intermediaries continued to play an important role in the tourism value chain. 
Figure 3.20: Effects of Electronic Communication

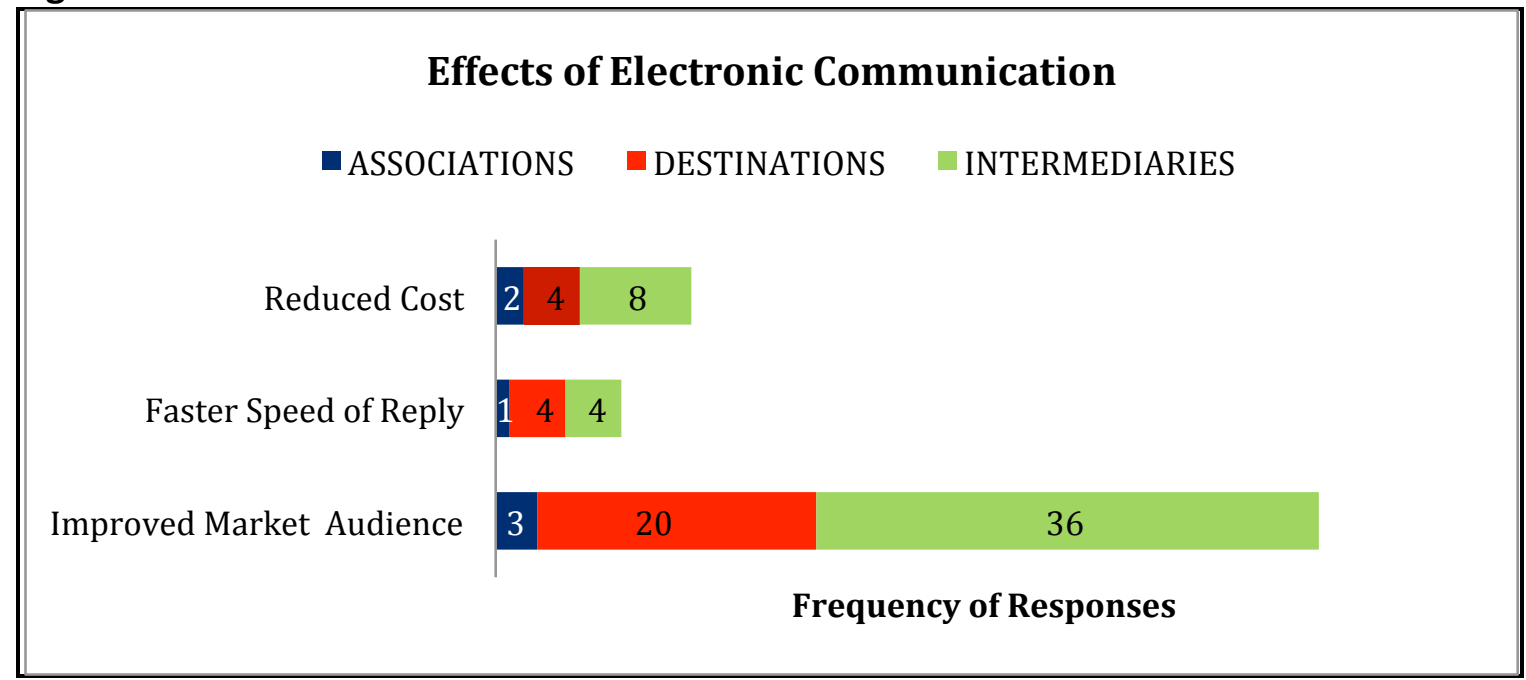

Source: Study

We also found out that broadband connectivity had enabled existing actors to access wider markets because of the ability to form global and local partnerships. They therefore could pose competition in new markets with these partnerships enabled by technology. Further, we found out that broadband connectivity had enabled many actors to access clients directly, without going through intermediaries, thereby increasing competition for their market share. These views shed some light on this important debate:

Yeah TripAdvisor, it is the strongest weapon and the strongest gift that a tourist has for or against a hotel. They go somewhere and comment, millions of people are reading and millions of people are making decisions based on those comments. So a lot of power has gone to the tourists. Initially a lot of power was with the tour operator. (Tourism Association)

It is only for them now as tour operators to enhance their marketing or they look for means in which they will prevent the hotelier from going directly to the client. But I don't think there is anything that stops me as a business person from using an intermediary. Remember if I use an intermediary who is the tour operator, he will require to be paid a certain amount and that certain amount I probably would have kept it for myself but if I go to a client directly, then I just talk to the client and it is direct interaction, there is no middleman. The tour operator here is the middleman. (Tourism Association)

The hotels have realized going through tour agents is a bit of a hustle because the tour operator will come negotiate the lowest rate that you can give them so that they can go and make profit out of charging their clients. So at the end of the day they will bring that business to us but it will be very low rate business while we can get ourselves out of here and go there like WTB and all that and get the clients ourselves at a higher rate. (Hotel) 
Hotels are coming up with their own websites where somebody can book direct. So travel agents, tour operators will have to adopt. Ticketing was for a long time a very good business, it is no longer. Now you can book your own ticket and fly. So if you are dependent on tickets you have to find another way of living. (Travel Agent)

What I would say, it has made the playing ground almost even. This means the small companies are giving the big companies a run for their money. With online presence, the Internet and all the facilities, a young Kenyan company can actually market itself online, get clients online and the clients actually travel. So I mean these companies did not have to open a branch or did not have to wait five to ten years or invest so as to open a branch so that a client can have faith in them. (Tour Operator)

The Internet has been a blessing to us, since anything which has been introduced brings good things. That happens but you must remember that all foreigners browse and use Internet. Many times bookings don't go through directly. A foreigner can call somebody like me and inform me, "We are a family of five people and we want to come to Kenya. We want you to look for a house for us, a place to stay for two weeks." Now, you see. I will personally take that responsibility. I will transfer him/her from the airport, get a house/private villaeverything. Now, $s$ /he pays me the money and then I go to pay the owner of the house. Now, you see it is only the commission I get. (Beach Operator)

\subsubsection{Managing Widened Local and Global Relationships}

Relationship management was a prominent theme that emerged from respondent interviews. As companies deal electronically with more suppliers and customers in the value chain, they found out that forming and managing relationships to be very important. Some companies were using the Internet to make direct connections with their customers for the first time. Others were using broadband Internet to enhance relations with some of their existing partners. Broadband Internet had enabled existing actors to access wider markets because of the ability to form local and global partnerships, as aptly captured by a respondent who said:

This is not something you would have imagined 15 years ago because for you to run a tour company you would have needed to travel to France, US to meet a travel agent to convince them that you can handle their clients. Now it is possible, you design a nice website. All you need is your skills and knowledge, you put 
together the services that you offer and you get people who own that service and if they actually come and consume the service and they are happy, you will get more coming. It is possible without you having to travel and meet those people. (Travel Agent)

Relationships can be formed via the Internet, but some respondents said they would never move away from providing face-to-face contact with their customers because of the criticality of face-to-face meetings in sealing deals. These comments from travel agents and tour operators illustrate the importance of physical meetings, even with the facilitative effect of the technology:

Like I said we have increased our online presence. That means we are interacting with these people directly, we do online sort of making ourselves known. We are also going there to market ourselves physically. We go for exhibitions in India, China. We are going there and we are marketing ourselves directly to them. The other thing we are doing is we are basically marketing ourselves as a country as well. (Travel Agent)

You see tourism is actually an export product if you want to put it that way. If you want to consume it you have to come here you know. You don't consume it out there, you have to come here to consume it. Based on that I can show you a lot of things over the Internet but unless I meet you, talk to you and you ask me all the questions and I take you through...You know some of the products we do have, it is usually a bit difficult to conceptualize especially if you have not been to Africa. So actually physical contact is actually very important. (Tour Operator)

Trying to access new markets, basically again you know the website and the trade fairs. You know when you go for the trade fairs you meet people from all over the world you know so you are able to meet people from the emerging markets as well and they are able to follow up through the Internet. (Tour Operator)

Besides, some respondents mentioned trust as a challenge when relationships are formed on the Internet. Physical meetings then become the means to counter the threat of trust, as these sampled comments by travel agents and tour operators show.

Yes it is very important. This is because the industry requires a lot of trust. If you are talking to someone either on email, Skype or phone they can sound interesting, nice, very honest, but then you find out it's a briefcase company, or the person is really dishonest. And you have to see the physical appearance, someone can have a very soothing voice and very nice...if actually you try and deal with them the first instance you see you don't want to deal with them. So it is very, very important, so that is why we have taken a lot of energy, a lot of resources putting together our office. (Tour Operator) 
We go check them out ourselves. For anything domestic, we check it out ourselves, we have been in business for over thirty years now, so we have built partnerships over the years. Some of the newer hotels that pitch up every now and again, we don't necessarily work with them right away. It is a little more cautious until we have actually gone and seen them. (Tour Operator)

What happens like here, if we want to sell a hotel to our clients, one of our staff has to go there and see the premises. Not only see one room but see the rooms, stay there for like one day and then he comes back with the pictures. You go and take the pictures for yourself, not what you have been given. You go and take the photos for yourself so that when I have the photo here I can show the client, when I was there I took this photo. So I sell what I know; so I take someone to a place which I already know, I have experienced how the place is. (Tour Operator)

Basically you have to meet and negotiate; they give you their prices and if you agree to those prices, you sign an agreement. Basically the agreement will dictate terms of the nature of business between the two companies so I would say briefly or rather in short is you identify the company that you want to work with, meet up with them and negotiate together. (Travel Agent)

\subsubsection{Enhanced Visibility and Reduced Marketing Cost}

Most tourism suppliers reported that they used websites, third party websites, social networks, and online advertisements to have an online presence. The principal advantages of using these platforms were enhanced visibility and, in some cases, reduced marketing costs as shown in figure 3.21.

Figure 3.21: Effects of Online Presence

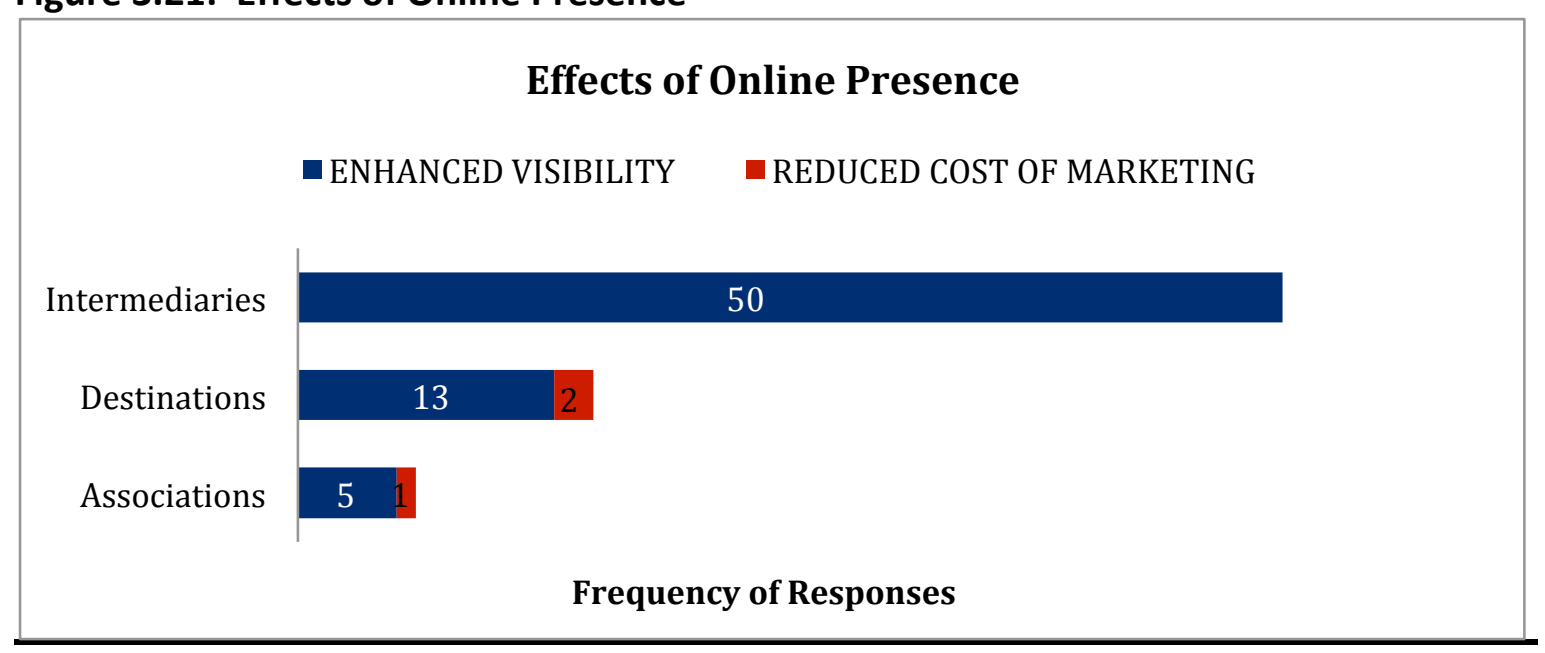

Source: Study 


\subsubsection{Reputation Management}

The growth in online travel reviews, and the trust which travellers place in such reviews, has significant implications for Kenyan tourism enterprises. Numerous websites publish online reviews about customer experiences with different actors along the tourism value chain.

Customers also share their good and bad experiences on social media sites such as Facebook and use their virtual contacts to seek recommendations. Monitoring and managing these channels is highly important for tourism businesses. A poor review on a site with such market reach and influence as TripAdvisor will have damaging consequences for any tourism enterprise.

The importance of maintaining company reputation was demonstrated by this comment from a hotel:

Positive comments we acknowledge, appreciate; negative comments we get back to the client directly and pick up the issue and address it and make sure that we communicate to the client and we make sure that we have addressed this issue and next time they book with us it will not happen again.

\subsubsection{Changes in Geography}

Changes in geography has been defined as scaling up into new areas, reconfiguring space, globalization, and regional integration, enabled by use of broadband Internet and related technologies. We have defined scaling up into new areas as "Efforts by stakeholders in the tourism sector to increase their offline presence to other areas so as to have a wider audience. This involves having multiple offices worldwide, representative offices etc." Reconfiguring space means Internet interactions in space that lead to forming, as well as strengthening the new and existing, relationships. Globalization is defined as any mention of the word 'world', 'global', 'global village' or 'worldwide' while regional integration is defined as the formation of relationships between countries in the East African region.

Figure 3.22-3.24 show the main effects of broadband Internet on geography among the respondents as scaling up into new areas, reconfiguring space, globalization and regional integration. It is evident from this figure that scaling up into new areas, reconfiguring space/distance and globalization were the more important effects of broadband Internet on geography.

\section{Associations}

Figure 3.22 shows that the main effects of broadband Internet on geography by the associations was globalization. 
Figure 3.22 Effects of Broadband Internet on Geography-Associations

\section{Effects of Broadband Internet on Geography-Associations}

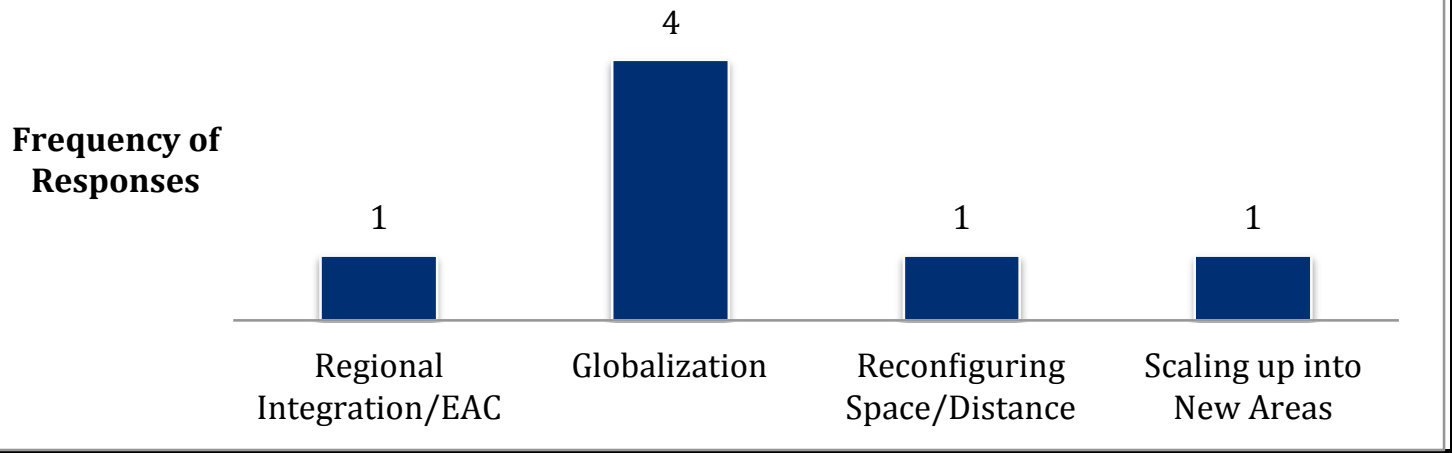

Source: Study

These statements highlight this globalization:

Our target market is the world, I would say, because with Twitter you cannot restrict people or say you only target tour operators or we are only targeting hotels.

One of the communication tools we have is the Internet, Facebook, Twitter and LinkedIn and one of the ways it has helped us is to market our members to the whole world.

\section{Intermediaries}

Most intermediaries agreed that broadband Internet and related ICTs had brought interesting opportunities to scale up into new areas, facilitate regional integration, promote globalization and reconfigure space because the new technologies were used as work tools, as shown in figure 3.23 .

Figure 3.23 Effects of Broadband Internet on Geography-Intermediaries

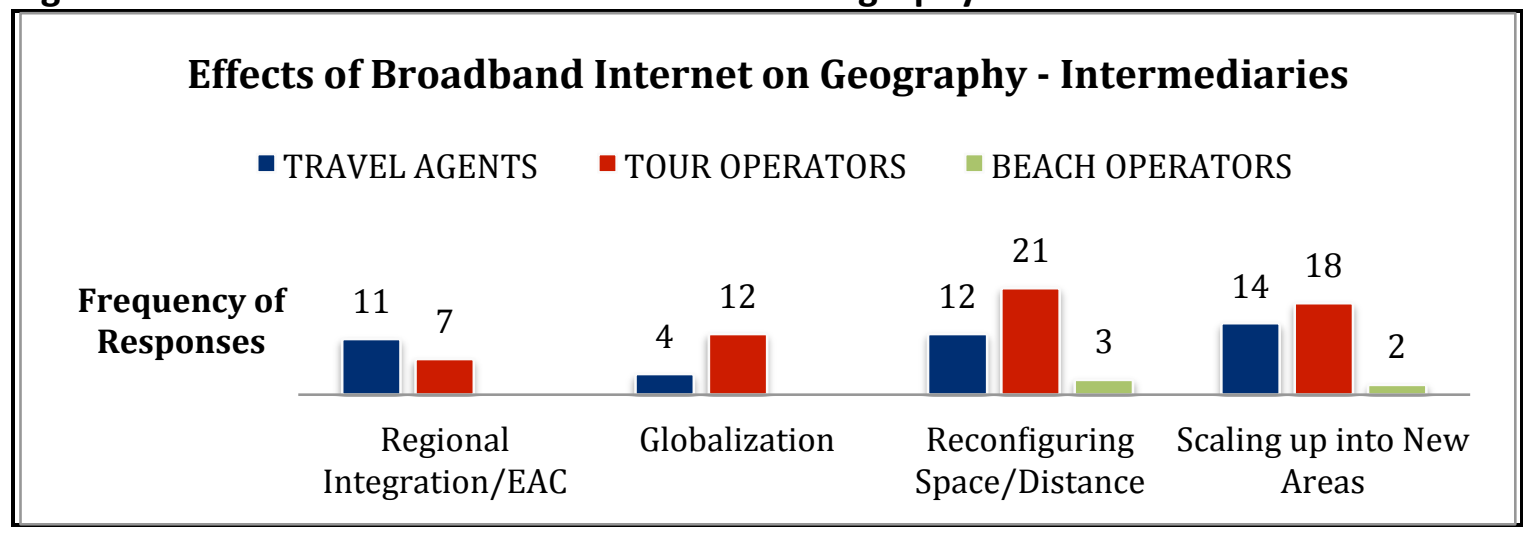

Source: Study 


\section{Destination Service Providers}

Figure 3.24 shows that scaling up into new areas and reconfiguring space/distance were the main effects of broadband Internet on geography by destination service providers.

\section{Figure 3.24 Effects of Broadband Internet on Geography-Destination Service Providers}

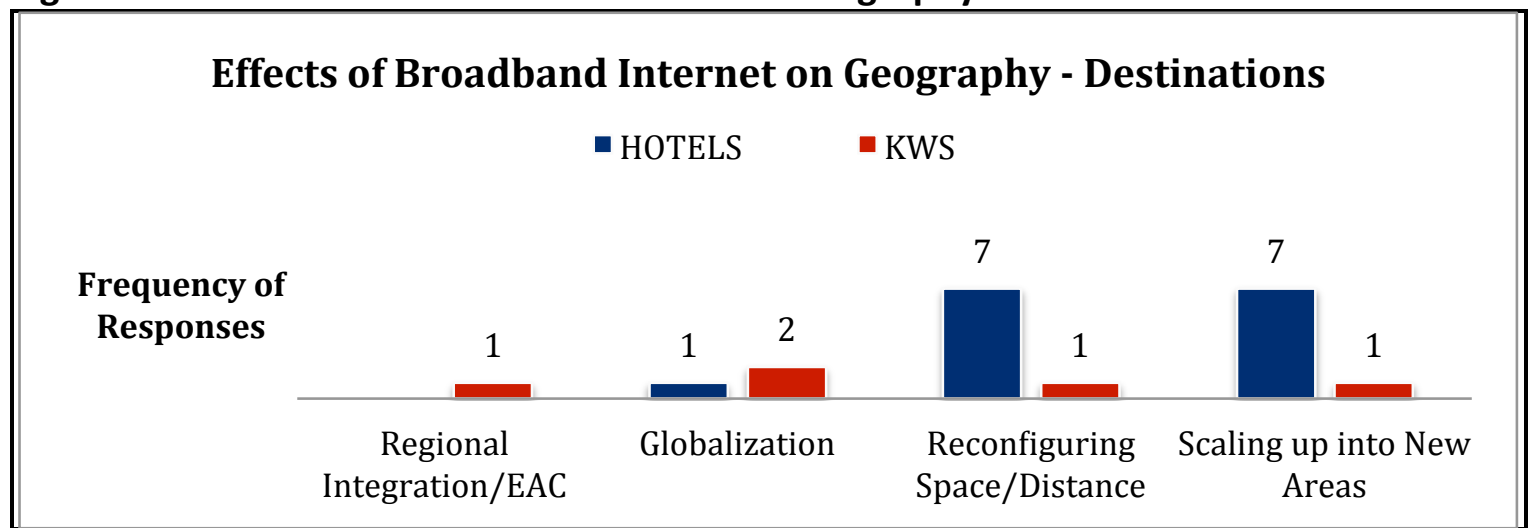

Source: Study

Here are some statements from respondents highlighting effects of broadband Internet and related ICTs on geography:

This is because we want to tap into the UAE market, and that is like the hub for the UAE market according to our investigations. It is very strategic and we want to tap into that market, considering getting ourselves into the Asian market. So we also would like to get a country and go there as well as us being in Africa; we just might get affiliate agencies in the rest of Africa instead of opening another office. But if another office was to be opened, most probably we will move to South Africa.

We don't target locals; we target foreigners because our target tourism is not domestic tourism. Our major target is America and Europe that is our first one, we don't target Africa basically.

\section{Summary}

A review of the research on the socio economic impacts of broadband internet on the tourism value chain indicates multiple effects. First and foremost, the evidence is fairly conclusive about the impacts on the productivity and efficiency of both small and large actors along the value chain. With the adoption of broadband internet and related technologies, there were changes that led to improved business processes. Secondly, broadband internet and related technologies contributed to growth. This is as a result of widened market audience which translates to increased customer volumes, in turn impacting on the rest of the economy. 
Finally, beyond productivity and economic growth, broadband internet and related technologies had a positive effect in terms of benefits to the service providers. These include enhanced visibility and reduced marketing costs, which can be measured in terms of the difference between the marketing cost before and after the adoption of broadband internet and related technologies.

\subsection{How Actual Changes Differ from Academic, Public and Political Discourses Surrounding Potential Effects (RQ5)}

In order to address this research question, it is necessary to consider the hoped for effects as represented in public and political discourses as identified in section3.1 and compare these effects with actual findings in sections 3.2 to 3.4. Fig 3.1 shows that dominant expectations of the arrival of undersea fibre optic connectivity were reduced Internet costs, improved speeds, and economic growth.

We now discuss the actual changes in relation to the hoped for effects of broadband Internet.

\subsubsection{Reduced Internet Costs}

There was an overwhelming expectation that the undersea cables bringing in broadband connectivity were to result in a massive reduction in Internet prices, as illustrated in section 3.1.1. Some actors complained that the cost had not come down as much as they had expected. More importantly, small actors in the value chain found broadband Internet very expensive, especially for uses that require huge amounts of bandwidth, like video clips. These actors were therefore not taking full advantage of the benefits brought about by broadband Internet. Other actors on the tourism value chain however stated that they found the price of Internet connectivity to be fair and that they were taking advantage of broadband Internet and related technologies.

\subsubsection{Better Quality of Internet Services}

Service quality focuses on user satisfaction of Internet connectivity and may include speed, reliability and availability. The public expected better quality of service, especially access to better speeds or high capacity bandwidth. Some respondents in the tourism sector were not satisfied with the quality of the service for Internet connectivity as illustrated by these sampled responses: 
It is good but at times we have challenges with speeds, the speeds are not as fast we would want them to be. (Travel Agent)

It is not as fast, as much as we are saying it is fast than it used to be it is not that fast, you still cannot watch a video without being interrupted. (Travel Agent)

We are having issues right now, being without Internet for a couple of hours is a tragedy; we lose lots of business. So we need reliable Internet. (Tour Operator)

As figure 3.14shows, cable breaks, power cuts and technical barriers, including service reliability, were some of the key connectivity challenges cited. These challenges degraded the quality of the service provided. There were however other actors who felt that their speeds had improved and were satisfied with their connections. The following are illustrative quotes:

We don't have any issues with downtime affecting our applications. (Travel Agent)

With fibre you have guarantee of $99.9 \%$ uptime, that means you can do anything you want, then you have faster speeds. (Tour Operator)

The speeds are very good. (Destination Service Provider)

\subsubsection{Further Benefits}

Respondents mentioned further effects of broadband Internet and related technologies, the key ones being:

- access wider markets because of the ability of existing actors to form local and global partnerships,

- enhanced productivity and increased efficiency (see figure 3.16-figure 3.18),

- offer actors new opportunities and strategies which were not available before broadband (see figure 3.19),

- new markets, reduction in costs and faster speed of reply due to electronic communication (see figure 3.20),

- enhanced visibility reduced marketing costs due to online presence (see figure 3.21), and

- effects of broadband Internet on geography (scaling up into new areas, reconfiguring space, globalization and regional integration) (see figure 3.22-figure 3.24). 
The research answers this question by reviewing the hoped for effects as represented in academic, public and political discourses and comparing to actual responses from actors in the tourism sector. Results show that some of the actors complained that the costs had not come down as much as they had expected. The small actors in the value chain were most affected, they found broadband internet to be very expensive. This prevented them from competing fairly with big actors who did not have any financial challenges adopting these technologies.

An improvement in the quality of internet service in terms of better speeds, availability and reliability was expected by the public. This had not been achieved because of the multiple challenges experienced by a majority of the actors. These include cable breaks, power cuts and technical barriers.

During the first focus group discussion workshop, we asked participants to indicate who benefitted most and least from broadband Internet and related technologies. Table 3.6 shows a summary of gainers and losers from answers to this question.

Table 3.6: Biggest Winners and Losers of Broadband Connectivity in the Tourism Value Chain

\begin{tabular}{|l|l|}
\hline \multicolumn{1}{|c|}{ BENEFIT MOST } & \multicolumn{1}{c|}{ BENEFIT LEAST } \\
\hline $\begin{array}{l}\text { Customers - who are able to reach service } \\
\text { providers and compare and get the best deal } \\
\text { Tour operators and travel agents - who have } \\
\text { embraced technology }\end{array}$ & $\begin{array}{l}\text { Operators who are still using offline } \\
\text { marketing methods such as offline } \\
\text { advertisements in magazines, newspapers, } \\
\text { and brochures }\end{array}$ \\
$\begin{array}{l}\text { Hotels have an easy way of selling, online } \\
\text { advertising and marketing through social }\end{array}$ & $\begin{array}{l}\text { Intermediaries (travel agents and tour } \\
\text { operators) because they are cut out of the } \\
\text { chain as easy and direct links have been }\end{array}$ \\
& $\begin{array}{l}\text { established between customer and service } \\
\text { provider }\end{array}$ \\
& $\begin{array}{l}\text { Destinations whose information is not } \\
\text { available online }\end{array}$ \\
\hline
\end{tabular}

Source: Study

\subsubsection{Challenges}

The main challenge that was anticipated with broadband availability was increased cyber insecurity. We found that cost, which goes beyond the cost of the broadband, was still 
one of the challenges of adopting broadband Internet and related technologies. A respondent for example complained that the cost of developing and maintaining a website was too high for his business. He also complained that clients were not able to use third party websites and online booking systems due to a lack of access to ICT infrastructure. This cost challenge was best illustrated by a respondent who argued over the cost challenge of website optimization:

Optimization because I am getting a lot of requests from India, US people trying to tell us how they can improve our visibility in the Internet. Yeah but it is not for free. You have to pay money. We have tried here, we have a site and we have to employ somebody to develop it and it costs money. In fact Google does it on hits. I used to do it on hits and it is very expensive. When they charge you on the hits you have, you see because not every hit translates to business, so we tried that and found it to be very expensive. So for optimization is for those who can afford to have something. You see even our graduates here I don't think they are very smart on that. And you need to employ them and they are very expensive and their work is just to try and improve your ranking online. There are people who say they have such things in India and in the US but they ask for a lot of money.

We also found the following challenges in the tourism sector:

- increased competition due to reduced barriers to entry (reduced start-up, distribution and operational costs),

- cybercrime,

- online scams,

- viruses,

- limited human skills,

- trust, and thus the need for physical visits to complement online engagements,

- challenges of payment platforms, especially lack of infrastructure, high transaction costs and lack of electronic payment skills, and

- disintermediation, with customers going directly to service providers. 


\section{Tea Sector Findings}

It is to be noted that research question 1 is addressed in section 3.1 and applies to both tourism and tea sectors.

\subsection{Integration of Broadband Internet and Related ICTs into Tea Value Chains (RQ2)}

This section presents broadband Internet and ICT technologies used by actors in the tea value chain. The technologies have been divided into six categories: last mile connectivity, access to customers, electronic communication, information access, online presence, and electronic payments.

\subsubsection{Last Mile Connectivity}

\section{Before the Fibre Optic Broadband Cables}

Respondents were asked to state Internet access types they used before the laying down of the fibre optic broadband cable in 2009. This question assisted in making a comparison between the changes in connectivity before and after 2009. Figure 4.1 shows information on the types of Internet access methods used.

Figure 4.1: Types of Internet Access before Fibre-Optic Broadband

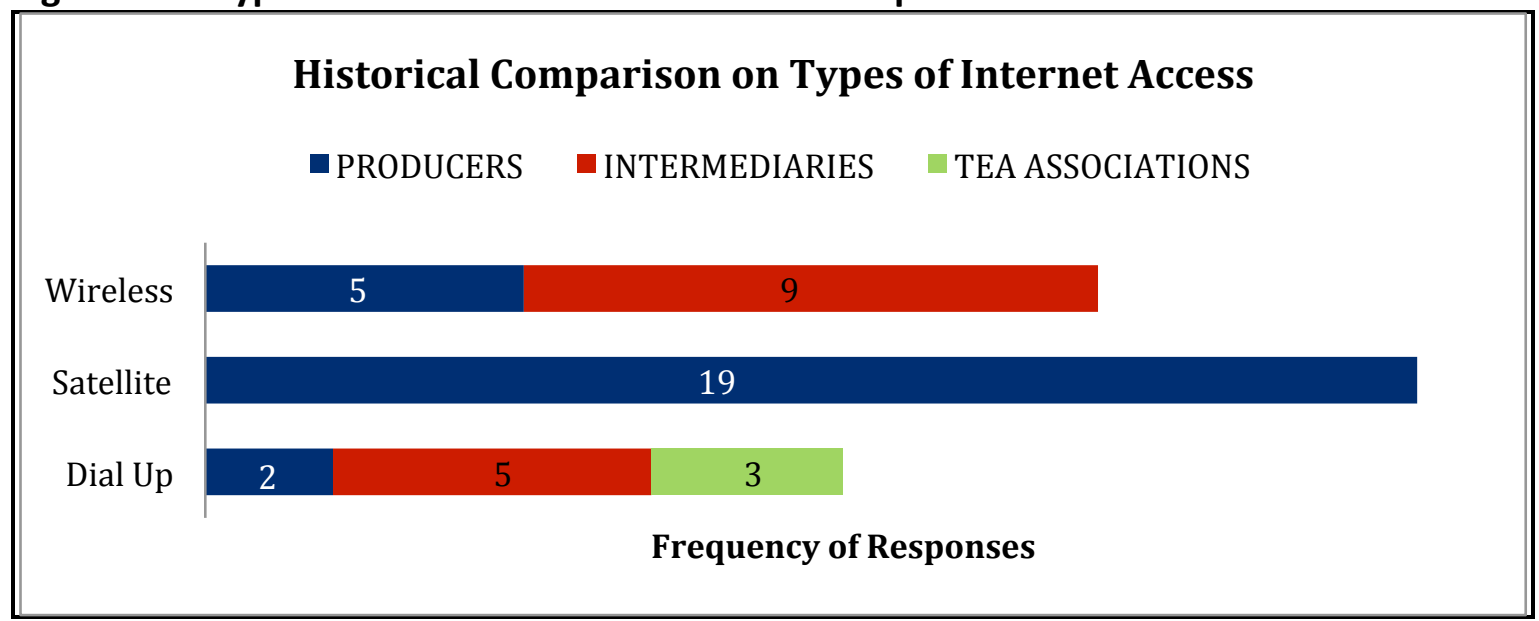

Source: Study

Figure 4.1 shows that only producers used satellites largely because most producers are located deep in the rural areas which are largely underserved by the mobile communication infrastructure and satellite was the only option before the fibre optic cables landed. For the intermediaries and tea associations, the most popular access to 
the internet was wireless links because stakeholders are largely based in urban areas where wireless communication infrastructure is readily available.

\section{After the Fibre Optic Broadband Cables}

Respondents were asked to state Internet access types they used after the laying of the fibre optic broadband cable in 2009. This question assisted in making a comparison between the changes in connectivity before and after 2009. Table 4.1 below shows information on the types of last mile access methods used.

Table4.1: Types of Last Mile Connectivity after Laying of Fibre-Optic Broadband Cables

\begin{tabular}{|l|l|l|l|l|}
\hline & DSL & Fibre & Modems & Wimax \\
\hline Producers & 1 & 19 & 5 & 4 \\
\hline Intermediaries & 0 & 4 & 4 & 5 \\
\hline Tea Associations & 0 & 1 & 0 & 0 \\
\hline
\end{tabular}

Source: Study

It is evident that a majority of the businesses had adopted fibre optic connectivity in their properties because the fibre optic cable had just landed. As a result, operators cancelled their contracts with satellite companies and provided fibre connections to their consumers at a cheaper cost. The other actors had migrated from digital subscriber lines (DSL) and wireless connections to fibre, modems and Wimax connections. Respondents expressed views regarding last mile fibre connections and their impact, as these views from two producers demonstrate:

Initially we were on satellite. So when we moved to fibre, no we went to Safaricom first. We were using modems on their GSM network which of course had its own limitations and then now we are on fibre and of course in terms of operation costs, it has really made an impact, one in terms of reliability we have a more reliable link. So more or less $99 \%$ of the time we have received the data, the speed.

I would say a big impact. One you know before it was on satellite and then the submarine cable came in. The costs came down for Internet and then we get bigger capacities at relatively cheaper cost. It was around KES 90,000 for $512 \mathrm{Kbps}$ [cost of internet before submarine fibre optic cables arrived], right now we are paying around KES 45,000 for $2 \mathrm{Mbps}$ [50\% the cost for four times the capacity].

\subsubsection{Access to Customers}

Respondents were asked to indicate on behalf of their respective companies which online channels were used most for accessing customers. This question was necessary as it enables the researcher to have an insight into online channels commonly used by tea 
stakeholders in Kenya, giving the researcher a clear idea of what is happening in the tea sector in Internet usage. Figures 4.2 and 4.3 show the popularity of a number of online platforms that are used by producers, tea cooperatives, and intermediaries.

Figure 4.2: Forms of Online Access to Customers by Producers and Cooperatives

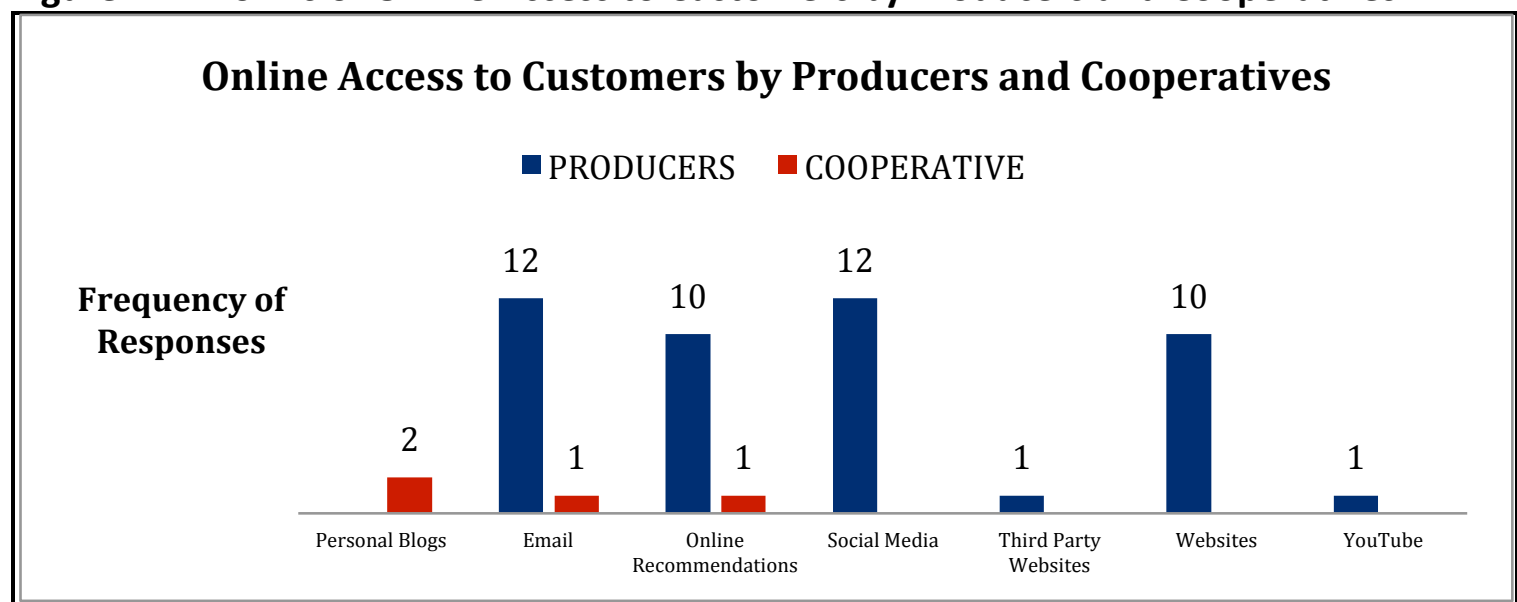

Source: Study

Figure 4.3: Forms of Online Access to Customers by Intermediaries

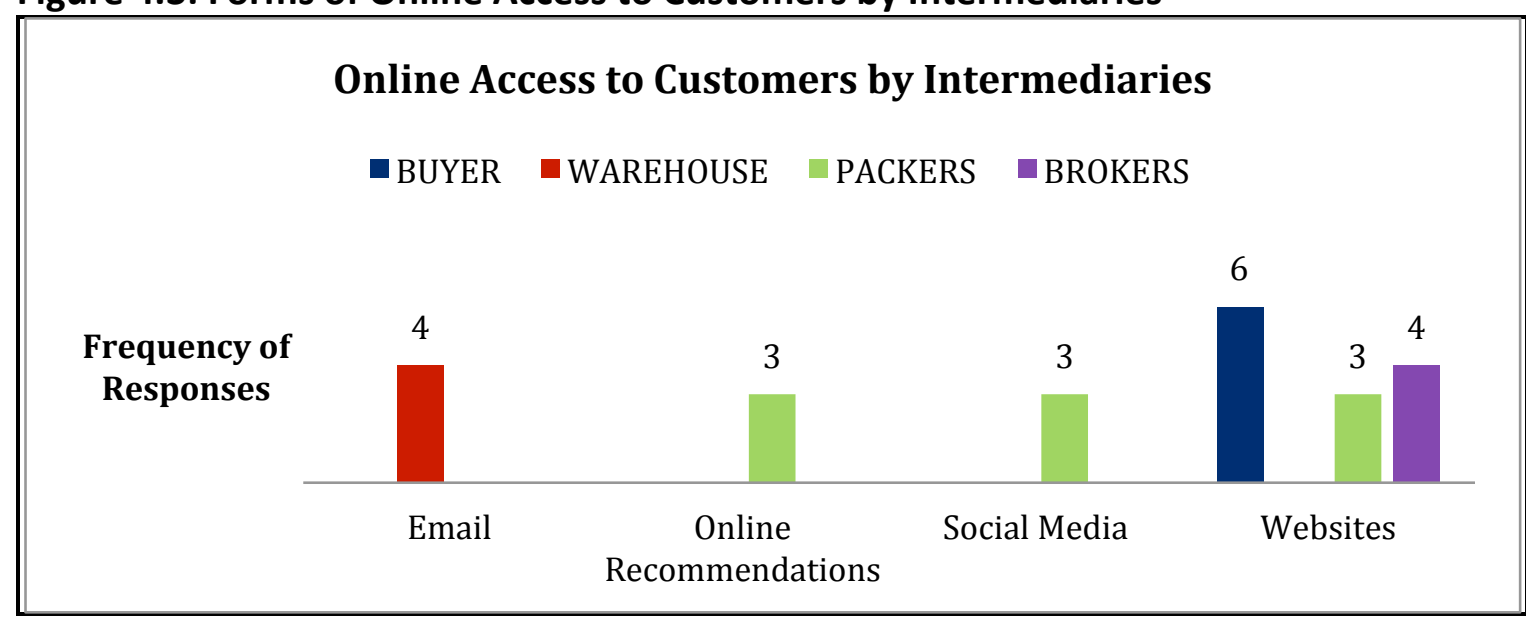

Source: Study

It can be observed that producers used most online platforms as channels of accessing customers. A majority of the tea stakeholders used websites as a means of accessing customers. There were very few respondents who indicated that they used personal blogs, third party websites and YouTube as a means of accessing customers. The importance of email was demonstrated by these two comments from producers:

Even yesterday I got somebody very small asking for a dust grade from Mombasa and all it takes is getting my contact from a friend who knows me and then drops 
a mail and then gets a reply and the next thing probably is a phone call. If I sound pleasant he can come in here, that sort of thing.

If I see an email address probably @lipton.com probably out of curiosity I might log into Lipton just to see, like many websites there will be a contact and you can just query. Again most of the correspondence is through other buyers here through interacting with other buyers so then you will have a buyer writing a request even directly to the factory; "I was introduced or I saw this...Can you tell us the procedure?" It is usually through electronic mail, of course we now route them through the head office.

In addition, we found out that non-electronic means were still important, including physical visits and 'word of mouth'. The study found out that websites and online platforms enabled some discovery amongst clients. These however were normally supported by face-to-face interactions, as a broker observed:

Most people prefer to come and talk to people because a website can give you all kinds of stuff and when you come here people say, don't touch that guy. So I think we are definitely going to provide a website. That would be to market us so that people can contact us. That would be useful and of course it gives us an opportunity. That is, if there is a producer in Malawi who decides to search for a broker in one of the websites that will be there.

It is from the website and through referrals. We also go to conventions, to trade fairs. That is where we get our clients from. But lately we are seeing quite a number of inquiries through the Internet. (Producer)

\subsubsection{Electronic Communication}

Respondents were asked to reveal the forms of electronic communication they normally use to communicate with their customers. The responses by interviewees are represented in Figure 4.4. 
Figure 4.4: Forms of Electronic Communication with Customers

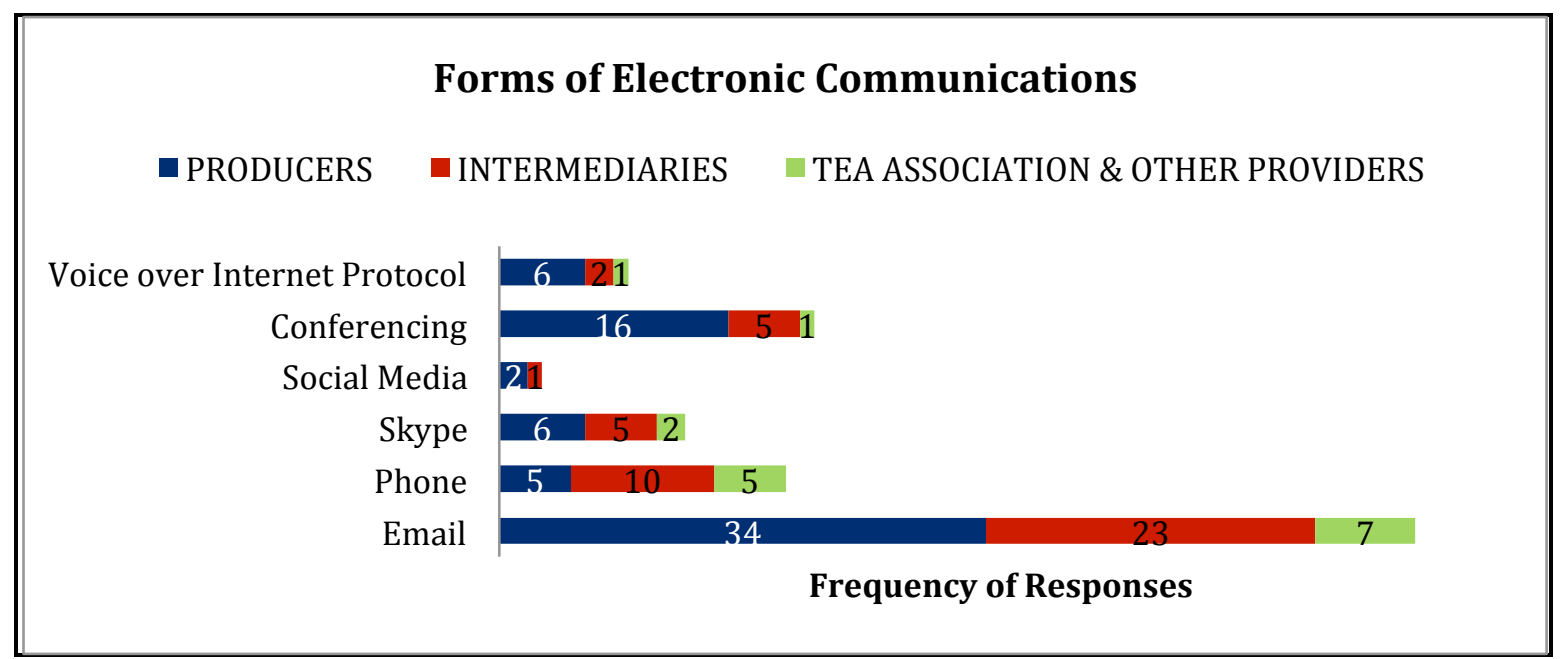

Source: Study

Most respondents indicated that they used email in their communication with respective clients or customers as figure 4.4 shows. This communication is often between intermediary customers both local and international in the tea value chain rather than to the "end customers." A customer in this context is defined as any firm or individual who supplies black tea from the primary producer to an ultimate trader, an exporter, a local market operator, or an international market operator. It is evident that producers utilized a majority of the electronic communication tools in linking with customers both locally and internationally. The importance of email as the primary means of electronic communication with customers was captured by the following comment from a producer:

I still hold the same view, reason being all our communication and all our transactions of late is purely on the Internet. Even Kenya Tea Packers (KETEPA) here, for your information, we rarely communicate with them using phone. In fact bids which are being done by Kabianga Tea factory, negotiations which are being done, okay we may confirm through the phone but most of the communication that we have always done is through the Internet. So many instances we have had to refer back to the emails that we had done and that avoids a lot of mistrust and a lot of ambiguity in terms of setting the prices for tea. ICT has revolutionized how we are doing things and it has been a marvellous way of doing things.

One interesting point emerging from this statement is that putting everything in writing in an email had reduced mistrust in the tea sector. This was not the case in the tourism sector where mistrust was still rampant despite the use of email. Perhaps this is because the tea sector has relatively smaller number of actors, most are well known and majority are corporate organizations. This is in comparison to the tourism sector where the customers are largely individuals from anywhere in the globe. 
A respondent however aptly captures the importance of the remaining electronic means of communicating with customers:

By far that is it, now it is easy to work as teams, the geographies are there but we are still able to form one team. Through virtual meetings, webcasts, it is easy for us to share information and travel has reduced drastically. Yeah because if I have to work with my colleagues in Singapore, India, South Africa, it is just a question of setting up a virtual meeting, in the next one hour I can have a team meeting with people from all over the world. We share the same presentations and we even see each other's faces, yeah I mean that is a beautiful thing.

A producer explained that the Internet had made it easier to communicate and interact with actors locally and globally:

With the Internet that is so much helpful to us, in fact we exchange with a good number of organizations, both locally and internationally. Like we have international certification bodies, in fact our company has undergone certification, what is called ISO 9001:2008. We also have ISO 22000 on food safety, and we are now carrying out another certification on sustainable agriculture, and all these we actually exchange with the head office in Nairobi and abroad electronically.

\subsubsection{Information Access}

Respondents spoke about various forms of access to information. A producer mentioned the importance of publications:

There are some publications that we look at which gives information about the global prices and from that we can tell that this country is fetching better prices than ourselves. So information is available...[in] publications.

A tea association respondent explains the shift from paper to IT as a means of accessing information:

Because for buyers they depend on their principal buyers to give them the information, and as huge as it is and if they want to produce hard copies and then they had to scan them for buyers because they used to disseminate it to the buyers, the buyers scan them if they want to send them to the principal buyers. So the communication from that used to be very huge, and now we had to reduce everything to be in MS Excel format. The extent to which we have incorporated the fibre, now it is easier and at the same time we get copies...we can also upload the copies to the website, we have a portal where we upload all this information. 
Overall, the research found that most of the respondents used email and websites to access information as shown in figure 4.5. This is information regarding their suppliers, customers and also their competitors.

Figure 4.5: Information Access Channels

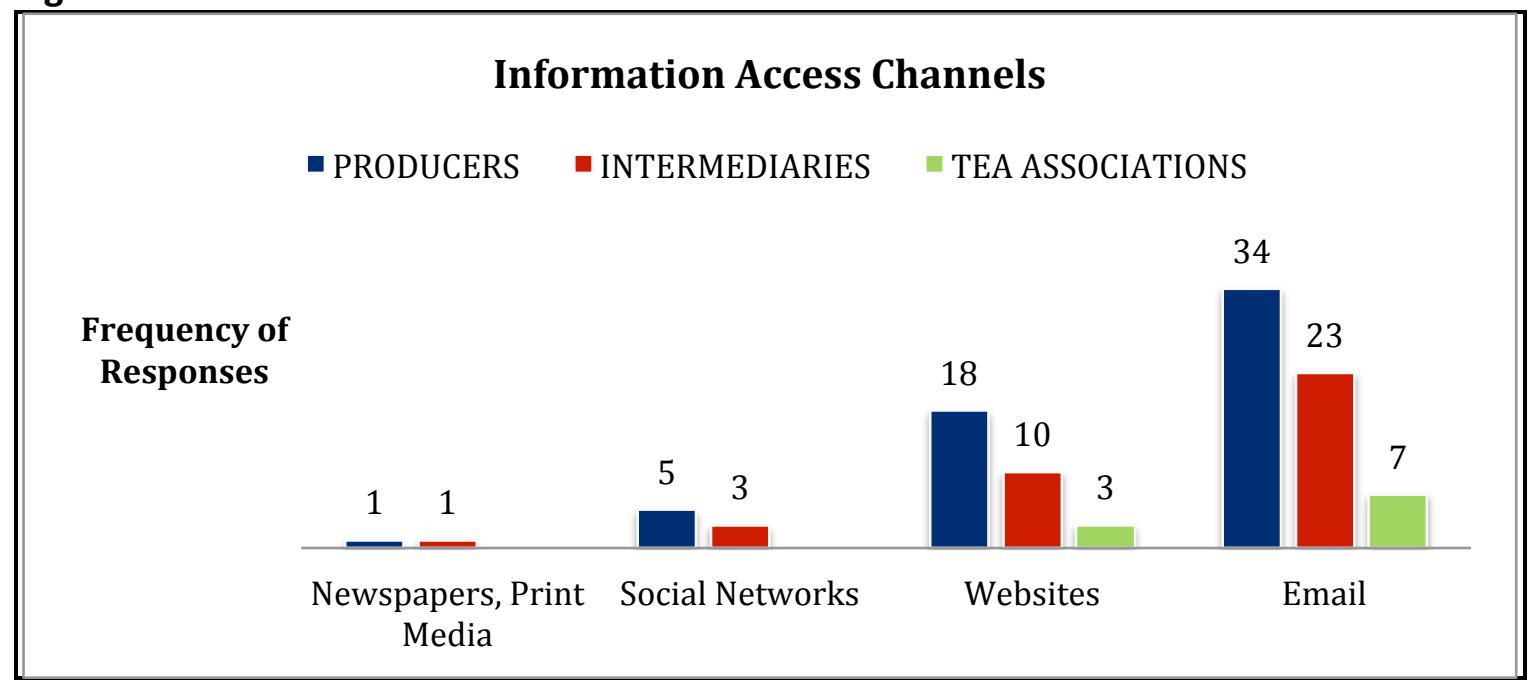

Source: Study

Some of the participants spoke about lack of information flow in the value chain. Most of the information that producers mostly need is still kept with brokers instead of it information being shared to all the stakeholders, especially the producers. As an example, one producer made the following comment:

We cannot tell because for us now Cargill becomes now our end user. We don't know what happens to the teas thereafter. If they have complaints they will communicate to Cargill (broker) then Cargill will communicate to us, there is that information flow. But you see now there is a cut-off point, you know with a broker now, yes, it would have been important we have that information but at the end of the day how do you source that information?

Similar sentiments were expressed by one producer in Kericho who complained:

They will tell you what the customer said about the quality of your teas, but then that is already history they cannot tell you what to do. For example, they cannot tell you that are a lot of buyers are coming from this side, they would want this type of grade, can you shift your production matrix to favour that so that you are able to net these buyers. They will always give you information retrospectively.

From these two comments, the brokers therefore act as information gatekeepers. It can be argued that they can exploit the information asymmetry to serve their interests. Automation of the tea auction would bring about information transparency and get rid of 
the information asymmetry. This is why the brokers were the biggest resistors to the automation of the tea auction as argued elsewhere in this report.

\subsubsection{Online Presence}

Respondents were asked to state the types of online presence platforms or strategies they normally use to market their tea. Respondents were given a list of the commonly used types of Internet marketing ways. Figure 4.6shows responses regarding the different features of the Internet used by different stakeholders.

Figure 4.6: Strategies for Online Presence

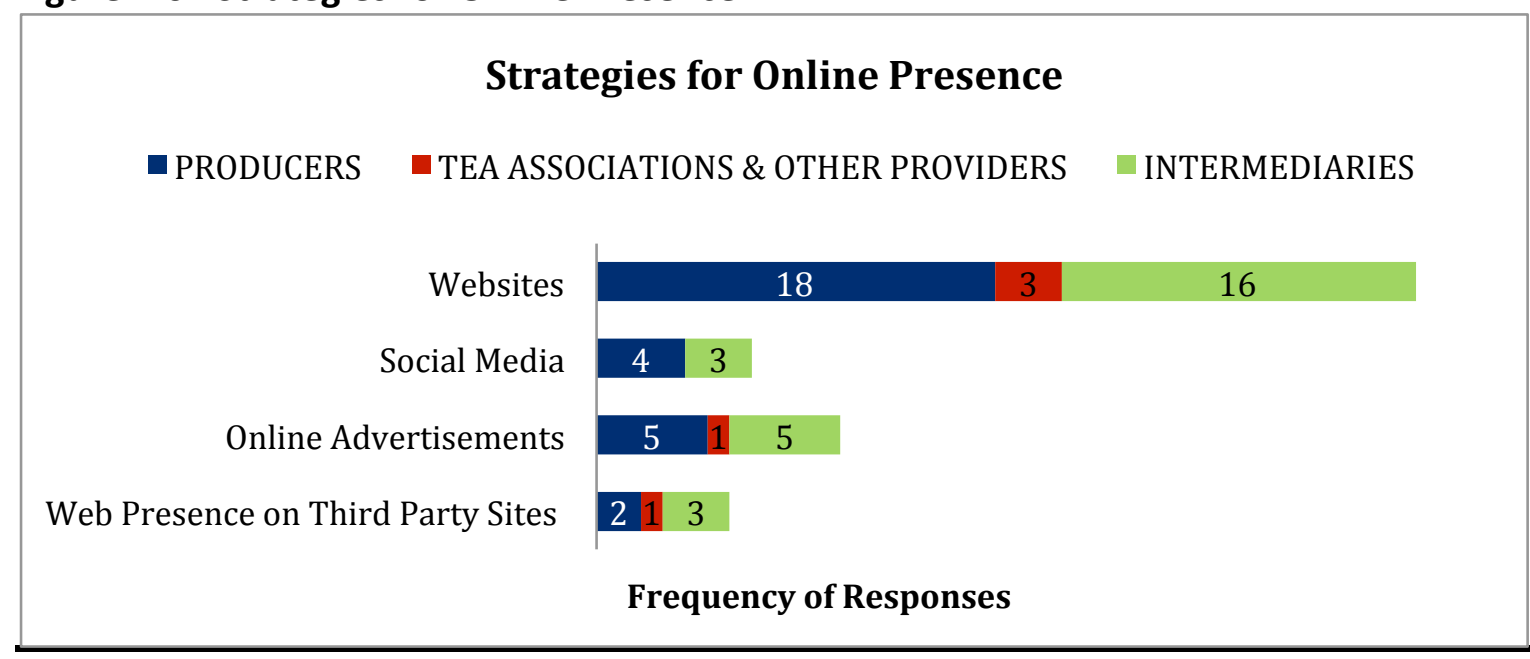

Source: Study

Figure 4.6shows that most respondents indicated that their businesses used websites for marketing, while brokers and tea associations used websites as the only means of marketing themselves. The websites were updated regularly and most of the website are informational-they describe the company, what they do, the various tea grades they deal in and how they can be contacted. It is evident that producers use all the marketing platforms available to them such as third party websites, online advertisements, social media and websites when marketing their businesses. One of the tea producers from Kericho stressed the importance of websites as a primary means of access to information by their customers:

Through the products that we offer to the market, if you Google, we would like to be among the first people, a conglomerate of Kabiangas because we have products that are eye catching. So like when you click on Kabianga Tea Factory there are some good products that we can have a look at from this point of view. And also making our website to be very attractive. I know of some good websites which you would always want to visit even if you are not buying anything from 
there, you would always want to be just browsing. But in our case we want to offer quite a range of products. If somebody in Egypt because I know they are interested in tea, they look at Kabianga and they are like I must buy this tea because of the products that we are offering. I think that is the key thing that we want to have a look at as an institution.

A tea association respondent explained that the Internet had made it possible for small and big actors to have access to vital information:

Right now in my opinion I believe Internet is empowering all the actors across the value chain. That is, information is now at the palm of every player, the small producers, the small factories can access the information they want on their mobile phones. They can...access on their iPads and on their computers whenever it is required. So it is not like before when information was a preserve...accessing information you would pay a premium for it, so it is only the Finlay's that would be able to do that.

A producer too acknowledged the importance of websites:

As much as marketing of our products is concerned, we are using the Internet, we have developed a website, where we have put the products that we have on the same. So we get people visiting the website and making inquiries though rarely but once in a while you will find an inquiry coming through indicating that we got your contacts and the information through the website and we are interested in knowing much about the product.

A buyer concurred with the producer:

As a company, yes, we are using faster Internet to make ourselves visible because technologically the world is moving and definitely it is the best interest of any business to try and catch up. So what we do is we avail ourselves through the websites and more than that, just as I stated earlier, the respective clients we serve, we make sure that even in their advertisement or not, even in their advertisement at least they indicate where the tea originated from. So in the advertisement which, most of them advertise through the Internet, at least we are mentioned, so that is how we utilize the Internet facilities in terms of marketing.

Similar sentiments were expressed by producers, with one of them remarking:

In terms of research, the Internet can assist where much of the information is there on the Internet and through that you will be able to get contacts and also you will be able to get what they are engaging in. For example, there are those grades which are for some certain uses. People will buy tea for consumption; 
others will buy tea for processing. So when you are able to get that information what they do you will be able to say that for this certain grade I can...approach this certain customer in this country and probably he might offer me a market. So I would say much of this is through research and this can be accessed from the Internet.

\subsubsection{Electronic Payments}

Respondents were asked to state what electronic platforms they used in the payment of both goods and services with suppliers, customers and related agencies. This question assisted in modelling the relationship between Internet usage and the effects of changing connectivity. Figure 4.7 gives information on electronic payment methods used.

Figure 4.7: Electronic Payment Methods

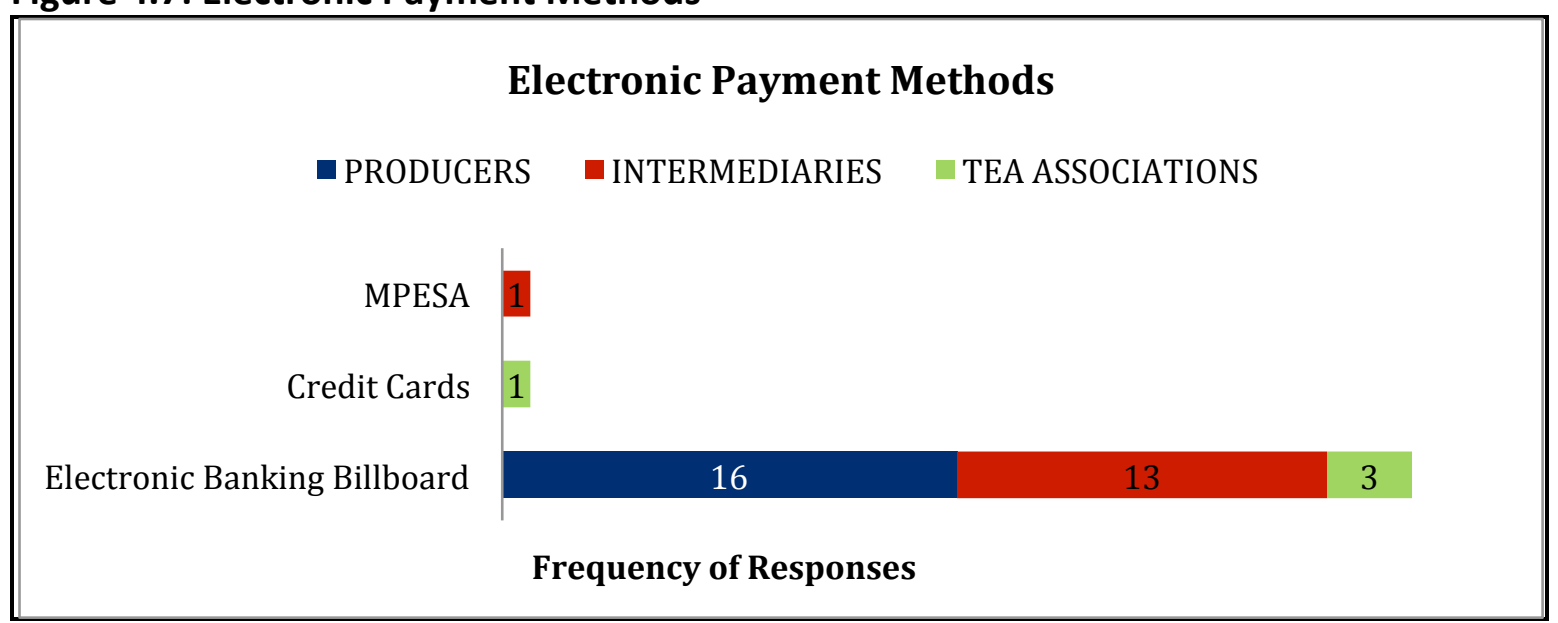

Source: Study

It is evident that electronic banking billboards ${ }^{3}$ account for the majority of online transactions-apparently because most of the teas are sold through the auction and payment is settled through an electronic payment platform, the Electronic Banking Billboard (EBB), which is managed by EATTA in partnership with CfC Stanbic Bank. The other tea is sold directly and this involves bank transfers into individual bank accounts.

\footnotetext{
${ }^{3}$ This is a mobile payment solution conceptualized and implemented by the Transactional Products and Services team at CFC Stanbic Bank in conjunction with other bank stakeholders. It entails availability of information required to purchase and release teas via an electronic platform. CfC Stanbic Bank has partnered with Safaricom, the largest mobile telephony company in Kenya, to facilitate payments to mobile phone beneficiaries. This has heralded a hitherto unprecedented opportunity to improve the efficiency of the tea value chain.
} 


\section{Summary}

Our research on the integration of broadband internet and related technologies on the tea value chain shows a number of platforms used to facilitate communication and information exchange. The platforms are based on new technologies such as the web and mobile technologies that enable users to communicate, collaborate and conduct transactions in real time. These platforms include social networking sites, video content sites, third party websites, virtual worlds and electronic payment methods.

Emails and websites are seen as the main platforms for communication and interaction with customers and suppliers. With many interactions taking place for free on these platforms, most of the figures presented above indicate how broadband internet and related technologies continue to grow in the tea value chain. Online banking e-payment methods, such as the Electronic Banking Billboard is the main mode of payment in the tea sector. However, alternative modes of payments are also gaining ground in the sector, including credit cards and MPESA, with the latter having a domestic reach. 


\subsection{Unexpected Challenges to Broadband Use (RQ3)}

This section discusses the impacts of broadband connectivity. Most respondents highlighted positive impacts of broadband Internet and related ICTs, pointing out how these technologies for example had eased the ways in which tea stakeholders deal with important issues in their businesses such as accessing customers, maintaining existing relationships, and forming new relationships. One producer emphasized the role of email in accessing customers:

So as much as marketing of our products is concerned we are also using it [email]. We have also developed a website, where we have put the products that we have on the same, so we get people visiting the website and making inquiries though rarely but once in a while you will find an inquiry coming through indicating that we got your contacts and the information through the website and we are interested in knowing much about the product.

Broadband connectivity and related technologies have some negative effects on the tea sector, however. This section therefore focuses on the negative impacts of broadband Internet and related technologies on the tea industry.

\subsubsection{Overview of Challenges}

Respondents were answering a question on the challenges brought about by the changes in connectivity, but their answers represent an overview of challenges of broadband connectivity. Figure 4.8 provides a summary of the challenges of connectivity.

Figure 4.8: Summary of the Challenges of Connectivity

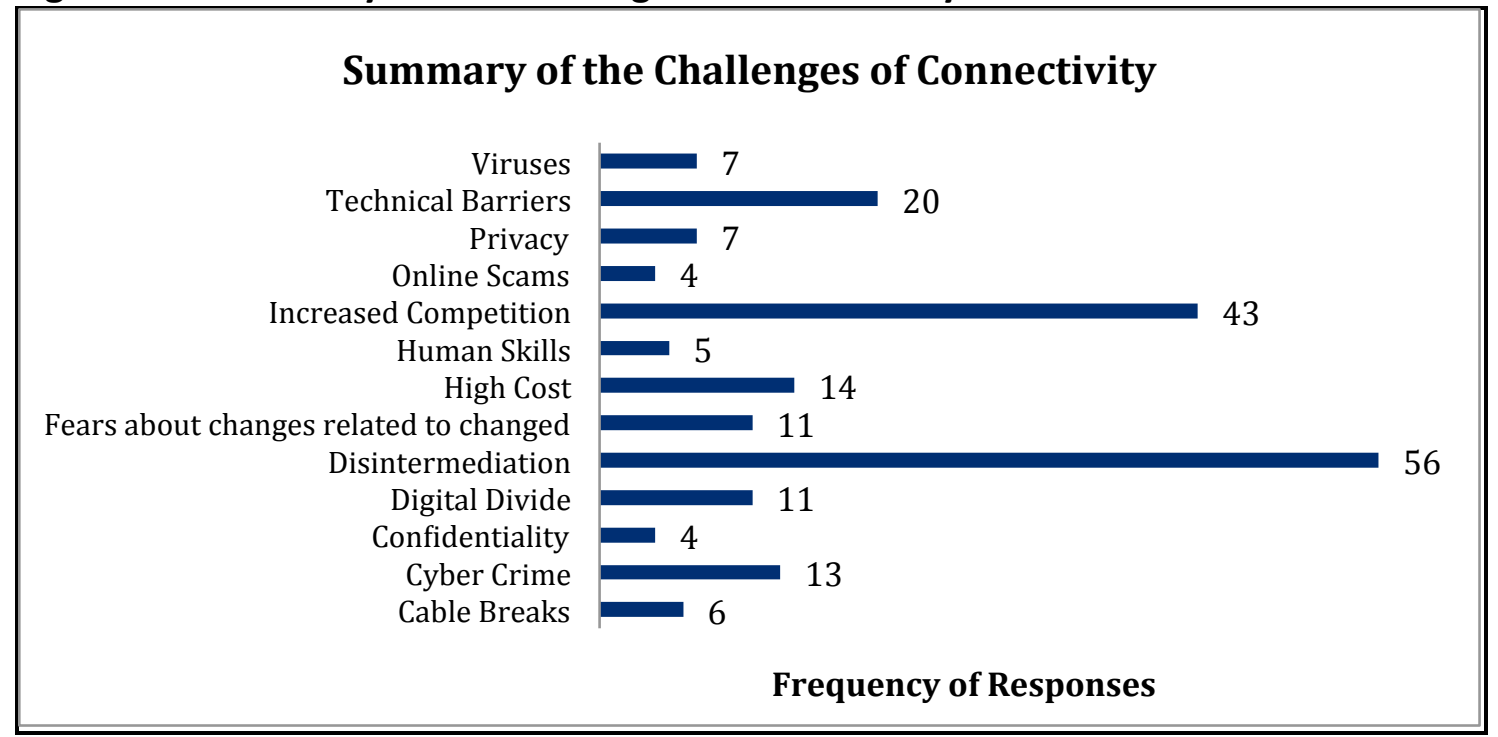

Source: Study 
Further challenges are summarized in figure 4.9, which was obtained after a question on the effect of broadband Internet on actors in the tea value chain.

Figure 4.9: Effects of Broadband Internet on Actors in the Tea Value Chain

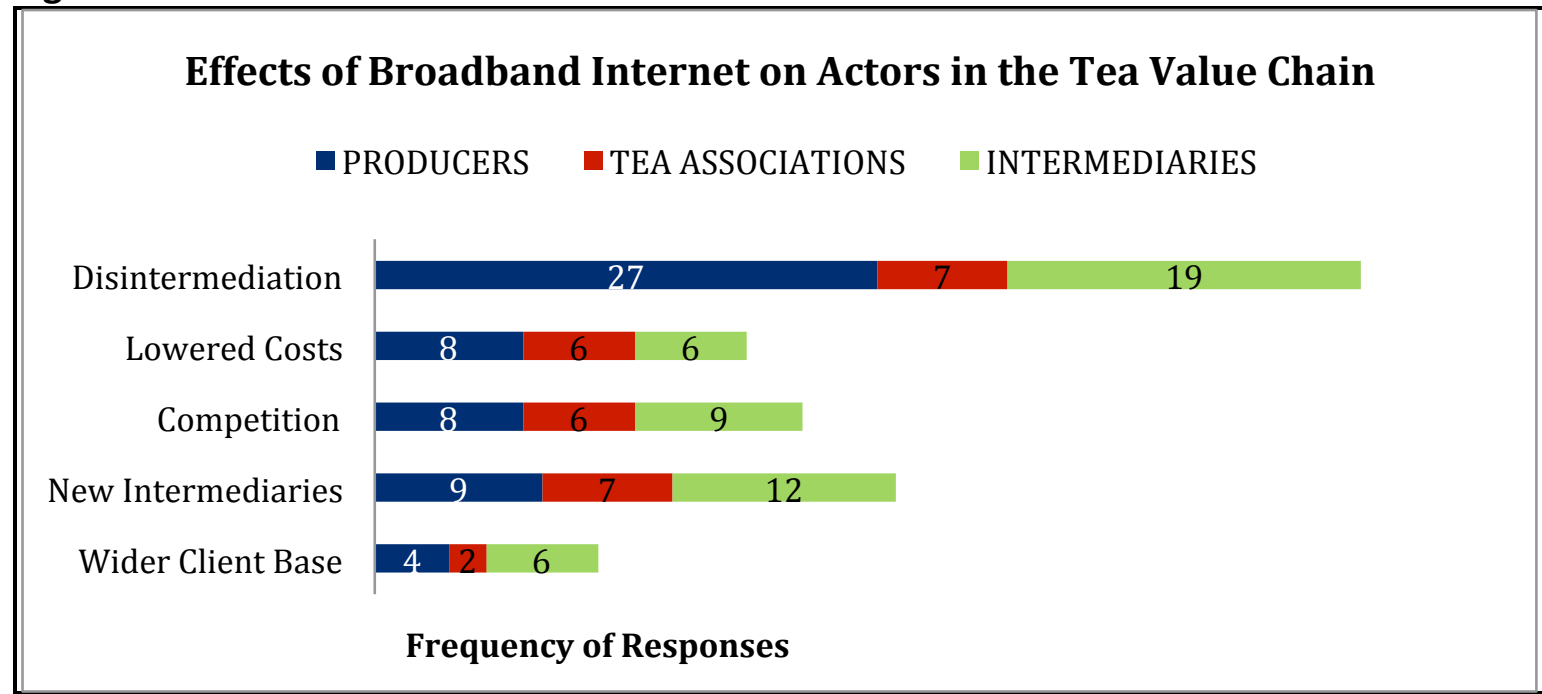

Source: Study

In subsequent sub-sections, we provide details of some of the key challenges, especially last mile connectivity from figure 4.8 and competition and disintermediation from figure 4.9.

\subsubsection{Last Mile Connectivity}

Complaining about the reliability of last mile connectivity, a producer said:

In terms of the group systems the way I see it working is that if the connectivity to the remote...to the rural areas improves because it is still a challenge. Although we are saying that the connectivity has improved it has only improved up to the point where service providers like Safaricom ${ }^{4}$ have terminated the last point for fibre but from that point to the factories which I would call the last mile, that portion is still not reliable.

A tea producer in Kericho too complained about the challenge of last mile connectivity:

I am using an Orange ${ }^{5}$ Modem but the main service provider here is Safaricom. We are still to pull the fibre optic cable to this place and it is very expensive, we need to talk to Kabianga University, and you know with Kabianga Factory, Kabianga University and Momul Tea Factory so when we join forces the cost will

\footnotetext{
${ }^{4}$ Safaricom is the biggest mobile operator in Kenya.

${ }^{5}$ Orange is one of the four mobile operators.
} 
come down. But as of now we normally depend on modems. With the university we might be able to get that.

\subsubsection{Disintermediation}

Most respondents said that faster Internet and related technologies had brought about disintermediation, allowing producers to contact customers directly without having to involve intermediaries. Disintermediation favours the producer, but it presents a challenge to the remaining stakeholders on the chain, but especially tea brokers in the auction. Several respondents indicated experiences with disintermediation:

We also do direct sales over the Internet where, for example, they need some tea. They communicate to us through emails indicating that we require this amount of tea, are you able to supply. Once we agree on the quantities and the prices, the invoices are raised. Still costing of the invoices is done online, they send the money to the account through online transfers and once that has been confirmed, the release of the goods is authorized from the Mombasa warehouse. (Producer)

At the same time, the international market through the globalization of activities, what we call the international village, it is becoming smaller because of information sharing. So the brokers are finding themselves in very precarious situations. In fact, if they don't sit down and become more creative, I don't see their place in the future trading as we are talking the tea auction is handling less than two thirds of tea in this country. Most of the tea is being bought direct through contract. You supply a certain company and with that kind of development and with the kind of other misgivings we have EATTA and Tea Board. I think in the next two years we might even go higher, 50:50; 50\% through the auction, and 50\% through direct sales. I don't think there is anything else brokers can do, they need to reposition themselves in the value chain and be more professional. (Tea Association)

There is a large amount of private sales even if you don't automate the auction. Private sales will keep increasing, it has been there. You see even for the next five years even if you don't automate the auction, growth of private sales will continue. Because of the bandwidth and Internet connection, people from other countries can easily connect with sellers here. (Solution Provider)

Definitely, the Internet tries to. It eliminates the need to, of utilizing the middlemen per se on getting information about the market, because with the Internet most of these people that we are targeting can easily be reached and we can easily get feedback from them directly and get to know the dynamics that is happening at their places. (Tea Association) 
It has brought the customers who were away closer to us. If at all I can...communicate with a buyer who is outside the country it is very easy now. Even the buyers themselves they can give us feedback on the teas they have bought from us. (Producer)

With disintermediation, we found out that a lot more tea had been sold through forward contracts and private sales. During the focus group discussions, participants indicated that direct sales were about $5 \%$ of total but were steadily rising. This differs from the close to $30 \%$ given by the Tea Association respondent. As the following comment by a producer illustrates, some key benefits of direct sales to the producers were faster payments, less uncertainty about sales and price, reduced cost by eliminating the charges associated with auctioning tea (brokers' fees and warehousing costs), and reduced cost of customers' agents (buyers) having to be physically present in Mombasa:

What will change is this, with the online auction it breaks the boundaries so people in the US will be able to access the information, what we have and what we are selling from here so they don't have to come all the way to Mombasa to buy tea. They can access our tea from our systems, trading can be done online and will ship the tea and they will wait for the tea on the other side without to use of a broker in Mombasa or a buyer in Mombasa.

A number of respondents felt disappointed about being cut off the tea value chain because of the changes in connectivity. If the intended plans to implement an electronic tea auction materialize, the other stakeholders felt that producers would not fetch better prices because of collusion by the buyers on the floor of the house. Most of them felt that there was still need for brokers in the tea value chain, as these responses by a sample of respondents show:

You could do without a broker on the following circumstance, that is, if there was a way all the producers in Africa could send all their samples to buyers and exporters. Because that is a principal function of a broker. The other principal function is we taste teas, give reports and we liaise with the buyers to find out what they want, what is it they are unhappy with about teas; we are a link, we are a bridge. If you cut us out and be dealing with 50 buyers or 40 buyers, if you feel that it is worthwhile, then again we will be out of that link, so there are some...there is a danger that in an extreme case you could say we don't need a broker. (Broker)

There is a degree of collusion there, the gentleman's agreement we do business, you don't push me, I buy for you....and I don't know the agreements they have, you can talk to them to get the finer details. Yes, collusion can occur but in its current form we feel we are protected by our physical presence at the auction. As a broker, as I sit at the front, I look at a trader and I know his market. Over time, on one-on-one interaction, we have come to know this one serves this market and 
this one serves this market. If a trader buying for Yemen goes quiet and there are no issues with his market, one week, second week, third week, and I will see the kind of tea he was buying are now being bought by another one who was buying tea for Egypt, something straight away clicks in my mind that something is wrong here. (Broker)

When you look at that Internet auction, I don't know the advantage that it will give to the farmers. My option is that it is going to reduce the earnings of the farmer. Because if it is through the e-auction, somebody seated in Singapore can auction tea and bid for it. We would not necessarily control the monopoly. People can collude to buy tea at any price. What about the conglomerates? They can buy teas at the kinds of prices that they want so long as they bid and there is no other bidder in the market then you would find that that can easily destroy the market. As opposed to the local tea brokers here who also want to earn their margin, the warehouses may want to earn their margin and they also want to take care of the farmer or the producer for that tea. So yes it has a flip side of it. (Producer)

Some respondents felt that there was need for intermediaries to exist in the value chain and for human intervention in the tea auction, as these views illustrate:

You see there are two ways that a producer can sell tea, one is through the Mombasa auction the other one is you circumvent the broker then you sell direct to a producer, to an exporter either here in Mombasa or overseas, that is possible. There are reasons...a lot of teas come to the auction. It is because of competition and competition gives you the true price and has a likelihood to give you an enhanced price. When you sell directly you are going to discuss the price with one individual and he will say no the best price I can give you from theses teas I have tasted them I know the market is $\$ 2.60$. (Broker)

First of all, I would say because of the pricing, because if there is a bad price on offer, he [broker] will advise you to hold on your teas. You know that kind of a thing, this tea can fetch a better price, or this may not be our best buyer, let us go to this other market and see what they will give us. So that clearly tells you that their interest is on the producer. (Producer)

There are people who know the good tea and they value it knowing that this tea can definitely fetch that amount, and you see the value here and you see the price it went with. You see like this one it is US\$ 3.97 it went with US\$ 3.72; this was US\$ 4.05 it went with US\$ 3.90 , the difference is +15 , and that +15 they know clearly, the person putting that he knows, one, what is expected out there; two, the volumes of that tea that is available; three, the probable buyers. That human interaction in itself it is an experience on its own. (Tea Association) 
Price discovery in the e-auction is not there, the major issue is price discovery, the end producer will not get value of the money as such and also with the e-auction I believe competition is not there. (Buyer)

The tea industry, like in any other industry, you can automate it to a large extent because it is common but there are some specific parts in the industry you cannot automate like that. You have to leave room for human touch. IT will play the role of an enabler, e-auction yes, it is definitely required but if you are looking at an eauction that people will stay at their homes and do the auction, it won't work; it is not practical. They need to see each other. If you have been to the tea auction you will see a lot of discussions. It is very dynamic. It is very fast and that speed only humans can really support. The system has to be back-end supported. So automation is required so that it can speed up, improve the efficiency and reduce the number of errors that happen when passing documents but the e-auction cannot be fully automated, there has to human touch in certain places. (Solution Provider)

The brokers argued that with their knowledge and experience in the tea industry, some of their roles can be difficult to replace through the adoption of the electronic tea auction, as indicated in the forgoing arguments. Thus, we note mixed results between benefits of electronic disintermediation on the one hand and the value-added services provided by intermediaries on the other.

We acknowledge that full or partial automation of the auction process can have significant benefits such as attracting more buyers, allowing more remote buying outside intermediaries, reducing the cost of transporting tea to Mombasa for neighbouring countries, and increasing value to the farmers. The forgoing sentiments are very brokercentric, however, and represent defensive positions taken by brokers and their sympathizers in their resistance for automation, associated with a fear that their roles and power would be significantly reduced or even disappear. Indeed, when we brought out these positions in the final focus group workshop, almost all the participants, none of whom was a broker, disagreed with these positions and dismissed them as forms of resistance by brokers.

When asked to sketch their desired tea value chains after the use of new ICTs, a participant in the tea sector focus group came up with Figure 4.10. This figure shows producers having direct sales to the customers. After some discussion, this was adopted by the group as the desired value chain. It illustrates the desire to get rid of tea intermediaries. 
Figure 4.10: Desired Tea Value Chain

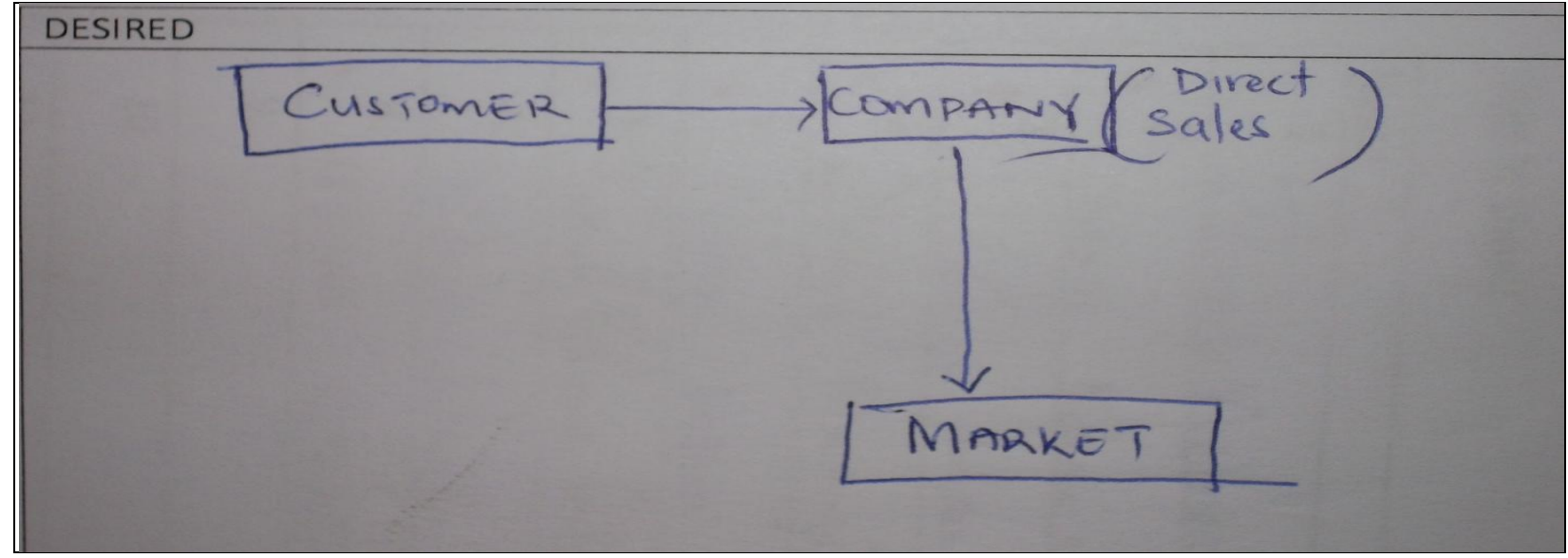

Source: Study

Figure 4.11 shows the tea value chain after the use of broadband internet and related ICTs as an outcome of the study findings and the focus group discussions. It shows a limited degree of intermediation in comparison to that in the tourism sector. Intermediation takes place between producers and international market operators. The intermediaries-specifically, brokers and warehouse operators-still fit their roles and faster Internet had not yet removed them from the value chain. The conclusion is that broadband Internet and related technologies at the time of the study played the role of an enabler in the value chain.

Figure 4.11: Tea Value Chain after the use of Broadband Internet and Related ICTs

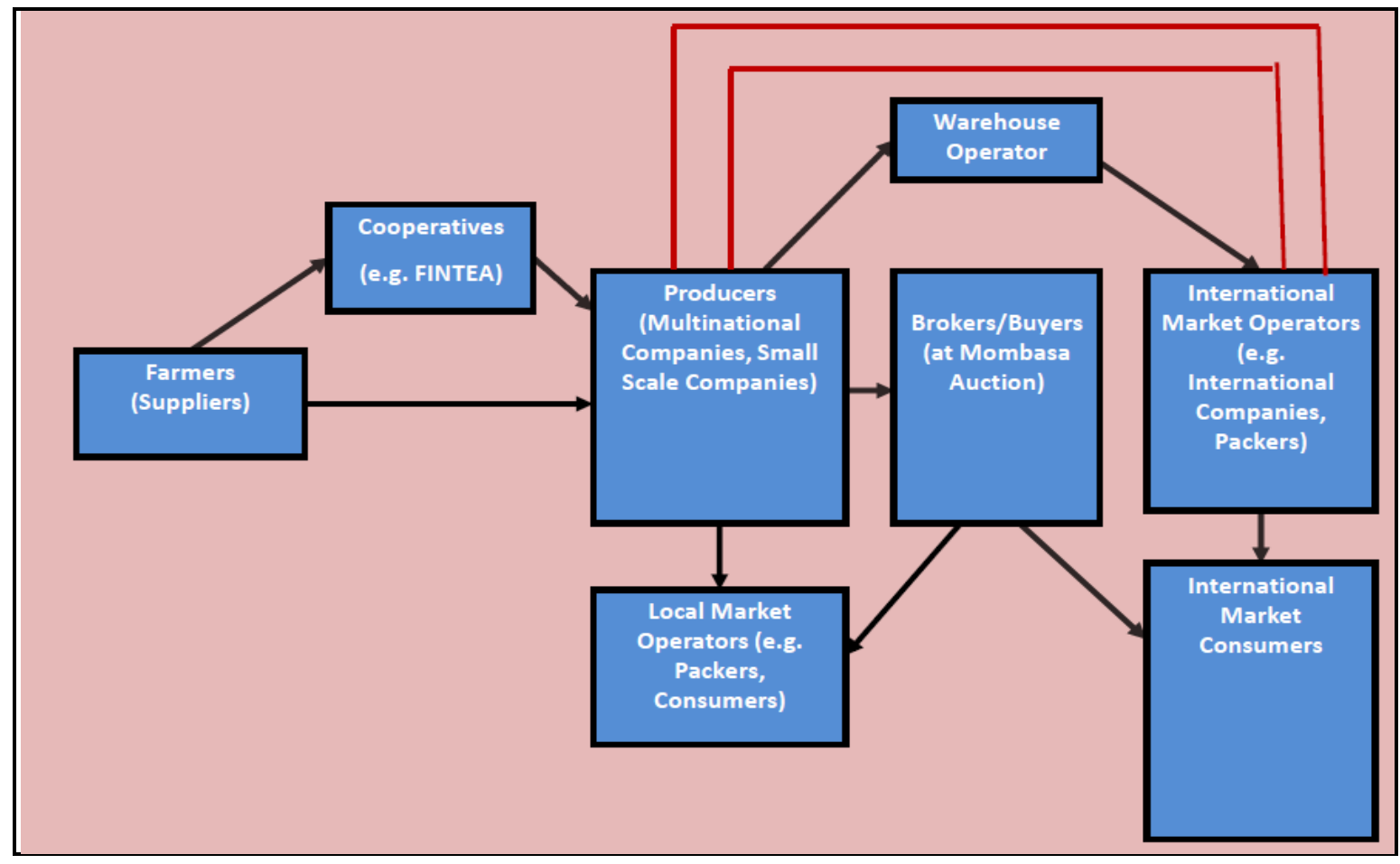


Source: Study

Legend: Red lines - new relationships enabled by broadband Internet and related technologies

Black lines - existing relationships

\subsubsection{Increased Competition}

Increased competition arises from broadband Internet and related technologies empowering customers with too much information and an ability to choose customers' suppliers. This was pronounced in the tea sector as it was in the tourism sector, however, perhaps because there was limited use of broadband Internet and related ICTs to access customers. It may also be due to the small size of the tea industry. Stakeholders literally recognize each other by face, if not by name, as these statements attest:

The tea industry is such that traditional buyers are known. They are actually known and if new ones come up, yes, you cannot deny them. But it is always safe to work with the traditional buyers who are credible who are known and even the tea markets in terms of countries that actually big consumers of tea. (Producer)

For local customers, we go looking for them. We have a sales and marketing department with staff and the infrastructure for distribution. So they go to the market to look for customers. We also advertise, we do market storms, those below the line and above the line market activities to get more and more customers. So for those ones we are more active, but for export where much of it goes through the auction, the market is structured and the buyers are there and it is being run by EATTA. So for that we are not very actively involved. We are involved in looking for customers. (Producer)

Most people actually will come here and they will talk to people. Even when they come here, who I should go to, they will be told okay, Venus is one, so and so, go and talk to those three. So we hope that when they come here that we will be able to persuade that we are better than the other two. You also need to go to the factory because you need to have a physical assessment or audit of what is happening to understand the challenges of the guy on the factory floor is having. Maybe you have been saying your teas are like this. (Broker)

\subsubsection{Quality of Internet Services}

Most respondents were satisfied with the Internet services provided to their businesses, as evident in these two respondents who were satisfied with Internet costs and services: 
Two years ago...but obviously the speeds of communication have gone up significantly. A few of us have taken advantage of using these software like Skype to communicate to our clients, and that means the cost of telecommunication, at least the cost of telecommunication has significantly come down, and at the same time we use a lot of Skype in place of the telephones. (Broker)

First of all there is reliability because sometimes back there was...like four years back we were using Very Small Aperture Terminal (VSAT) and of course VSAT comes with its own challenges. Then we came to modems then you know modems was now restricted to...The bandwidth was small, so we just did minor things just like sending an email or something like that. But now after the fibre I can say it is more reliable, it doesn't matter about the weather conditions, yeah basically it is reliable, it is fast. (Producer)

In contrast, a number of respondents were dissatisfied with their Internet services, especially slow speeds and poor availability, these comments by two producers illustrate:

There are times you want to communicate but you cannot access the Internet, and you are wondering what could be the problem. Yes you are connected but you are not communicating; you have the units but unfortunately you cannot communicate. And that poses a lot of challenges especially when you have critical information to send out to a recipient or maybe someone was waiting, like you have a seminar somewhere and you want information to download so that you can disseminate to others and then it becomes a big challenge.

At times it is not that reliable. For us we are connected to radios in Ngong Hills and sometimes our connection is not that good. Some signals are lost somewhere along the way and it can take some time before we are back on the Internet. So when it is there it is fast but sometimes it can be a problem.

\subsubsection{Cost of Broadband Internet and Related ICTs}

A factor that poses a challenge to accessing faster Internet and related technologies is the cost. A number of stakeholders in the tea industry felt that the cost of broadband was still high despite the promises of reduced costs, preventing the actors from benefiting from these ICTs and related technologies. Concerned over the high cost of broadband Internet and related technologies, two producers said:

I think by and large most of the things we do we can do them but the IT cost is still high...quite high especially for small-scale tea growers because as much as we can see in the papers that so much was paid, when you move down to what gets to the farmer we need to do a lot in terms of cutting cost and IT is one of the greatest costs. 
In my opinion it is still too expensive in Kenya. The reasons they give I am still not convinced because I think as of this month there is a fifth cable landing, LION 2. I think it has even gone live, if you look at the Internet costs they have not gone down. Then there is the issue with penetration in rural areas, if you were to compare that with what we are saying, we have five cables that have landed and yet if I was to walk into a cyber café in Othaya and decide to open Yahoo it will still drag. So thinking in terms of rolling out the infrastructure, guys in the rural areas are still not connected. Funny enough even in Nairobi you may go in a cyber and it really drags. I don't know if it is their machines or it is the link. But that is not what you would expect, you know when you [are] in town you would expect better speeds.

As the following views demonstrate, some respondents indicated their businesses had not been able to fully benefit from the broadband Internet platforms and technologies due to lack financial resources to acquire both the technologies and staff with the requisite skills:

Possibly the knowledge on usage, the technical knowledge of the producers or of the growers is not as savvy as the brokers here. The Internet can be there but they don't have the expertise to understand the trends. (Warehouse Operator)

If we had financial backing, for example, we would be able now to enter into more forums with the Western world to tell them that this is our product, we are here but we cannot because of limited resources. We would rely maybe on partners at the moment, we will rely on what we are developing like the websites, we won't say that we are operating at full capacity, [and] there are things we are visualizing asking ourselves whether we should come to this. (Cooperative)

For example, the issue of websites, we don't have an internal guy who can do that and truly it is taking time for the guy who is handling it. We are failing to understand why it is taking such time, if we had somebody dedicated here on permanent basis who knows what should be done, it should be done already. But that guy is taking time so that limits our presence in the Internet. (Buyer)

\subsubsection{0ther Challenges of Broadband Use}

Bureaucracy was perceived to be a challenge to broadband use by some respondents. That is, specific offices in a corporate organization were charged with electronic communication and other departments of the same organization could not communicate electronically except through these offices. A producer said: 
That one is handled in Nairobi, you know us here we manufacture, the guys from Nairobi have a website, they have details for all the factories, then they have the marketing department, so if the broker, so if the buyers, want our teas they can be able to get us through the marketing department.

Similarly:

The marketing arm of KTDA is basically dealing with that, even if we were to come up with our own. Even our webpage is managed by KTDA, it is one of the 65 factories managed by KTDA. At some point some factory was interested in what you are saying going online, but because of the management agreement we have with KTDA, if we are to do that independently we leave that to the marketing department of KTDA because we cannot be different marketers outside of KTDA.

Particularly after the introduction of the electronic weighing scales/machines, and as the following statement indicates, broadband Internet led to loss of jobs for some of the actors in the tea industry:

So these are some of the advantages that we are getting. It is about planning, management, saving on time, saving on labour. These are things that have been tangible, we have been able to reduce our staff. The tea bought used to be keyed in by three-four clerks, nowadays we have removed those clerks. (Producer)

\section{Summary}

Results on the unexpected challenges of broadband internet and related technologies indicated multiple challenges. A major challenge was that of disintermediation whereby brokers as actors in the value chain felt threatened that producers would in future contact customers directly without having to involve them. At the time of the study, anecdotal evidence indicated that direct sales to customers by producers represented about $5 \%$ of total sales. However, this percentage was deemed to be steadily growing. On the other hand, adoption of broadband internet did not necessarily translate to disintermediation. Producers were found to still depend on the auction prices while selling their teas directly to customers. This shows that brokers can survive in the value chain even with the current technological changes.

Broadband internet and related technologies also posed other challenges to actors in the value chain. These include increased competition, technical barriers, cyber crime and high costs. 


\subsection{Socio-Economic Impacts on Economic Actors (RQ4)}

In summary, we found out that broadband Internet and related ICTs had brought about positive socio-economic benefits to economic actors, the key ones being enhanced productivity, increased efficiency, reduced costs, improved communication, enhanced visibility and reduced marketing cost, and changes in geography.

\subsubsection{Overview of Impacts}

We asked respondents what the actual benefits or impacts of improved connectivity were in their businesses. Figure 4.12details how most respondents reported on the actual impacts of improved connectivity, as it shows that producers experienced all the four benefits, with enhanced productivity, increased efficiency and reduced cost as the most pronounced. The other actors experienced the same benefits to some extent.

Figure 4.12:Overview of Impacts of Improved Broadband Connectivity

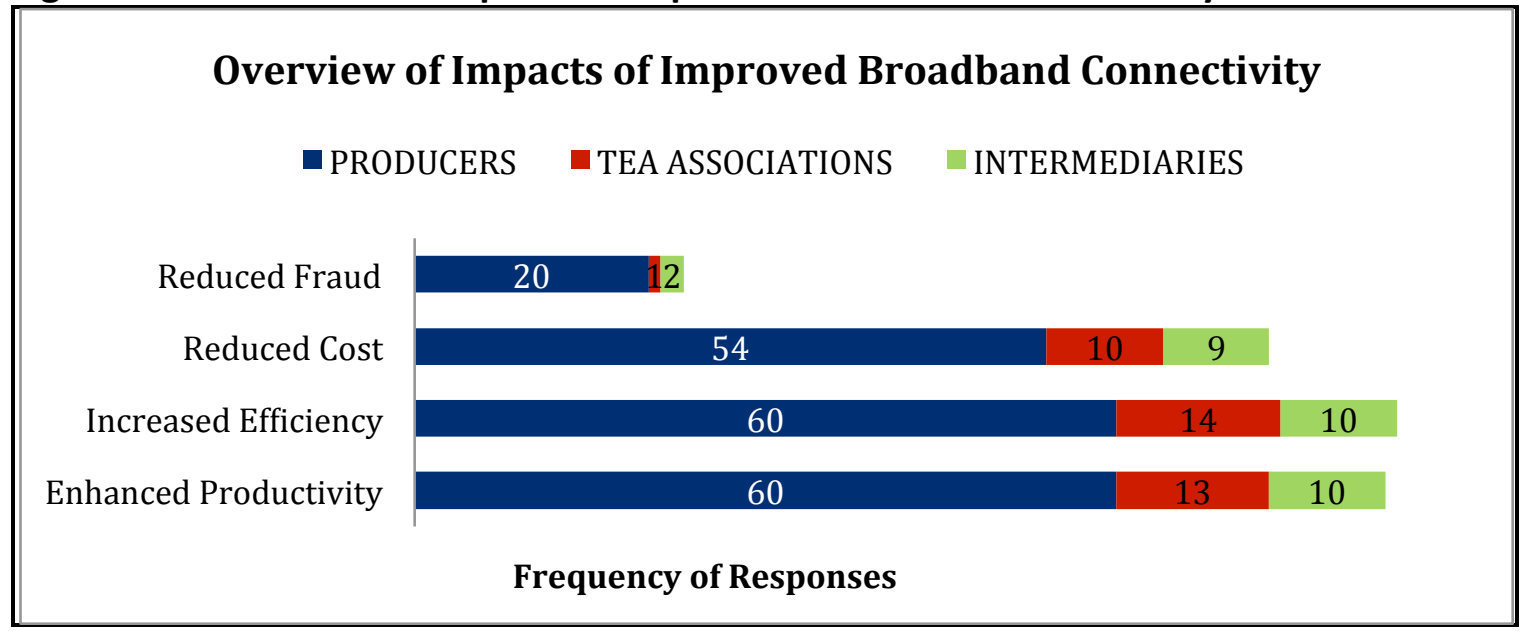

Source: Study

Broadband Internet and related ICTs lower the cost of sending and receiving many forms of data, including documents and audio and video content. A producer captured the impact of the Internet on communication with this remark:

To us Kabianga Tea Factory Internet has played an integral part. I will be very sincere and tell you that to us Internet has been the integral part of our business especially in terms of communication, in terms of passing messages, in terms of sourcing markets and even attaining our certifications, quite a lot of communication.

This explanation from a producer clarifies the cost impacts of the Internet with: 
It has really revolutionized the way we are thinking and the way we are doing things because for one, I wouldn't need to spend. You see the amount of money that I am spending to surf the Internet is very minimal than I would have called in the UK...In terms of cost, I am spending minimal.

Explaining the impact of an electronic weighing system on fraud in purchasing tea from the farmers, a producer said:

With the manual scales there is a lot of manipulation, so the farmers have benefited a lot. Yes they are the winning guys...Initially they did not know the tare weight of their teas, right now you are shown. The Electronic Weighing Scale [EWS] cannot print the receipt until the EWS captures the weight. It has also assisted us a lot because I am able now to see if the clerk decides to do something out there, I am able to see, the system will tell me that this guy was buying teas on a different route. So I can question whether that was authorized.

Echoing similar sentiments, a producer explained how connectivity had enabled producers to monitor operations in real time, thereby improving productivity, and reduce costs and increasing the efficiency of management operations:

We have been able to improve on our monitoring of how operations are taking place because as our clerks buy leaf in the field, we have a system where we are able to check on the Web on what is happening on the ground that is in real time. I can see what that person is actually doing. So that helps in better management. Likewise when we talk about the head office operations and the factory operations being linked and actually data being replicated from here to Nairobi and vice versa, we are also improving our management approach because the guys in head office can...see for example the amount of leaf a factory received in a particular day and also from our side, as these guys are buying this on the field.

\subsubsection{Improved Communication}

Faster Internet and related ICTs have made it possible for people to link up, in real time, and attend to activities located at great distances. There is a generally positive attitude towards ICT use and its impacts in those interviewed. Some advantages of employing different forms of electronic communication are access to wider audience, improved access to information, faster speed of reply, lowered costs of communication, and widened geographical reach. In this connection, a producer remarked how automation and electronic transfer of information in the value chain had improved turnaround time and efficiency in general:

With information being available what has improved is that we are able to communicate to our traders in Mombasa and our warehouses the amount of 
manufactured tea that we have almost immediately because today I can know that this is the amount of tea that I have manufactured and I can have that information sent to the traders. Yes previously it used to take about two weeks because of all those paper work from the field to Mombasa and at every point there was manual entry, basically for the same information, I will show you from here.

\subsubsection{Reduced Costs}

Some stakeholders mentioned reduced costs as another benefit of electronic communication. An example is provided by a producer with the following comment:

There is the part of cheaper communication. You know you can see someone, you can communicate either through Skype or Google doc [platform for sharing documents] which has proved or rather cut down on costs [of] calling the normal telephone lines.

\subsubsection{Enhanced Visibility and Reduced Marketing Cost}

We asked respondents what effects the actors had experienced as a result of adopting online platforms. Figure 4.13shows a summary of these effects for a number of actors. It illustrates that enhanced visibility was the number one effect of online presence, with a majority of the producers and packers pointing out enhanced visibility and reduced cost of marketing.

Figure4.13: Effects on Visibility and Marketing Cost

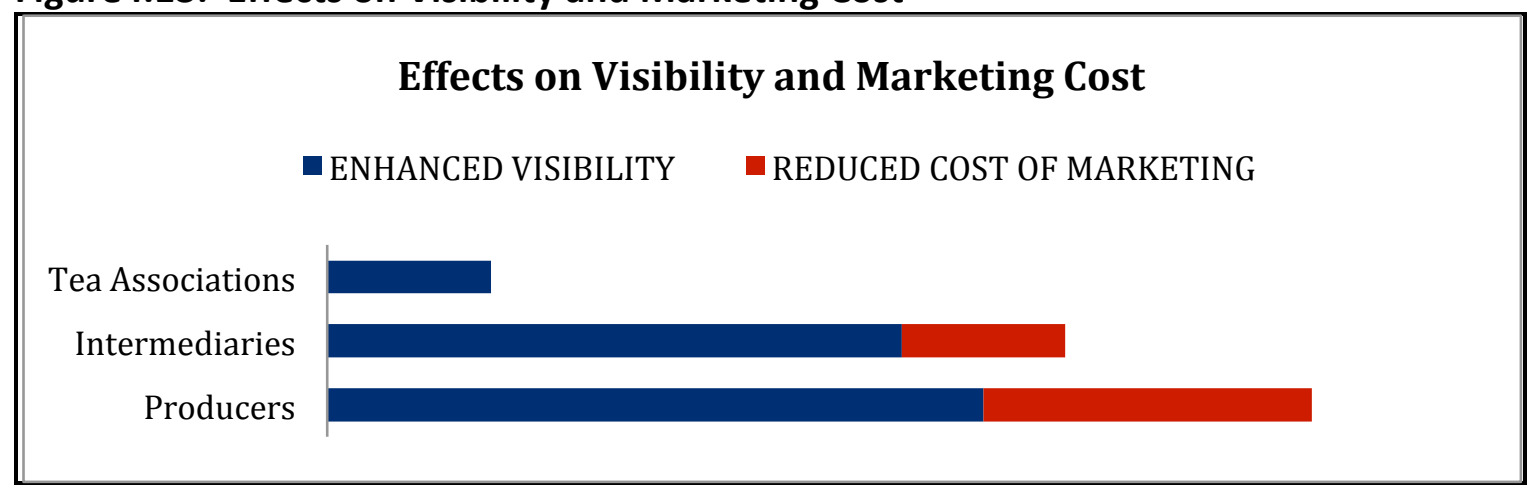

Source: Study

These accounts by respondents illustrate these effects:

As a company, yes, we are using faster Internet to make ourselves visible because technologically the world is...the world is moving and definitely it is [in] the best interest of any business to try and catch up. So what we do is we avail ourselves 
through the websites and more than that, just as I stated earlier the respective clients we serve we make sure that even in their advertisement or not, even in their advertisement at least they indicate where the tea originated from. So in the advertisement which, most advertise through the IT, at least we are mentioned, so that is how we utilize the Internet facilities in terms of marketing. (Buyer)

So far so good it has been effective because through the Internet as opposed to earlier on, there are more inquiries, very many inquiries, more and more inquiries definitely. (Producer)

Yes, I think it has assisted them. They [new actors] are able to market themselves in better ways which are cost effective. Using the tools available on the Internet, it has assisted them. Because they would not be known that they exist without the Internet, us we are already known, we are big actors the name was already been there but for a small player who has just come up the Internet has assisted them as a producer of tea somewhere. (Producer)

It really helps on advertising, you know with advertising using the Internet you can reach very many people at a very low cost. (Producer)

\subsubsection{Changes in Geography}

One of the most prominent attributes of faster Internet and related ICTs is the relative ease with which the new technologies can overcome constraints of time and distance. Figure 4.14shows some of these attributes. It is evident from this figure that producers felt very strongly that broadband internet and related ICTs enabled access to global customers, and led to a reconfiguration of space, to scaling up into new areas and to globalization. This is perhaps because producers are the ones who are more likely to interact with customers, most of whom are foreign.

Figure4.14: Effects of Broadband Internet on Geography

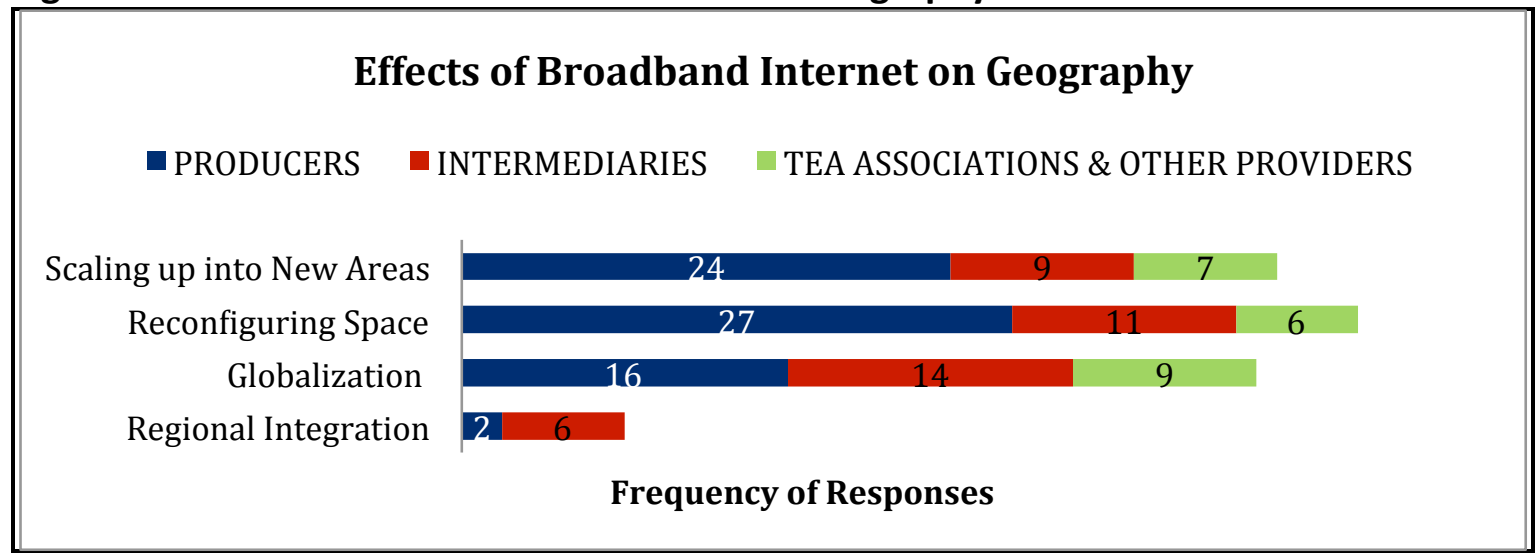

Source: Study 
These statements by respondents underline the effects of faster Internet and related ICTs on geography:

Of course as producers that will give us an opportunity to access more markets including in continents where we have not been participating, like the US. For us as producers, we think it is a good opportunity for us to penetrate new markets. (Producer)

Ideally it has become a small village. I mean the Internet has brought things closer, I mean you can communicate with someone one-on-one. You can see him, you don't need to imagine someone if you have Skype you can talk to him easily. (Producer)

There is no more geography, there are no more barriers geographically when you are using the Internet. I chat with friends in India, they tell you what they are doing with their tea associations back in India. I go to Skype and I am able to access all of them like one in Taiwan, one in India and me here and we chat, so there is no more geography, even travelling is not necessary. (Producer)

We are now more or less global. It is like we do not have boundaries anymore; it is more seamless between us, you there and anybody in the world. Well, a few countries still have their grips on it like in India I will not visit a cyber café and login into my Yahoo address, I need to leave a copy of my passport, I need to leave, they need to register then time that I logged in and the time that I logged out, well they talk of the incidences of cybercrime, so they try to arrest such incidences. (Broker)

Despite these positive effects on geography, however, there was little evidence that the use of the broadband Internet and related technologies had led to a reduction in people having face-to-face meetings. The Internet for example can create virtual communities of interest that encourage people to travel to meet those with whom their first contact was online-and might not have been in touch with at all without access to Internet-enabled interactions. This indicates that the Internet does not act primarily as a substitute for travel. This is supported by a respondent as evident in these account:

You know in any consumer commodity you have to shop for clients. So what happens we know the destinations, we travel and our biggest marketer are our clients themselves. So the good-will in which we have created ever since we started operations from the people we have dealt with, those are the people who I can call our lieutenants overseas because the good name is there. Once the good name is there, inquiries come. Because client $A$ will make an inquiry on who supplies tea to let's say client B. Then he will be told that it is Imperial Teas, so client A will come to us and when he comes to us we do our background check on 
client $A$ and we start dealing with him, so that is the avenue which we utilize most, our already existing clients. But also once in a while we do travel and try to seek audience from the tea traders overseas. (Buyer)

\subsubsection{Further Impacts}

Faster Internet and related technologies have been rapidly incorporated into daily business operations. Most respondents actually depend on the Internet and related technologies in their operations. A producer agreed that broadband Internet had transformed communication with the following comment:

I would say it has significantly improved the way we communicate with our stakeholders when I say stakeholders from my point of view it is the auction organizers in Mombasa, our factories who are spanned around the country and buyers who are located outside the country.

Several systems deployed to transform business operations in the tea value chain and have been instrumental in creating trust and minimizing opportunism. The systems include the weighing of the tealeaves using electronic weighing scales, the traceability mechanism, and the monitoring systems within organizations using Enterprise Resource Planning Systems (ERPs).Two producers indicated a variety of systems/technologies work with broadband Internet to transform the way business is carried out; there was no mention of the degree of integration of these systems, however:

We do have tailored software because there is CHAI PRO that basically does the financials. We have another one [software] that does the production and it is dealt with by the people from the production side. We have another one that deals with the growers, and it is done by the field services coordinator, it is called the growers management system. Then we have another one called the fleet management system which deals with the management of the fleet. The field services coordinator is the one who operates it. Then we have the system that we use in-house. So some of these systems generate data, then we replicate the data to Nairobi.

As of now we are using the electronic weighing solution to buy tea. But for that one we use Safaricom to relay information to our servers which are here with us from the field. We use Safaricom to send data from the field to here and then using the Internet we are able to monitor the way they are buying the leaf.

A grower indicated that faster Internet and related technology had enhanced productivity and improved efficiency: 
Distribution of auction information through the Internet is faster because initially information would be generated at the auction used to be done by a single broker who would distribute the reports manually. But right now the reports are electronically circulated because no sooner the auction ends [than] would you get the reports on how the auction fared and how the markets represented themselves at the particular auction. So when you look at it, the information access part of it, it is definitely much faster.

\section{Summary}

A review of the research on the socio economic impacts of broadband internet on the tea value chain indicated multiple effects. These included the impacts on the productivity and efficiency of both small and large actors along the value chain, reduced fraud cases and reduced costs. In addition, the new technologies increased benefits for their users by enhancing their visibility online and reducing marketing costs. 


\subsection{How Actual Changes Differ from Academic, Public and Political Discourses Surrounding Potential Effects (RQ5)}

Overall, results from a review of public discourse analysis shows that the dominant expectations on the arrival of undersea fibre optic connectivity were reduced Internet costs, improved speeds and economic growth as shown in figure 3.1.

\subsubsection{Reduced Internet Costs}

The extent of expected reductions in Internet cost ranged from US\$ 400 to US\$1,000 from a high of between US\$3,000 to US\$ 6,500 during the satellite era as shown in table 3.1. The results from the study show that broadband prices varied substantially. A number of respondents complained that broadband prices were still high despite the promises of reduced internet prices, which prevented the respondents-especially the small actors - from taking advantage of broadband internet and related ICTs and their associated benefits. Some actors however felt that the cost had come down but had not some down substantively enough, as a tea buyer observed:

It is not cheap, it is still cheaper than what we used to pay. For example, I used to pay... whatever I used to pay for $250 \mathrm{Kbps}$ is now slightly less from what I am paying for $2 \mathrm{Mbps}$. In short what I used to pay for $250 \mathrm{kbps}$ is more than what I am currently paying for $2 \mathrm{Mbps}$ but I still feel it can go lower than that, I still feel that the $2 \mathrm{Mbps}$ that we are paying if I compare with the rest, it is still high.

If one analyses the figures in the above comment, however, the cost had actually come down by about eight times for the same amount of bandwidth. The observation therefore means that the expectations on price reductions were very high. As one respondent observed, however, big actors and multinational companies felt that costs had reasonably gone down:

The costs came down for Internet and then we get bigger capacities at relatively cheaper cost (Interviewer: How has this...like you said that now you are able to get bigger capacities and the costs are down, compare these costs and before you had the fibre, you said you were using satellite, what were you paying before and what are you paying now?) it was around KES 90,000 for 512Kbps, right now we are paying around KES 45,000 for $2 \mathrm{Mbps}$.(Producer)

Analysing this comment, one can see that the company pays $50 \%$ of the original cost but for four times the capacity. This translates to eight times price reduction for the equivalent bandwidth, like the previous respondent who thought it was quite high. It therefore means that there was a substantial price reduction because at KES 45,000 for 2 Mbps, the cost of $1 \mathrm{Mbps}$ was just about US\$300. This is in line with what was expected 
as shown in table 3.1. As a result, the key difference in the extent of price reduction was in terms of the differences in expectations in price reductions. Another way of explaining this is that broadband Internet service providers took a strategy not to reduce customers' bills but provided customers with more bandwidth for the same price. This was to encourage consumption of the increased capacity and to prevent their revenues from dipping. Customers therefore did not realize a reduction in their recurrent Internet costs - though most of them did not acknowledge the increased bandwidth, often eight times more than the previous bandwidth, at the same price.

A further interesting point is about the rural/urban cost comparison. One of the actors said that providing broadband services in the rural areas was more expensive than in urban areas because of the need to install, operate and maintain a local fibre network in rural areas, for example, to interconnect factories. In urban areas, service providers would have fibre infrastructure in most places an organization would wish to interconnect, as a respondent explained:

The other thing is that in a remote place like this, I am sure if we [were] in a place like Nairobi even the linking up of our establishments and the factories and the estates and these other establishments we are not able to do it but it is our duty to put this fibre in place. I mean it would have been someone else doing it. We would just be buying the service but we are going through the trouble of putting the fibre by ourselves, we are maintaining it by ourselves. So being in a remote place you tend to do things which are not your core business, our core business is not to lay fibre cables around, we would love if somebody was to do that but I am sure if it was Nairobi there [are] people who would have laid the cables but here being a remote place we are forced to do it.

\subsubsection{Better Quality of Internet Services}

Service quality focuses on user satisfaction of Internet connectivity and may include speed, reliability and availability. The public expected better quality of service, especially access to better speeds or high capacity bandwidth. In reality, most respondents expressed a certain level of satisfaction with the Internet services provided to their various businesses. Typical responses were:

The speeds of communication have gone up significantly. (Broker)

The speed is quite reliable and we don't have a lot of outages. (Warehouse Operator)

After the fibre, I can say it is more reliable. (Producer)

A number of respondents however were dissatisfied with their Internet services, especially slow speeds, low reliability and poor availability. Typical comments were: 
Yes, you are connected but you are not communicating; you have the units but unfortunately you cannot communicate. (Producer)

Some signals are lost somewhere along the way and it can take some time before we are back on the Internet. (Producer)

We are saying that the connectivity has improved; it has only improved up to the point ...that portion [last mile] is still not reliable. (Producer)

The key causes of quality degradation were cited as technical barriers, cable breaks and viruses (see Figure 3.30).

\subsubsection{Enhanced Economic Development}

Broadband Internet and related technologies were expected to enable socio-economic development in all development sectors, especially in BPO and ITES. This was supposed to happen through a tremendous growth in the ICT sector. The benefits revealed by the research were restricted to the level of the organization. As Figure 3.32 shows, the key economic impacts cited were enhanced productivity, increased efficiency and reduced costs.

During the first focus group discussions with key stakeholders, we asked participants to indicate who were the winners and losers of broadband internet and related ICTs. Table 4.2 shows the results. It is evident that most intermediaries would be the key losers of adoption of broadband connectivity and related ICTs in the tea value chain.

Table 4.2: Biggest Winners and Losers of Broadband Connectivity in the Tea Value Chain

\begin{tabular}{|c|c|}
\hline BENEFITS MOST & BENEFITS LEAST \\
\hline $\begin{array}{l}\text { - } \quad \text { Producers } \\
\text { - } \quad \text { Farmers } \\
\text { - } \quad \text { Cooperatives } \\
\text { - } \quad \text { Transport Service Providers } \\
\text { Through broadband Internet, these } \\
\text { stakeholders are able to contact } \\
\text { customers directly without having to go } \\
\text { through intermediaries. }\end{array}$ & $\begin{array}{l}\text { - Warehouse operators, reduced business since no teas } \\
\text { - } \quad \text { Buyll have to be stored in their warehouses } \\
\text { - } \quad \text { Brokers } \\
\text { These stakeholders are cut off the value chain once } \\
\text { producers are able to directly contact customers without } \\
\text { having to involve intermediaries. Though the intermediaries } \\
\text { play a very important role of price discovery, the producers } \\
\text { peg their direct sale prices on auction prices. This means } \\
\text { reduced business volumes for them as producers are able to } \\
\text { sell teas at a premium to any customer on the globe without } \\
\text { having to be linked with any of these intermediaries }\end{array}$ \\
\hline
\end{tabular}

Source: Study 


\subsubsection{Other Effects of Broadband Connectivity}

Positive effects of broadband connectivity and related technologies were:

- access to wider audiences, improved access to information, faster speed of reply, lowered costs of communication and widened geographical reach due to electronic communication,

- enhanced visibility and reduced cost of marketing due to online presence, and

- effects on geography (a reconfiguration of space, scaling up into new areas and globalization).

\subsubsection{Challenges}

The key challenge anticipated before the arrival of fibre optic cables was increased cyber insecurity. This research found out a number of key challenges associated with broadband Internet and related technologies in the tea sector:

- fear of disintermediation, especially with planned automation of the tea auction,

- increased competition, and

- cybercrime, online scams, privacy, and confidentiality issues.

\section{Summary}

The research answers the question of how actual changes differ from academic, public and political discourses surrounding potential effects by reviewing the hoped for effects as represented in academic, public and political discourses and comparing to actual responses from actors in the tea sector. Results show that small actors complained that the costs had not come down as much as they had expected. This prevented them from competing fairly with big actors who did not have any financial challenges adopting these technologies. A number of actors were disappointed with the quality of service; they complained of slow speeds, low reliability and poor availability as discussed in the sections above. 


\section{Summary of Findings}

\subsection{Tourism Sector}

\subsubsection{Expectations vs. Reality}

Overall, results from a review of public discourse analysis shows that the dominant expectations of the arrival of undersea fibre optic connectivity were reduced Internet costs, improved speeds, and economic growth as shown in figure 3.1.

\section{a) Reduced Internet Costs}

The extent of the expected reduction in Internet costs varied. Table 3.1 shows the varied expectations. This varied from US\$400 to US\$1,000 per Mbps. The satellite cost seems to vary from US\$3,000 to US\$6,500, indicating that there were great differences in operators' charges.

The actual initial prices per Mbps were within the range expected as shown in table 3.1, but there were disappointments that the prices did not go down as expected. This means the expectations were perhaps lower than reported-though anecdotal evidence suggests that the expectation was about US\$200 per Mbps. The main reasons given for the prices not going down as much as expected were:

i) operators had to recover their investment cost (Waema et al. [2010]; Bitange Ndemo [Business Daily, July 2009]),

ii) low bandwidth consumption-6-8\% of supply,

iii) government-controlled regulation: "The market is regulated by the 'invisible hand' of the government. The prices might go down, but the industry is regulated by the government, which can easily determine the market prices" (BBC, April 2009). Similar perspectives were expressed in two local dailies: a lack of competitive pressure that would yield better pricing (Daily Nation, January 2010); and lack of competition in the industry (Business Daily, January 2010),

iv) the relatively high cost of the local loop, and

v) false expectations: "Some of the industry actors had fed the market with false expectations. They were not realistic, mostly because they did not factor in the cost of local infrastructure, the maintenance and other logistics that resulted in prices remaining relatively high" (Mr. Somen, CEO, Access Kenya, February 2012).

In reality, we also found out disappointments that the prices had not gone down to the extent expected in both sectors. More importantly, the smaller actors in the value chain found broadband Internet very expensive, especially for uses that require huge amounts of bandwidth, like video clips. These actors therefore were not taking full advantage of the benefits brought about by broadband Internet. 
In the tea sector, a number of respondents complained that the broadband prices were still high despite the promises of reduced internet costs. This was especially so with the small actors. Some actors felt that the cost had gone down but not substantially enough. In comparison, big actors and multinational companies felt the costs had been reasonably reduced.

One interesting finding is that upon further analysis of the actual prices actors were paying for $1 \mathrm{Mbps}$ of bandwidth, the prices were within the initial expectations as shown in table 3.1. The disappointments therefore indicate that the expectations were even lower than reported. What the expectations were is something that needs further research.

One way to explain the difference between expectation and reality is that broadband Internet service providers took a strategy not to reduce customers' bills but provided customers with more bandwidth for the same price to encourage consumption of the increased capacity and to prevent their revenues from dipping. Customers therefore did not realize a reduction in their recurrent Internet costs. Most did not acknowledge the increased bandwidth, often eight times more than the previous bandwidth, at the same price.

\section{b) Better Speeds}

The public expected better speeds for Internet connectivity or high capacity bandwidth after the landing of the fibre optic cables. This expectation is also linked to better quality of service, cost reduction, and socio-economic development. We found out that some respondents in the tourism sector were not satisfied with the quality of service for Internet connectivity. Cable breaks, power cuts and technical barriers, including service reliability, were some challenges cited that degraded the quality of service. There were however other actors who felt that their speeds had improved and, therefore, were satisfied with their connections.

In the tea sector, most respondents expressed a certain level of satisfaction with the Internet services provided to their businesses. A number of respondents were dissatisfied with their Internet services, especially slow speeds, low reliability, and poor availability. The key causes of quality degradation were cited as technical barriers, cable breaks, and viruses.

\section{c) Economic Development}

In the tourism sector, we found out economic benefits at the level of the organization such as increased efficiency and productivity, reduced costs and improved quality of service delivery. Similarly, the study found out the key impacts in the tea sector to be enhanced productivity, increased efficiency, and reduced cost. How these effects at the firm level translate into economic benefits at the national level was not explored and may be subject for a further study. 
Table 5.1 (derived from table 3.6)shows a summary of the perceptions of the tourism sector participants of the biggest gainers and losers of use of broadband connectivity.

\section{Table 5.1: Biggest Winners and Losers of Broadband Connectivity}

\section{BENEFIT MOST}

- Customers

- Tour Operators and Travel Agents-who have embraced technology

- Hotels
- $\quad$ Operators who are still using offline marketing methods

- Tour operators and travel agents because they are cut off the chain, as an easy and direct link has been established between customers and service providers

- Destinations whose information is not available online

\subsubsection{Use and Effects}

Most respondents had embraced broadband Internet and related ICTs: Internet connectivity, information systems applications (such as online reservation systems, online marketing systems, and online payment systems), Web hosting, social networks (such as LinkedIn, YouTube, and Facebook), and third party websites. They use these ICT platforms to market their packages and wait for inquiries from clients who are spread globally. Some respondents mentioned that they had more than one website at their disposal just to boost their chances of being found online. Table 5.2summarizes various technologies adopted by actors in the tourism sector. 
Table 5.2: Use of Different Technologies by Actors in the Tourism Sector

\begin{tabular}{|c|c|c|}
\hline Use & Players & Main technologies used \\
\hline \multirow[t]{3}{*}{$\begin{array}{l}\text { Online access to } \\
\text { customers }\end{array}$} & Tour operators & $\begin{array}{l}\text { - Online recommendations and referrals, websites, trip } \\
\text { advisor, social media }\end{array}$ \\
\hline & Travel agents & $\begin{array}{l}\text { - Websites, social media, online recommendations and } \\
\text { referrals }\end{array}$ \\
\hline & Hotels & - Websites, TripAdvisor, social media \\
\hline \multirow{4}{*}{$\begin{array}{l}\text { Forms of electronic } \\
\text { communication }\end{array}$} & Tour operators & - Emails, Skype, phone, social media \\
\hline & Travel agents & - $\quad$ Emails, phone, social media, Skype \\
\hline & Hotels & - Emails, phone, social media, Skype \\
\hline & KWS & - Emails, phone \\
\hline \multirow[t]{2}{*}{$\begin{array}{l}\text { Means of access to } \\
\text { information }\end{array}$} & $\begin{array}{l}\text { Tour operators \& } \\
\text { travel agents }\end{array}$ & - Websites, print media, social media, trip advisor \\
\hline & $\begin{array}{l}\text { Hotels \& other } \\
\text { destinations }\end{array}$ & - Websites, print media, trip advisor \\
\hline \multirow[t]{2}{*}{$\begin{array}{l}\text { Strategies for online } \\
\text { presence }\end{array}$} & $\begin{array}{l}\text { Tour operators \& } \\
\text { travel agents }\end{array}$ & $\begin{array}{l}\text { - Websites, social media, web presence on } 3^{\text {rd }} \text { party } \\
\text { websites }\end{array}$ \\
\hline & $\begin{array}{l}\text { Hotels \& other } \\
\text { destinations }\end{array}$ & $\begin{array}{l}\text { - Websites, social media, web presence on } 3^{\text {rd }} \text { party } \\
\text { websites }\end{array}$ \\
\hline \multirow[t]{6}{*}{ Last mile connectivity } & Tour operators & - $\quad$ Fibre, modems \\
\hline & Travel agents & - Fibre \\
\hline & Hotels & - WiMax, fibre, satellite, modems \\
\hline & KWS & - $\quad$ Modems, WiMax, satellite \\
\hline & Associations & - Modems, WiMax \\
\hline & Beach operators & - Modems \\
\hline
\end{tabular}

Red - main technology - this means that the technology is the most adopted by respective players to conduct daily business operations.

Source: Study

The use of these technologies had brought about a number of opportunities and effects, chief among them being:

- access to wider markets because of the ability of existing actors to form local and global partnerships,

- enhanced productivity and increased efficiency,

- new opportunities and strategies not available before broadband Internet,

- improved market audience, reduction in costs and faster speed of reply due to electronic communication,

- enhanced visibility and reduced marketing costs due to online presence,

- intermediation/disintermediation, and

- effects on geography (scaling up into new areas, reconfiguring space, globalization and regional integration).

We now further explore theeffects of broadband Internet and related technologies on increased competition and disintermediation. 


\section{a) Increased Competition}

Broadband Internet and related technologies had lowered barriers to entry through reduced start up, distribution, and operational costs, allowing small actors-notably beach operators - to enter the tourism sector. New entrants had been able to for example represent themselves to customers through websites and social media, thereby threatening the position of existing rivals and their control of the market (Waema and Katua, 2013). Existing actors had been enabled to access wider markets because of an ability to form global and local partnerships. They could therefore pose competition in new areas with these partnerships enabled by technology. We found out that broadband connectivity had enabled many actors to access clients directly without going through intermediaries. All these opportunities created by broadband internet and related ICTs had in turn led to increased competition.

The study found out that broadband connectivity and related technologies had increased the bargaining power of suppliers by offering more cost-effective distribution platforms, offering resources to carry out research to meet customers' requirements and enabling direct interactions with customers(Waema and Katua, 2013). The word supplier refers to a company that handles or supplies the final tea product to the final consumers who buy the product in small quantities. At the same time, however, these technologies had enhanced the bargaining power of customers vis-à-vis suppliers. Broadband connectivity and related technologies achieved this through the cost transparency that they cause and the cost savings they enable(Waema and Katua, 2013). They enable customers to access a wide range of suppliers, reducing their loyalty to specific suppliers; this in turn affected competition in the tourism sector.

\section{b) Disintermediation}

Broadband Internet had the following effects on disintermediation/intermediation:

- actors cutting off others in the value chain,

- customers by-passing the intermediaries,

- new intermediaries joining the value chain, for example ASPs, and

- lowering of costs.

It was evident that the disintermediation effects of broadband Internet and related ICTs were a threat to traditional intermediaries who did not provide value addition to customers. This is because customers could access the services and information directly from the destination service providers. There was evidence that several travel agents had closed their businesses, but this might not be because of disintermediation though it could have contributed to the closures. A number of respondents argued that tour operators and travel agents were changing their strategy and embracing the Internet and related new technologies. 
The study found mixed results on the question of intermediation and disintermediation. On the one hand, hotels and tourist destinations were making concerted efforts to cut out intermediaries by moving their businesses online. This way, some customers booked directly to these destinations without going through intermediaries. On the other hand, there were still customers who believed in the role of travel agents and tour operators. While acknowledging that Internet connectivity and related technologies were transforming the tourism sector, several policy makers were of the view that these intermediaries are still required, largely because of trust issues-only their role will change. Further reasons intermediation may still be required are:

- connectivity is not universally available to all potential tourism customers,

- not all customers have embraced the new technologies while others may lack the knowledge to use electronic gadgets, access internet, search for information,

- not all customers have the time to spend on the internet looking for bargains, and

- many tourism destinations do not have adequate online content in the web portals for customers to make decisions.

\subsubsection{Challenges}

changes in competition and disintermediation/intermediation are key challenges and have forced existing actors in the value chain to redesign their business models and change their roles to safeguard their positions as well as to cope with an increasingly complex and competitive environment. Some actors for example have set up websites and embraced all forms of social media as part of new strategies for marketing.

The main challenge that was anticipated with broadband availability was increased cyber insecurity. We found out that cost, which goes beyond the cost of the broadband, was still one of the challenges of adopting broadband Internet and related technologies in the tourism sector. Further challenges are summarized in figures 3.12and 3.13under connectivity and payment challenges, respectively. 


\subsection{Tea Sector}

\subsubsection{Use and effects}

Table 5.3 shows the technologies used by the actors in the tea sector.

Table 5.3: Use of Different Technologies by Actors in the Tea sector

\begin{tabular}{|c|c|c|}
\hline Use & Actors & Main technologies used \\
\hline \multirow[t]{6}{*}{$\begin{array}{l}\text { Online access to } \\
\text { customers }\end{array}$} & Producers & $\begin{array}{l}\text { Emails, social media platforms, websites, online } \\
\text { recommendations and referrals, third party websites } \\
\text { and YouTube }\end{array}$ \\
\hline & Packers & $\begin{array}{l}\text { - Social media, online recommendations and referrals, } \\
\text { websites }\end{array}$ \\
\hline & Brokers & - Websites \\
\hline & Buyers & - Websites \\
\hline & Warehouses & - Emails \\
\hline & $\begin{array}{l}\text { Cooperatives/ } \\
\text { Unions }\end{array}$ & $\begin{array}{l}\text { - Personal blogs, emails, online recommendations and } \\
\text { referrals, }\end{array}$ \\
\hline \multirow{3}{*}{$\begin{array}{l}\text { Forms of electronic } \\
\text { communication }\end{array}$} & Producers & - $\quad$ Emails, video conferencing, VolP, Skype, phone \\
\hline & Intermediaries & - $\quad$ Emails, phone, Skype \\
\hline & $\begin{array}{l}\text { Tea associations \& } \\
\text { other providers }\end{array}$ & - Emails, phone \\
\hline \multirow{3}{*}{$\begin{array}{l}\text { Means of access to } \\
\text { information }\end{array}$} & Producers & - Emails, Websites, social media \\
\hline & Intermediaries & - $\quad$ Emails, Websites, social media \\
\hline & Tea associations & - Emails, Websites \\
\hline \multirow{3}{*}{$\begin{array}{l}\text { Strategies for online } \\
\text { presence }\end{array}$} & Producers & - Websites, online advertisements, social media \\
\hline & Intermediaries & $\begin{array}{l}\text { Websites, online advertisements, social media, web } \\
\text { presence on third party websites }\end{array}$ \\
\hline & $\begin{array}{l}\text { Tea associations \& } \\
\text { other providers }\end{array}$ & - Websites \\
\hline \multirow[t]{2}{*}{ Last mile connectivity } & Producers & - $\quad$ Fibre, modems, WiMax \\
\hline & Intermediaries & - WiMax, fibre, modems \\
\hline
\end{tabular}

Red - main technology- this means that the technology is the most adopted by respective players to conduct daily business operations.

Source: Study

Broadband Internet and related ICTs play a key role in reducing information and communication asymmetries between stakeholders in the tea value chain in Kenya. With the varied online tools, stakeholders in the tea sector were able to access vital information in real time. The brokers for example were able to relay reports to producers in real time, informing them on how their teas performed in the auction. This had enabled producers to make informed decisions about their teas and they could target different markets using this information.

The producers however felt that there was the problem of information hoarding. While acknowledging that internet connectivity and related technologies were transforming the 
tea sector, several producers were of the view that brokers and buyers (intermediaries) had some sort of market intelligence which was rarely documented or disseminated to them. The lack of this information prevented stakeholders from directly accessing respective consumer markets, rendering them dependent on brokers and buyers in accessing markets.

The bargaining power of producers had increased in that they could contact foreign clients directly and were able to agree on tea prices. Producers had begun selling directly to clients overseas. They have websites which they use to market themselves, and through which they get inquiries. The study shows that the number of direct sales is increasing, and more private companies are directly targeting clients and not going through the auction in order to sell their teas. The benefit of the direct sales to producers is often considerable as they get their payments faster, have less uncertainty over sales and prices and can avoid charges associated with auctioning tea such as brokers' and warehouse fees.

Respondents were disappointed about their being cut off the tea value chain because of changes in connectivity. With the development of broadband Internet and related technologies, the process of bringing buyers and sellers more directly together was already taking place at the pre- and post-auction stages. Combined with technological advancements, this trend suggests that there is a possibility that auction houses will become redundant. Producers will not have to send their teas to the auction since they will be able to sell their teas directly to buyers without having to go through brokers or auctioneers.

Despite their need of controlling the market, producers still depend on the auction to provide a market for their commodities. Producers relied on the auction prices when selling their teas directly to clients. This shows that brokers as intermediaries at the auction still had roles and, even with the recent technological changes, producers still relied on the auction to fetch better prices as they did with their private sales. In conclusion, the study shows that the intermediaries (brokers) can survive and coexist perfectly with the current technological changes, each one focused on one's kind of business and attending to their market segments.

The intermediaries in the sector still had their roles and broadband Internet had not removed them from the value chain. These technologies however played the role of an enabler in the value chain. Whether these technologies can replace the intermediaries with complete automation of the auction process is debatable and is subject for further research.

The study revealed that broadband Internet and related technologies allowed businesses to make new, and maintain existing, connections. The trend is that companies get to work with other companies because of referrals or long-term relationships they had established over time. If there was need to form a relationship, however, a stakeholder 
would search online for a company one would want to work with but would still depend on referrals from stakeholders in the industry for the connection to materialize. This illustrates the importance of face-to-face communication in the sector. This is not the case as has been observed in the tourism industry where stakeholders would form relationships either locally or internationally through engagements online.

Yet, some of these new technologies were often not recognized as part of core development strategies by many actors in the value chain. The big actors, who are mainly multinationals, were the biggest consumers of technology. These companies had heavily invested in technology, had ERPs to monitor all their processes and their network infrastructure connected on fibre optic and use these technologies to remotely connect to their head office, branch offices, field offices, estates, and factories. These actors communicated with their buyers and suppliers, researched, sold and marketed their tea and connected to the e-banking platform used for payments. This use of ICT had led to enhanced productivity, increased efficiency and reduced cost.

Small actors in the industry had basic IT infrastructure to enable them to conduct daily operations because of lack financial resources to acquire such technologies. There was general consensus that cost and acquiring staff with requisite skills were additional challenges.

Due to disintermediation effects of these technologies, respondents were able to contact customers directly without having to involve intermediaries. Some respondents said that faster Internet and related ICT developments had posed a threat to intermediaries, while some respondents said that there was a need for intermediaries to exist in the tea value chain and resisted the idea of disintermediation, especially the automation of the tea auction process.

Table 5.4 (derived from table 4.2)shows a summary of biggest gainers and losers of use of broadband connectivity as perceived by the participants in the tea sector.

Table 5.4: Biggest Winners and Losers of Broadband Connectivity in the Tea Sector

\begin{tabular}{|c|c|}
\hline BENEFIT MOST & BENEFIT LEAST \\
\hline $\begin{array}{ll}\text { - } & \text { Producers } \\
\text { - } & \text { Farmers } \\
\text { - } & \text { Cooperatives } \\
\text { - } & \text { Transport Service Providers }\end{array}$ & $\begin{array}{ll}\text { - } & \text { Warehouse Operators } \\
\text { - } & \text { Buyers } \\
\text { - } & \text { Brokers }\end{array}$ \\
\hline
\end{tabular}

\subsubsection{Challenges}

The key challenge anticipated before the arrival of fibre optic cables was increased cyber insecurity. This research found that the key challenges associated with broadband internet and related technologies in the tea sector were: 
- fear of disintermediation, especially with planned automation of the tea auction,

- increased competition,

- technical barriers,

- cybercrime, online scams, privacy and confidentiality issues, and

- the cost of ICT. 


\title{
6. Conclusions and Recommendations
}

\subsection{Conclusions}

From the findings, we make the following conclusions.

\begin{abstract}
a) Broadband Internet Costs
From the public and political discourse, there were widespread disappointments that the reductions in broadband Internet prices had not gone as low as had been expected. In the two sectors, some of the actors were satisfied with the cost of broadband Internet services, especially the large corporate actors. Small actors tended to find the cost of broadband still very expensive, however.
\end{abstract}

\section{b) Quality of Broadband Services}

The public expected better speeds for Internet connectivity or high capacity bandwidth after the landing of the fibre optic cables, but the study found out that some respondents in the tourism sector were not satisfied with the quality of service of Internet connectivity. Cable breaks, power cuts and technical barriers, as well as service reliability, were some key challenges cited that degraded the quality of the service. There were however actors who felt that their speeds had improved and were satisfied with their connections. In the tea sector, most respondents expressed a certain level of satisfaction with the quality of Internet services provided to their businesses. A number of respondents were dissatisfied with their Internet services, especially slow speeds, low reliability and poor availability. The key causes of quality degradation were technical barriers, cable breaks, and viruses.

\section{c) Effect of Broadband Internet on Actors in the Tea and Tourism Value Chains}

The study found a high degree of disintermediation taking place in the tourism sector, where new intermediaries had taken advantage of broadband Internet and offered their services virtually. This was informal when beach operators formed relationships with customers abroad through online platforms and facilitated their visits back in the country. There was evidence however that the large actors had begun to embrace the new transformative technologies enabled by broadband access to prevent them from losing business. There was overwhelming evidence that intermediation and disintermediation will continue to co-exist in the foreseeable future in the tourism sector because of trust, connectivity, human capacity and content challenges. 
The tea sector had a comparatively limited level of disintermediation. Broadband Internet and related ICTs largely played the role of an enabler in the value chain. Disintermediation was only beginning to take place, especially at the pre- and postauction stages. Full disintermediation could only take place once the auction process was fully automated. This automation had been in the planning stage for a while, but there was a lot of resistance to an automated tea auction, with many brokers believing that it was not possible to fully automate the auction process.

\section{d) Challenges}

The key challenge anticipated before the arrival of fibre optic cables was increased cyber insecurity. In the tourism sector, the research identified these key challenges:

- the cost of ICT,

- increased competition from both physical and virtual companies,

- cybercrime and online scams,

- quality of broadband services, including cable cuts, power cuts, and viruses,

- a lack of human skills,

- technical barriers, and

- $\quad$ payment platform challenges, including trust and the high cost of transactions.

Fairly similar challenges key challenges in the tea sector were:

- fear of disintermediation, especially with the planned automation of the tea auction,

- increased competition,

- technical barriers,

- cybercrime, online scams, privacy, and confidentiality issues, and

- the cost of ICT

In the two sectors, there was a differential adoption of broadband and related technologies by actors, which can be considered as a further challenge.

\subsection{Recommendations}

The Kenyan economic blueprint, Vision 2030, prioritises tourism and agriculture as two key economic sectors in the economic pillar. If this sector is to make significant contribution to economic development, then bottlenecks associated with the cost of developing ICT platforms for the sector, as well as the relatively high cost of broadband, must be addressed. We therefore recommend policy and regulatory interventions to reduce the cost of ownership and use of ICTs by the consumer, a key intervention here is being a reduction in the retail cost of broadband. The interventions should aim at increasing affordability of broadband internet which, in turn, would enhance its universal 
access and utilization. This goal can be achieved through fast-tracking the implementation of the universal access through utilizing the universal service fund created by the Kenya Communications (Amendment) Act, 2009 as recommended by Waema and Obadia (Waema and Okinda, 2011).

Kenya has witnessed huge growth in university education, often at the expense of middle level education. A key force to drive the economy into a middle-income level status as envisaged in the Vision 2030 is rapidly developing human resource capabilities especially in engineering and technology. With respect to a lack of technical skills, therefore, we recommend incentives for the private sector to create technical education and training (technical and vocational education and training [TVET]) centres of excellence focused on training ICT professionals.

Since the launch of the world-famous M-PESA platform for mobile money transfers and payments, Kenya has witnessed the growth on many local payment platforms that work for and in the country-but the platforms are not integrated and are expensive. We therefore recommend the implementation of the planned integrated national payment system to be accelerated and that the two regulators (the Central Bank of Kenya and the Communications Commission of Kenya) to work together to make regulatory interventions for M-PESA as a common good and to bring down the cost of transactions on payment platforms.

In the tea sector, the automation of the auction process has taken long to agree on whether to fully adopt the electronic auction. The automation, together with the automation of the other segments of the value chain, would increase efficiency and reduce costs in the chain. The participants in the two focus group discussion workshops strongly supported the automation of the auction process, which would be-starting with tea-the beginning of setting up a national agriculture commodity exchange (the other agricultural commodities can be included in such an electronic auction platform).The platform would enable tea farmers and producers to access timely and accurate marketing and price information and sell their produce through the platform. In turn, this action would empower tea farmers in increased income from their tea and reduced turnaround time to receive payments.

Customers have for many years experienced low quality of services from the mobile operators (for example, dropped calls, uncompleted calls, undelivered and hanging messages (SMSes), and low Internet speeds) and broadband service providers. The regulator monitors the quality of service by the licensed operators, but no serious action has been taken against providers who do not meet the quality of service standards required by their license obligations. The only action that we are aware of in this regard is that the regulator has given one of the largest mobile operators a condition of adhering to the set minimum quality of services standards before the renewal of its GSM licence in June 2014. With actions of this kind, operators are unlikely to take the regulator seriously, and customers will continue to experience low quality services. We therefore 
recommend that the regulator takes serious action against operators who do not meet the set minimum quality of service standards. The public, the government and diverse stakeholders should join hands to make the regulator more independent and have teeth.

We found very little support for informal tourism entrepreneurs such as beach operators, yet informal entrepreneurial efforts are critical in solving the huge unemployment problem among the youth in the country. We therefore recommend that the government provides support-in the form of facilitating licensing, credit access and training-to informal entrepreneurs who are making efforts to enter the tourism sector. This will help the tourism market and, in turn, the economy to grow.

\section{Acknowledgements}

This research was made possible with through ESRC-DFID Grant RES-167-25-0701 in collaboration with co-investigators Dr. Mark Graham and Dr. Christopher Foster. 


\section{References}

Bouman, H., Hoof, B.V.D., Wijngaert, L.V.D. and Dijk, J. V., 2004.Information and Communication Technology in Organizations. Sage Publications, CA: 91320, USA, 1-2. Central Bank of Sri Lanka, 2007. Annual Report (National Output and Expenditure).

Chong, S., Pervan, G., and Bauer, C. (2001). Implementation Success of Internet-based Electronic Commerce for Small-and Medium-sized Enterprises in Australia. 14th International Bled Electronic Commerce Conference, Bled, Slovenia, June 25-26.

Cobb, A. K., and Forbes, S. (2002). Qualitative research: What Does It Have to Offer to The Gerontologist? The Journals of Gerontology, 57A(4), M197-M202.

Government of Kenya (2013). Second Medium Term Plan, 2013 - 2017. Government of Kenya, 2013.

Government of Kenya (2007). Kenya Vision 2030.

Government of Kenya (2003). Economic Recovery Strategy for Wealth and Employment Creation Strategy.

Waema, T., Adeya, C. and Ndun'gu, (2010). Kenya ICT Sector Performance Review 2009/2010: Towards Evidence-Based ICT Policy and Regulation, Volume Two, Policy Paper 10, ResearchICTAfrica

Waema, Timothy Mwololo and Katua, Charles (2013), The Impacts of Broadband Internet and Related Technologies on the Value Chain of the Tourism Sector in Kenya. Proceedings of the CPRsouth8/CPRafrica2013 conference.

Available at SSRN: http://ssrn.com/abstract=2363896

Waema, T.M. and Okinda, O. (2011). Policy Implications of the Relationship Between ICT Access and Usage and Well-being: A Case Study ofKenya, African Journal of Science, Technology, Innovation and Development (AJSTID), 3(3), 30-56.

Yin, R. K. (2003) Case Study Research, 3rd ed. London, England: Sage Publications. 
Annex 1: Code Tables

\section{A1.1: Tourism Sector Codes}

\begin{tabular}{|c|c|c|}
\hline Grand Parent Themes & Parent Themes & Codable Themes \\
\hline \multirow{22}{*}{ Connectivity (con) } & Bandwidth/speed (bnd) & 5-10 Mbps (cn-bnd-5to10) \\
\hline & & 2-5 Mbps (cn-bnd-2to5) \\
\hline & & 1-2 Mps (cn-bnd-1to2) \\
\hline & & Below 1 Mbps (cn-bnd-blw1) \\
\hline & & $\begin{array}{l}\text { Above 10Mbps (cn-bnd- } \\
\text { abve10) }\end{array}$ \\
\hline & Challenges (chl) & \\
\hline & & $\begin{array}{l}\text { Increased competition (con- } \\
\text { chl-ic) }\end{array}$ \\
\hline & & Virtual companies (con-chl-vc) \\
\hline & & Disintermediation (con-chl-dis) \\
\hline & & $\begin{array}{l}\text { Technical barriers, including } \\
\text { reliability (con-chl-tecb) }\end{array}$ \\
\hline & & Cybercrime (con-chl-cc) \\
\hline & & Viruses (con-chl-vir) \\
\hline & & Confidentiality (con-chl-confi) \\
\hline & & Privacy (con-chl-pri) \\
\hline & & $\begin{array}{l}\text { Fears about changes related to } \\
\text { changed connectivity (con-chl- } \\
\text { frc) }\end{array}$ \\
\hline & & High Cost(con-chl-hc) \\
\hline & & $\begin{array}{l}\text { Digital divide, for example, lack } \\
\text { of infrastructure in rural areas } \\
\text { (con-chl-dd) }\end{array}$ \\
\hline & & Human skills (con-chl-hs) \\
\hline & & Online scams (con-chl-os) \\
\hline & & $\begin{array}{l}\text { Power cuts (con-chl-pc-power } \\
\text { cuts) }\end{array}$ \\
\hline & & $\begin{array}{l}\text { Cable breaks (con-chl-cb-cable } \\
\text { breaks) }\end{array}$ \\
\hline & Quality of service (qos) & Good (con-qos-good) \\
\hline & & Average (con-qos-ave) \\
\hline
\end{tabular}




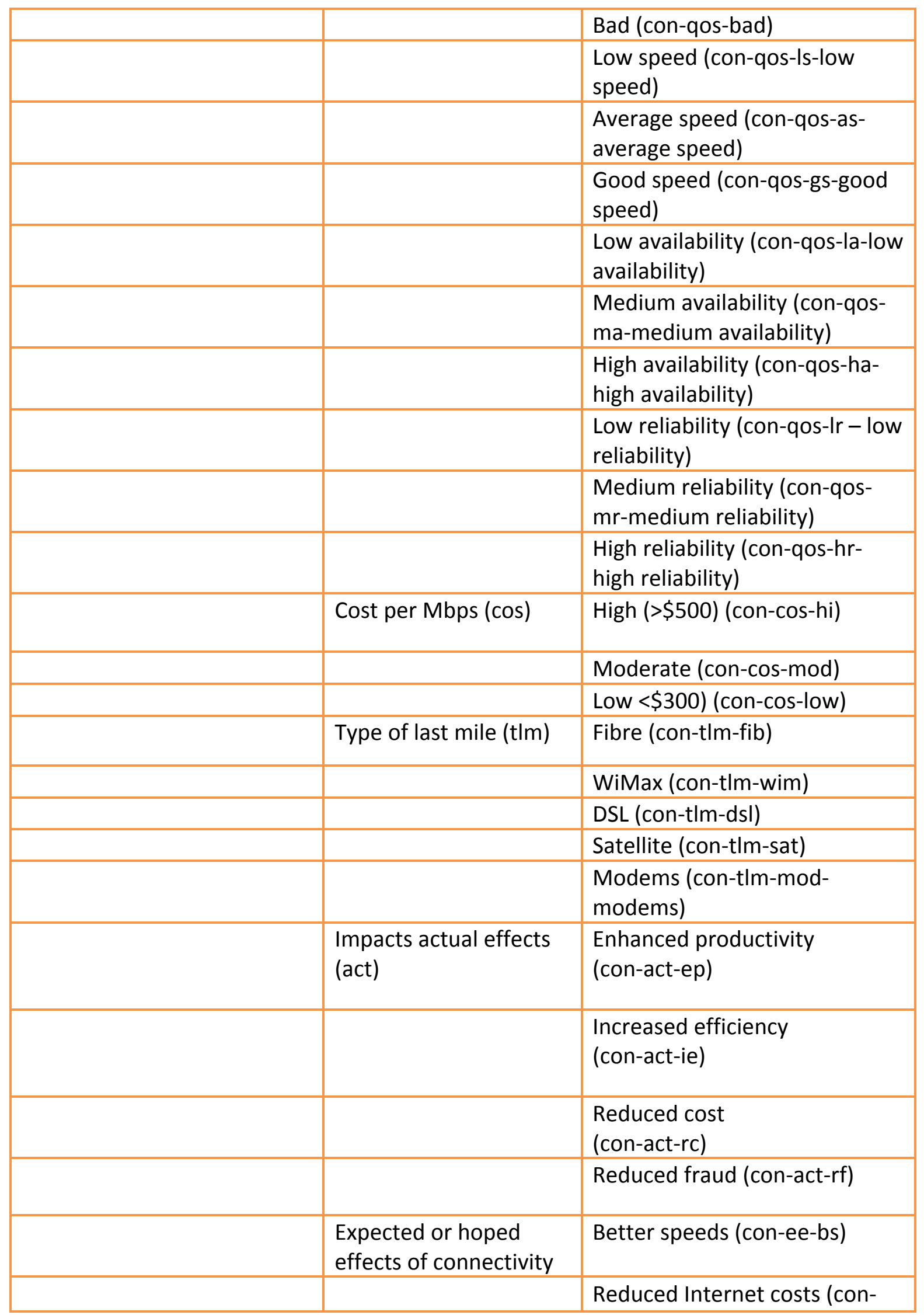




\begin{tabular}{|c|c|c|}
\hline & & ee-ric) \\
\hline & & Better QoS \\
\hline & $\begin{array}{l}\text { Changing tasks, } \\
\text { strategies or } \\
\text { opportunities (cts) }\end{array}$ & New jobs (con-cts-nj) \\
\hline & & New strategies (con-cts-ns) \\
\hline & & New businesses (con-cts-nb) \\
\hline & & $\begin{array}{l}\text { New markets/market growth } \\
\text { (con-cts-nm) }\end{array}$ \\
\hline & $\begin{array}{l}\text { Unintended } \\
\text { consequences of } \\
\text { connectivity (ucc) }\end{array}$ & $\begin{array}{l}\text { Creation of new jobs (con-ucc- } \\
\text { cnj) }\end{array}$ \\
\hline & & Enhanced jobs (con-ucc-ej) \\
\hline & & Increased cost (con-ucc-ic) \\
\hline & $\begin{array}{l}\text { Ideas about } \\
\text { connectivity (ic) }\end{array}$ & Fast Internet (con-ic-fi) \\
\hline & $\begin{array}{l}\text { Unique and interesting } \\
\text { metaphors for the } \\
\text { Internet (met) }\end{array}$ & Super highway (con-met-sh) \\
\hline & & WWW (con-ucc-www) \\
\hline \multirow[t]{4}{*}{ Image/ representation (ir) } & Positive effects (pe) & Enhanced awareness (ir-pe-ea) \\
\hline & & Increased customers (ir-pe-ic) \\
\hline & Negative effects (ne) & $\begin{array}{l}\text { Negative comments from } \\
\text { competitors (ir-ne-ncomp) }\end{array}$ \\
\hline & & $\begin{array}{l}\text { Negative comments from } \\
\text { customers (ir-ne-ncus) }\end{array}$ \\
\hline \multirow[t]{10}{*}{$\begin{array}{l}\text { Electronic communication } \\
\text { (ec) }\end{array}$} & $\begin{array}{l}\text { Forms of electronic } \\
\text { communication (fec) }\end{array}$ & E-mail (ec-fec-eml) \\
\hline & & Phone (ec-fec-phn) \\
\hline & & Skype (ec-fec-skyp) \\
\hline & & Social media (ec-fec-sm) \\
\hline & & $\begin{array}{l}\text { Teleconferencing (ec-fec-tc- } \\
\text { teleconferencing) }\end{array}$ \\
\hline & & Video conferencing (ec-fec-vc) \\
\hline & & $\begin{array}{l}\text { VOIP (ec-fec-voip-voice over } \\
\text { Internet protocol) }\end{array}$ \\
\hline & $\begin{array}{l}\text { Effects of electronic } \\
\text { communication (eec) }\end{array}$ & $\begin{array}{l}\text { Faster speed of reply (ec-eec- } \\
\text { fsr) }\end{array}$ \\
\hline & & Reduced cost (ec-fec-rc) \\
\hline & & Access to wider audience (ec- \\
\hline
\end{tabular}




\begin{tabular}{|c|c|c|}
\hline & & fec-awa) \\
\hline & & $\begin{array}{l}\text { Widened geographical reach } \\
\text { (ec-fec-wgr) }\end{array}$ \\
\hline \multirow[t]{17}{*}{ Access to customers (ac) } & Offline access (ofa) & Exhibitions (ac-ofa-exh) \\
\hline & & Walk in (ac-ofa-wi) \\
\hline & & $\begin{array}{l}\text { Referrals from other customers } \\
\text { (ac-ofa-rc) }\end{array}$ \\
\hline & & Trade shows (ac-ofa-ts) \\
\hline & & Other partners (ac-ofa-prt) \\
\hline & Online access (ona) & TripAdvisor (ac-ona-ta) \\
\hline & & Email (ac-ona-eml) \\
\hline & & Website (ac-ona-web) \\
\hline & & $\begin{array}{l}\text { Referrals from other customers } \\
\text { (ac-ona-rc) }\end{array}$ \\
\hline & & $\begin{array}{l}\text { Online customer } \\
\text { recommendations/ comments } \\
\text { (positive or negative) (ac-ona- } \\
\text { ocr) }\end{array}$ \\
\hline & & Personal blogs (ac-ona-blgs) \\
\hline & & YouTube( ac-ona-YouTube) \\
\hline & $\begin{array}{l}\text { What convinces } \\
\text { customers to sign in } \\
\text { (wcc) }\end{array}$ & $\begin{array}{l}\text { Fast email response to } \\
\text { customer queries (ac-wcc-frcq) }\end{array}$ \\
\hline & & Good reputation (ac-wcc-gr) \\
\hline & & Quality service (ac-wcc-qs) \\
\hline & & $\begin{array}{l}\text { Provision of adequate } \\
\text { information to make decision } \\
\text { (ac-wcc-pai) }\end{array}$ \\
\hline & & Low cost (ac-wcc-lc) \\
\hline \multirow[t]{7}{*}{ Access to information (ai) } & $\begin{array}{l}\text { Means of access to } \\
\text { general information } \\
\text { (mai) }\end{array}$ & Search engines (ai-mai-se) \\
\hline & & Websites (ai-mai-web) \\
\hline & & TripAdvisor ((ai-mai-ta) \\
\hline & & $\begin{array}{l}\text { Social networks (Linkedln, } \\
\text { Facebook, Twitter) (ai-mai-sn) }\end{array}$ \\
\hline & & $\begin{array}{l}\text { Third party websites, online } \\
\text { directories or online market } \\
\text { places (ai-mai-tpw) }\end{array}$ \\
\hline & & Brochures (ai-mai-broc) \\
\hline & & Client forms (ai-mai-cf-client \\
\hline
\end{tabular}




\begin{tabular}{|c|c|c|}
\hline & & forms) \\
\hline & & $\begin{array}{l}\text { Exhibitions and trade shows } \\
\text { (face-to-face) (ai-mai-exh) }\end{array}$ \\
\hline & & Newspapers (ai-mai-pm) \\
\hline & $\begin{array}{l}\text { Positive effects of } \\
\text { access to information } \\
\text { (peai) }\end{array}$ & Open access (ai-peai-oa) \\
\hline & & $\begin{array}{l}\text { Increased customers (ai-peai- } \\
\text { ic) }\end{array}$ \\
\hline & $\begin{array}{l}\text { Negative effects of } \\
\text { access to information } \\
\text { (neai) }\end{array}$ & $\begin{array}{l}\text { Information overload (ai-neai- } \\
\text { io) }\end{array}$ \\
\hline & & $\begin{array}{l}\text { Negative aspects cannot be } \\
\text { hidden, for example exposed } \\
\text { through TripAdvisor (ai-neai- } \\
\text { na) }\end{array}$ \\
\hline & & $\begin{array}{l}\text { Validity challenges (of } \\
\text { information and its sources) } \\
\text { (ai-neai-vc) }\end{array}$ \\
\hline & & $\begin{array}{l}\text { Posting negative comments by } \\
\text { a customer (ai-neai- } \\
\text { negtcomm) }\end{array}$ \\
\hline \multirow[t]{2}{*}{ Classification (cls) } & Forms of branding (fob) & Online branding (cls-fob-onb) \\
\hline & & Offline branding (cls-fob-offb) \\
\hline \multirow[t]{7}{*}{ Online presence (op) } & Strategies (str) & Websites (op-str-web) \\
\hline & & $\begin{array}{l}\text { Social media and social } \\
\text { networks (op-str-sm) }\end{array}$ \\
\hline & & $\begin{array}{l}\text { Web presence on third party } \\
\text { sites or platforms like (op-str- } \\
\text { tpw) }\end{array}$ \\
\hline & & $\begin{array}{l}\text { Online advertisements (op-str- } \\
\text { oa-online advertisements) }\end{array}$ \\
\hline & $\begin{array}{l}\text { Effects of online } \\
\text { presence (eop) }\end{array}$ & Enhanced visibility (op-eop-ev) \\
\hline & & $\begin{array}{l}\text { Reduced cost of marketing (op- } \\
\text { str-rcm) }\end{array}$ \\
\hline & & Others (op-str-oth) \\
\hline \multirow[t]{4}{*}{ Costs (cos) } & Start-up costs (suc) & High (cos-suc-hi) \\
\hline & & Moderate (cos-suc-mod) \\
\hline & & Low (cos-suc-low) \\
\hline & $\begin{array}{l}\text { Impact of Internet on } \\
\text { operational costs (ioc) }\end{array}$ & Radically reduce (cos-ioc-rr) \\
\hline
\end{tabular}




\begin{tabular}{|c|c|c|}
\hline & & Reduce (cos-ioc-red) \\
\hline & & No change (cos-ioc-nc) \\
\hline & & Increase cost (cos-ioc-ic) \\
\hline \multirow[t]{26}{*}{$\begin{array}{l}\text { 9. Company information } \\
\text { (coi) }\end{array}$} & $\begin{array}{l}\text { Size-noof employees } \\
\text { (noe) }\end{array}$ & $\begin{array}{l}\text { Big (> } 50 \text { employees) (coi-noe- } \\
\text { big) }\end{array}$ \\
\hline & & $\begin{array}{l}\text { Medium (10-50 employees) } \\
\text { (coi-noe-med) }\end{array}$ \\
\hline & & $\begin{array}{l}\text { Small (<10 employees) (coi- } \\
\text { noe-sml) }\end{array}$ \\
\hline & & $\begin{array}{l}\text { One person (informal) (coi- } \\
\text { noe-inf) }\end{array}$ \\
\hline & Offices (off) & $\begin{array}{l}\text { Global offices (coi-off-go-global } \\
\text { offices) }\end{array}$ \\
\hline & & $\begin{array}{l}\text { Regional offices (coi-off-ro- } \\
\text { regional offices) }\end{array}$ \\
\hline & & $\begin{array}{l}\text { Country-wide branches (coi- } \\
\text { off-cwb) }\end{array}$ \\
\hline & & $\begin{array}{l}\text { One office,for example, } \mathrm{HQ} \\
\text { (coi-off-oof) }\end{array}$ \\
\hline & & No office (coi-off-nof) \\
\hline & Profit (pft) & High (coi-pft-hi) \\
\hline & & Medium (coi-pft-med) \\
\hline & & Low (coi-pft-low) \\
\hline & & Loss (coi-pft-los) \\
\hline & $\begin{array}{l}\text { Pricing of goods and } \\
\text { service (pgs) }\end{array}$ & $\begin{array}{l}\text { Use of market prices (coi-pgs- } \\
\text { ump) }\end{array}$ \\
\hline & & $\begin{array}{l}\text { Depends on origin (coi-pgs- } \\
\text { doo) }\end{array}$ \\
\hline & & Flat charge (coi-pgs-fc) \\
\hline & & Premium costing (coi-pgs-pc) \\
\hline & Location (loc) & Nairobi (coi-loc-nrb) \\
\hline & & North Rift (coi-loc-nor) \\
\hline & & Coast (coi-loc-msa) \\
\hline & & Central (coi-loc-ctl) \\
\hline & $\begin{array}{l}\text { Leverage of large } \\
\text { operators (levrg) }\end{array}$ & Financial muscle (coi-levrg-fm) \\
\hline & & Volume (coi-levrg-vol) \\
\hline & & Low cost (coi-levrg-Ic) \\
\hline & & Name/brand (coi-levrg-brnd) \\
\hline & $\begin{array}{l}\text { Growth strategy for } \\
\text { informal operators } \\
\text { (grwstr) }\end{array}$ & Associations (coi-grwstr-assoc) \\
\hline
\end{tabular}




\begin{tabular}{|c|c|c|}
\hline & & Use of ICT (coi-grwstr-ict) \\
\hline & & $\begin{array}{l}\text { Use of past customers abroad } \\
\text { (coi-grwstr-prcust) }\end{array}$ \\
\hline & & $\begin{array}{l}\text { Developing new tourism } \\
\text { products (coi-grwstr-newprd) }\end{array}$ \\
\hline \multirow[t]{9}{*}{ 10. Payment (pmt) } & $\begin{array}{l}\text { Electronic payment } \\
\text { methods (epm) }\end{array}$ & M-PESA (pmt-epm-mpsa) \\
\hline & & $\begin{array}{l}\text { EFT/ Bank Transfers (pmt-epm- } \\
\text { eft) }\end{array}$ \\
\hline & & PayPal (pmt-epm-pay) \\
\hline & & PesaPal(pmt-epm-pesa) \\
\hline & & Credit card(pmt-epm-cc) \\
\hline & Challenges (chll) & $\begin{array}{l}\text { High transaction cost (pmt-chll- } \\
\text { htc) }\end{array}$ \\
\hline & & $\begin{array}{l}\text { Lack of infrastructure (pmt- } \\
\text { chll-infr) }\end{array}$ \\
\hline & & Trust issues (pmt-chll-trs) \\
\hline & & $\begin{array}{l}\text { Lack of electronic payment } \\
\text { skills(pmt-chll-skil) }\end{array}$ \\
\hline \multirow[t]{6}{*}{ 11. Human resources (hr) } & $\begin{array}{l}\text { Capacity building } \\
\text { strategies (cbs) }\end{array}$ & $\begin{array}{l}\text { Recruitment for jobs (hr-cbs- } \\
\text { rfj) }\end{array}$ \\
\hline & & External training (hr-cbs-et) \\
\hline & & $\begin{array}{l}\text { In-house training in the firm } \\
\text { (hr-cbs-iht) }\end{array}$ \\
\hline & Challenges (chll) & Skills shortages (hr-chll-ss) \\
\hline & & $\begin{array}{l}\text { High cost of training (hr-chll- } \\
\text { hct) }\end{array}$ \\
\hline & & $\begin{array}{l}\text { High mobility of skilled staff } \\
\text { (hr-chll-hmss) }\end{array}$ \\
\hline \multirow{3}{*}{$\begin{array}{l}\text { 12. Research and } \\
\text { development (res) }\end{array}$} & Strategies (str) & Innovation \\
\hline & & $\begin{array}{l}\text { Company policy and programs } \\
\text { for } R \text { and } D \text { (res-str-pol) }\end{array}$ \\
\hline & & $\begin{array}{l}\text { Curiosity, playing around, } \\
\text { experimenting (res-str-exp) }\end{array}$ \\
\hline \multirow[t]{3}{*}{ 13. Competition (cmp) } & $\begin{array}{l}\text { Sources of competition } \\
\text { (soc) }\end{array}$ & $\begin{array}{l}\text { Reduced barriers to entry } \\
\text { (cmp-soc-rbe) }\end{array}$ \\
\hline & & $\begin{array}{l}\text { Reduced cost of } \\
\text { services/products (cmp-soc- } \\
\text { rcsp) }\end{array}$ \\
\hline & & $\begin{array}{l}\text { Entry of new actors (cmp-soc- } \\
\text { enp) }\end{array}$ \\
\hline
\end{tabular}




\begin{tabular}{|c|c|c|}
\hline & & $\begin{array}{l}\text { Privatization and liberalization } \\
\text { (cmp-soc-pl) }\end{array}$ \\
\hline & & $\begin{array}{l}\text { Competing with another } \\
\text { specific country (cmp-soc-csc) }\end{array}$ \\
\hline & & $\begin{array}{l}\text { Broadcasting, clients or } \\
\text { consumers shopping around } \\
\text { too much (cmp-soc-bc) }\end{array}$ \\
\hline & & $\begin{array}{l}\text { Market efficiency/free markets } \\
\text { (cmp-soc-me) }\end{array}$ \\
\hline & & $\begin{array}{l}\text { Entrepreneurship, self- } \\
\text { reliance, private sector growth } \\
\text { (positive and negative } \\
\text { comments) (cmp-soc-ent) }\end{array}$ \\
\hline & $\begin{array}{l}\text { Causes of barriers to } \\
\text { entry (cbe) }\end{array}$ & $\begin{array}{l}\text { High start-up cost (cmp-cbe- } \\
\text { hsc) }\end{array}$ \\
\hline & & $\begin{array}{l}\text { Domination by big actors (cmp- } \\
\text { cbe-dbp) }\end{array}$ \\
\hline & & Others (cmp-cbe-oth) \\
\hline & $\begin{array}{l}\text { Causes of lowered } \\
\text { barriers to entry (clbe) }\end{array}$ & $\begin{array}{l}\text { Affordable Internet cost (cmp- } \\
\text { clbe-aic) }\end{array}$ \\
\hline & & $\begin{array}{l}\text { Formation of associations to } \\
\text { formalize informal operators } \\
\text { (cmp-clbe-fas) }\end{array}$ \\
\hline & & Others (cmp-clbe-oth) \\
\hline & Effects of ICT (eoi) & Market growth (cmp-eoi-mg) \\
\hline & & Shrinking market (cmg-eoi-sm) \\
\hline & & $\begin{array}{l}\text { No market growth (cmp-eoi- } \\
\mathrm{nmg} \text { ) }\end{array}$ \\
\hline \multirow[t]{7}{*}{$\begin{array}{l}\text { 14. Intermediation and } \\
\text { disintermediation (intd) }\end{array}$} & $\begin{array}{l}\text { Forms of } \\
\text { exploitation by } \\
\text { intermediary (foe) }\end{array}$ & High costs (intd-foe-hc) \\
\hline & & $\begin{array}{l}\text { Minimal value addedness of } \\
\text { intermediary( intd-foe-mvai) }\end{array}$ \\
\hline & & $\begin{array}{l}\text { Lack of competition (intd-foe- } \\
\text { loc) }\end{array}$ \\
\hline & $\begin{array}{l}\text { Effects of } \\
\text { intermediation (eoi) }\end{array}$ & $\begin{array}{l}\text { Actors cutting others off the } \\
\text { chain (intd-eoi-pcoc) }\end{array}$ \\
\hline & & $\begin{array}{l}\text { Customers by-passing the } \\
\text { intermediaries (intd-eoi-cbi) }\end{array}$ \\
\hline & & $\begin{array}{l}\text { New intermediaries (intd-eoi- } \\
\text { ni) }\end{array}$ \\
\hline & & Old intermediaries/persistence \\
\hline
\end{tabular}




\begin{tabular}{|c|c|c|}
\hline & & $\begin{array}{l}\text { of brokers/brokerage (intd-eoi- } \\
\text { oi) }\end{array}$ \\
\hline & & $\begin{array}{l}\text { Smaller companies competing } \\
\text { with big companies(intd-eoi- } \\
\text { scc) }\end{array}$ \\
\hline & & $\begin{array}{l}\text { Levelling the playing field (intd- } \\
\text { eoi-Ipf) }\end{array}$ \\
\hline & & $\begin{array}{l}\text { Using third party websites, } \\
\text { online directories or online } \\
\text { marketplaces to get business } \\
\text { (intd-eoi-tpw) }\end{array}$ \\
\hline & & $\begin{array}{l}\text { Wider client base/getting new } \\
\text { clients (intd-eoi-wcb) }\end{array}$ \\
\hline & & $\begin{array}{l}\text { Lowered costs (intd-eoi-Ic- } \\
\text { lowered costs) }\end{array}$ \\
\hline & $\begin{array}{l}\text { Reasons for } \\
\text { intermediation to } \\
\text { remain (reaint) }\end{array}$ & $\begin{array}{l}\text { Human touch/trust (intd- } \\
\text { reaint-ht) }\end{array}$ \\
\hline & & $\begin{array}{l}\text { Kenya is far from source } \\
\text { markets (intd-reaint-mkts) }\end{array}$ \\
\hline & & $\begin{array}{l}\text { Adoption of ICT by clients } \\
\text { (intd-reaint-adopt) }\end{array}$ \\
\hline & & $\begin{array}{l}\text { Lack of ICT infrastructure (intd- } \\
\text { reaint-infra) }\end{array}$ \\
\hline & & $\begin{array}{l}\text { Lack of adequate/ appropriate } \\
\text { content (intd-reaint-cont) }\end{array}$ \\
\hline & & $\begin{array}{l}\text { Local knowledge required is } \\
\text { large and may not be available } \\
\text { online (intd-reaint- } \\
\text { localknowldge-local knowledge } \\
\text { required is large and may not } \\
\text { be available online) }\end{array}$ \\
\hline 15. Relationships (rlt) & $\begin{array}{l}\text { Strategies for } \\
\text { formation of local } \\
\text { relationships (sflr) }\end{array}$ & $\begin{array}{l}\text { Face-to-face meetings or } \\
\text { contacts (rlt-sflr-ffm) }\end{array}$ \\
\hline & & $\begin{array}{l}\text { Offline reputation or online } \\
\text { reputation (rlt-sflr-ofonr) }\end{array}$ \\
\hline & & $\begin{array}{l}\text { Private sector association and } \\
\text { coordination (rlt-sflr-psc) }\end{array}$ \\
\hline & & $\begin{array}{l}\text { Relationships and interactions } \\
\text { between businesses/referrals } \\
\text { (rlt-sflr-ref) }\end{array}$ \\
\hline & & Sales team (rlt-sflr-st-sales \\
\hline
\end{tabular}




\begin{tabular}{|c|c|c|}
\hline & & team) \\
\hline & $\begin{array}{l}\text { Strategies for } \\
\text { formation of regional } \\
\text { and global relationships } \\
\text { (sfgr) }\end{array}$ & Diaspora (rlt-sfgr-dsp) \\
\hline & & $\begin{array}{l}\text { Trade shows / trade fairs (rlt- } \\
\text { sfgr-ts) }\end{array}$ \\
\hline & & $\begin{array}{l}\text { Partnerships with } \\
\text { multinationals (rlt-sfgr-pat) }\end{array}$ \\
\hline & & $\begin{array}{l}\text { Face-to-face meeting (rlt-sfgr- } \\
\text { ffm-face to face meeting) }\end{array}$ \\
\hline & & $\begin{array}{l}\text { Sales team (rlt-sfgr-st-sales } \\
\text { team) }\end{array}$ \\
\hline & & $\begin{array}{l}\text { Overseas offices (rlt-sfgr-ovo- } \\
\text { overseas offices) }\end{array}$ \\
\hline & & $\begin{array}{l}\text { Representative offices (rlt-sfgr- } \\
\text { ro-representative office) }\end{array}$ \\
\hline & $\begin{array}{l}\text { Strategies to build trust } \\
\text { (sbt) }\end{array}$ & Physical visits (rlt-sbt-pv) \\
\hline & & Background checks (rlt-sbt-bc) \\
\hline & & Referrals (rlt-sbt-ref) \\
\hline & $\begin{array}{l}\text { Challenges of } \\
\text { relationships (cor) }\end{array}$ & Trust (rlt-cor-trst) \\
\hline & & Distance (rlt-cor-dist) \\
\hline & $\begin{array}{l}\text { Reason for relationship } \\
\text { (reason) }\end{array}$ & Client (rlt-reason-client) \\
\hline & & Supplier (rlt-reason-supplier) \\
\hline & & $\begin{array}{l}\text { Outsourcing (rlt-reason- } \\
\text { outsourcing) }\end{array}$ \\
\hline \multirow{5}{*}{$\begin{array}{l}\text { 16. Geography (local scale) } \\
\text { (geol) }\end{array}$} & Offline visibility (ov) & Office location (geol-ov-ol) \\
\hline & & Advertising (geol-ov-adv) \\
\hline & $\begin{array}{l}\text { Effects on geography } \\
\text { (eff) }\end{array}$ & Local spill-over (geol-eff-Iso) \\
\hline & & Urbanization (geol-eff-urb) \\
\hline & & $\begin{array}{l}\text { Perceptions of local exclusion } \\
\text { or disconnects (geol-eff-ple) }\end{array}$ \\
\hline \multirow[t]{2}{*}{$\begin{array}{l}\text { 17. Geography (global and } \\
\text { regional scale)(geog) }\end{array}$} & $\begin{array}{l}\text { Effects on } \\
\text { geography(eff) }\end{array}$ & $\begin{array}{l}\text { Ideas about closeness or } \\
\text { distance (geog-eff-iad) }\end{array}$ \\
\hline & & $\begin{array}{l}\text { Regional integration or East } \\
\text { African community (geog-eff- } \\
\text { eac) }\end{array}$ \\
\hline
\end{tabular}




\begin{tabular}{|c|c|c|}
\hline & & $\begin{array}{l}\text { Scaling up into new areas } \\
\text { (geog-eff-sna) }\end{array}$ \\
\hline & & $\begin{array}{l}\text { Locations of sellers and } \\
\text { changing location of sellers } \\
\text { (geog-eff-los) }\end{array}$ \\
\hline & & $\begin{array}{l}\text { Globalization and mention of } \\
\text { the word "global" or } \\
\text { "worldwide" (geog-eff-glo) }\end{array}$ \\
\hline & & $\begin{array}{l}\text { Reconfiguring space/distance } \\
\text { (geog-eff-rs) }\end{array}$ \\
\hline & $\begin{array}{l}\text { Location of customers } \\
\text { (loc) }\end{array}$ & Global (geo-loc-global) \\
\hline & & Regional (geo-loc-regional) \\
\hline & & Local (geo-loc-local) \\
\hline \multirow[t]{10}{*}{$\begin{array}{l}\text { 18. Historical comparisons } \\
\text { (his) }\end{array}$} & $\begin{array}{l}\text { Types of Internet } \\
\text { access (tia) }\end{array}$ & Dial Up (his-tia-du) \\
\hline & & VSAT (his-tia-vsat) \\
\hline & & Radio (his-tia-rd-radio) \\
\hline & & Wireless(his-tia-wl-wireless) \\
\hline & $\begin{array}{l}\text { Forms of } \\
\text { communication (fc) }\end{array}$ & Fax (his-fc-fax) \\
\hline & & Courier (his-fc-crr) \\
\hline & & Post office (his-fc-po) \\
\hline & & $\begin{array}{l}\text { Walkie talkies (radio calls) (his- } \\
\text { fc-rc) }\end{array}$ \\
\hline & Cost of service (cs) & Travel costs (his-cs-tc) \\
\hline & & Operation costs (his-cs-oc) \\
\hline \multirow[t]{8}{*}{ 19. Policies (pol) } & $\begin{array}{l}\text { Strategies to improve } \\
\text { sector (str) }\end{array}$ & Cost of Internet(his-cs-ci) \\
\hline & & Economic growth (pol-str-eg) \\
\hline & & $\begin{array}{l}\text { Government policies (pol-str- } \\
\text { gp) }\end{array}$ \\
\hline & & $\begin{array}{l}\text { Vision } 2020 \text { and Vision } 2030 \\
\text { (pol-str-vs) }\end{array}$ \\
\hline & & $\begin{array}{l}\text { Education policy/education in } \\
\text { schools/universities (pol-str- } \\
\text { ep) }\end{array}$ \\
\hline & & $\begin{array}{l}\text { National representation and } \\
\text { national branding (pol-str-nr) }\end{array}$ \\
\hline & $\begin{array}{l}\text { Politics and elections } \\
\text { (ele) }\end{array}$ & Positive effects (pol-ele-pe) \\
\hline & & Negative effects(pol-ele-ne) \\
\hline
\end{tabular}




\begin{tabular}{|c|c|c|}
\hline & $\begin{array}{l}\text { Relationships or } \\
\text { interactions (rel) }\end{array}$ & $\begin{array}{l}\text { Relationships with suppliers? } \\
\text { (pol-rel-rws) }\end{array}$ \\
\hline & & $\begin{array}{l}\text { Relationships with customers } \\
\text { (pol-rel-rwc) }\end{array}$ \\
\hline & $\begin{array}{l}\text { Relationship with } \\
\text { government (relgov) }\end{array}$ & $\begin{array}{l}\text { Not supportive (pol-relgov- } \\
\text { notsupp) }\end{array}$ \\
\hline & & Neutral (pol-relgov-neut) \\
\hline & & $\begin{array}{l}\text { Highly supportive (pol-relgov- } \\
\text { hisupp) }\end{array}$ \\
\hline & $\begin{array}{l}\text { Corruption/ favouritism } \\
\text { (corr) }\end{array}$ & High (pol-corr-hi) \\
\hline & & Medium (pol-corr-med) \\
\hline & & Low (pol-corr-low) \\
\hline & Policy effects (pef) & $\begin{array}{l}\text { Positive, give strategic } \\
\text { direction (pol-pef-pos) }\end{array}$ \\
\hline & & Neutral (pol-pef-neu) \\
\hline & & $\begin{array}{l}\text { No policy, no direction (pol- } \\
\text { pef-nodi) }\end{array}$ \\
\hline \multirow[t]{12}{*}{ 20. Role (rol) } & KWS (kws) & $\begin{array}{l}\text { Product development (rol-kws- } \\
\text { prodev) }\end{array}$ \\
\hline & & Regulatory (rol-kws-reg) \\
\hline & Government( gov) & $\begin{array}{l}\text { Policy development ( rol-gov- } \\
\text { poldev) }\end{array}$ \\
\hline & & $\begin{array}{l}\text { Low Financial support (rol-gov- } \\
\text { lowfinsupp) }\end{array}$ \\
\hline & & $\begin{array}{l}\text { High financial support (rol- } \\
\text { gov-highfinsupp) }\end{array}$ \\
\hline & $\begin{array}{l}\text { Tourism associations } \\
\text { (ta) }\end{array}$ & $\begin{array}{l}\text { Lobby government (rol-ta- } \\
\text { lobgov) }\end{array}$ \\
\hline & & $\begin{array}{l}\text { Lobby members (rol-ta- } \\
\text { lobmem) }\end{array}$ \\
\hline & & $\begin{array}{l}\text { Lobby other stakeholders (rol- } \\
\text { ta-lobsta) }\end{array}$ \\
\hline & & Supportive (rol-ta-supp) \\
\hline & & Not Supportive(rol-ta-notsupp) \\
\hline & Private sector (ps) & Supportive (rol-ps-supp) \\
\hline & & $\begin{array}{l}\text { Not supportive (rol-ps- } \\
\text { notsupp) }\end{array}$ \\
\hline \multirow[t]{3}{*}{$\begin{array}{l}\text { 21. Tourism product } \\
\text { (toupro) }\end{array}$} & $\begin{array}{l}\text { Conference tourism } \\
\text { (conf) }\end{array}$ & Growing (toupro-conf-gro) \\
\hline & & Stagnant (toupro-conf-stag) \\
\hline & & Shrinking (toupro-conf-shr) \\
\hline
\end{tabular}




\begin{tabular}{|l|l|l|}
\hline & Eco tourism (eco) & Growing (toupro-eco-gro) \\
\hline & & Stagnant (toupro-eco-stag) \\
\hline & & Shrinking (toupro-eco-shr) \\
\hline & Beach / hotel (bea) & Growing (toupro-bea-gro) \\
\hline & & Stagnant (toupro-bea-stag) \\
\hline & Parks (par) & Shrinking (toupro-bea-shr) \\
\hline & & Growing (toupro-par-gro) \\
\hline & Stagnant (toupro-par-stag) \\
\hline & Type of products (prod) & Shrinking (toupro-par-shr) \\
\hline & & Beach (tourpro-prod-beach) \\
\hline & & Parks (tourpro-prod-hotel) \\
\hline & & $\begin{array}{l}\text { Eco tourism (tourpro-prod- } \\
\text { ecotourism) }\end{array}$ \\
\hline & $\begin{array}{l}\text { Private villas (tourpro-prod- } \\
\text { villas) }\end{array}$ \\
\hline & Sports (tourpro-prod-sports) \\
\hline & & $\begin{array}{l}\text { Cultural (tourpro-prod-cultural) } \\
\text { Mountains (tourpro-prod- } \\
\text { mountains) }\end{array}$ \\
\hline & & $\begin{array}{l}\text { Conference tourism (tourpro- } \\
\text { prod-conference) }\end{array}$ \\
\hline & $\begin{array}{l}\text { Medical tourism (tourpro- } \\
\text { prod-medical-medical tourism) }\end{array}$ \\
\hline & &
\end{tabular}

\section{A1.2: Tea Sector Codes}

\begin{tabular}{|c|c|c|}
\hline Grand Parent Themes & Parent Themes & Codable Themes \\
\hline \multirow[t]{7}{*}{ Connectivity (con) } & $\begin{array}{l}\text { Bandwidth/speed } \\
\text { (bnd) }\end{array}$ & 5-10 Mbps (cn-bnd-5to10-5-10 Mbps) \\
\hline & & 2-5 Mbps (cn-bnd-2to5-2-5 Mbps) \\
\hline & & 1-2 Mps (cn-bnd-1to2-1-2 Mps) \\
\hline & & $\begin{array}{l}\text { Below } 1 \text { Mbps (cn-bnd-blw1-Below } 1 \\
\text { Mbps) }\end{array}$ \\
\hline & Challenges (chl) & $\begin{array}{l}\text { Increased competition (con-chl-ic- } \\
\text { increased competition) }\end{array}$ \\
\hline & & $\begin{array}{l}\text { Disintermediation (con-chl-dis- } \\
\text { disintermediation) }\end{array}$ \\
\hline & & $\begin{array}{l}\text { Technical barriers, including reliability } \\
\text { (con-chl-tecb-technical barriers, including }\end{array}$ \\
\hline
\end{tabular}




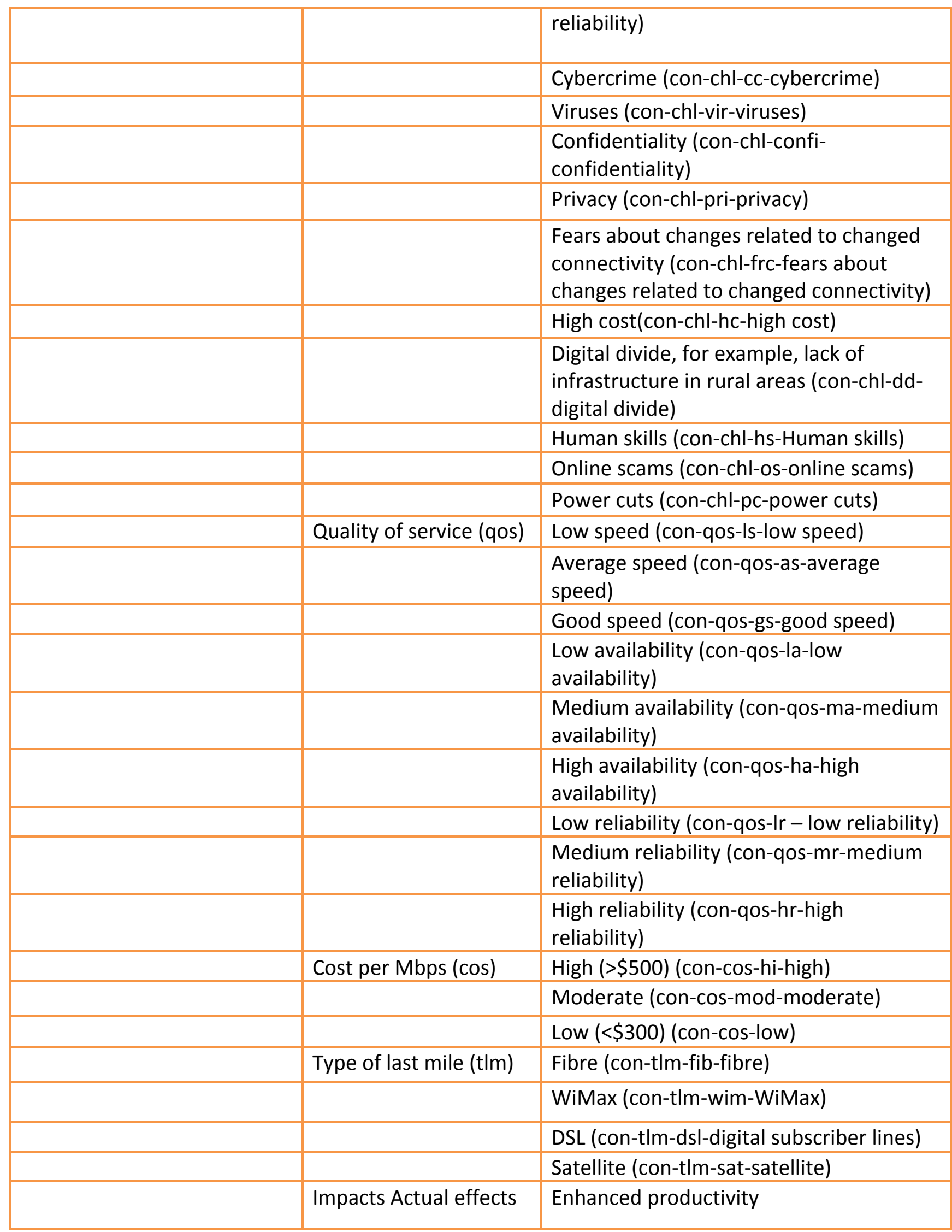




\begin{tabular}{|c|c|c|}
\hline & (act) & (con-act-ep-enhanced productivity) \\
\hline & & $\begin{array}{l}\text { Increased efficiency } \\
\text { (con-act-ie-increased efficiency ) }\end{array}$ \\
\hline & & $\begin{array}{l}\text { Reduced cost } \\
\text { (con-act-rc-reduced cost) }\end{array}$ \\
\hline & & Reduced fraud (con-act-rf-reduced fraud) \\
\hline & $\begin{array}{l}\text { Expected or hoped } \\
\text { effects of connectivity }\end{array}$ & Better speeds (con-ee-bs-better speeds) \\
\hline & & $\begin{array}{l}\text { Reduced Internet costs (con-ee-ric- } \\
\text { Reduced Internet costs) }\end{array}$ \\
\hline & $\begin{array}{l}\text { Changing tasks, } \\
\text { strategies or } \\
\text { opportunities (cts) }\end{array}$ & New jobs (con-cts-nj-new jobs) \\
\hline & & $\begin{array}{l}\text { New strategies (con-cts-ns-new } \\
\text { strategies) }\end{array}$ \\
\hline & & $\begin{array}{l}\text { New businesses (con-cts-nb-new } \\
\text { businesses) }\end{array}$ \\
\hline & & $\begin{array}{l}\text { New markets/ Market growth (con-cts- } \\
\text { nm-new markets/ Market growth) }\end{array}$ \\
\hline & $\begin{array}{l}\text { Unintended } \\
\text { consequences of } \\
\text { connectivity (ucc) }\end{array}$ & $\begin{array}{l}\text { Creation of new jobs (con-ucc-cnj- } \\
\text { Creation of new jobs) }\end{array}$ \\
\hline & & $\begin{array}{l}\text { Enhanced jobs (con-ucc-ej-enhanced } \\
\text { jobs) }\end{array}$ \\
\hline & $\begin{array}{l}\text { Ideas about } \\
\text { connectivity (ic) }\end{array}$ & $\begin{array}{l}\text { Increased cost??? (con-ucc-ic-increased } \\
\text { cost) }\end{array}$ \\
\hline & & Fast Internet (con-ic-fi-fast Internet) \\
\hline & $\begin{array}{l}\text { Unique and interesting } \\
\text { metaphors for the } \\
\text { Internet (met) }\end{array}$ & $\begin{array}{l}\text { Super highway (con-met-sh-super } \\
\text { highway) }\end{array}$ \\
\hline & & WWW (con-met-www) \\
\hline Image/ representation (ir) & Positive effects (pe) & $\begin{array}{l}\text { Enhanced awareness (ir-pe-ea-enhanced } \\
\text { awareness) }\end{array}$ \\
\hline & & $\begin{array}{l}\text { Increased customers (ir-pe-ic-increased } \\
\text { customers) }\end{array}$ \\
\hline $\begin{array}{l}\text { Electronic communication } \\
\text { (ec) }\end{array}$ & $\begin{array}{l}\text { Forms of electronic } \\
\text { communication (fec) }\end{array}$ & E-mail (ec-fec-eml-E-mail) \\
\hline & & Phone (ec-fec-phn-phone) \\
\hline & & Skype (ec-fec-skyp-Skype) \\
\hline & & Social media (ec-fec-sm-social media) \\
\hline
\end{tabular}




\begin{tabular}{|c|c|c|}
\hline & & $\begin{array}{l}\text { Video conferencing (ec-fec-vc-video } \\
\text { conferencing) }\end{array}$ \\
\hline & & $\begin{array}{l}\text { voice over Internet protocol (ec-fec-voip- } \\
\text { voice over internet protocol) }\end{array}$ \\
\hline & & $\begin{array}{l}\text { Teleconferencing (ec-fec-tc- } \\
\text { teleconferencing) }\end{array}$ \\
\hline & $\begin{array}{l}\text { Effects of electronic } \\
\text { communication (eec) }\end{array}$ & $\begin{array}{l}\text { Faster speed of reply (ec-eec-fsr-faster } \\
\text { speed of reply) }\end{array}$ \\
\hline & & Reduced cost (ec-fec-rc-reduced cost) \\
\hline & & $\begin{array}{l}\text { Access to wider audience (ec-fec-awa- } \\
\text { access to wider audience) }\end{array}$ \\
\hline & & $\begin{array}{l}\text { Widened geographical reach (ec-fec-wgr- } \\
\text { widened geographical reach) }\end{array}$ \\
\hline Access to customers (ac) & Offline access (ofa) & ac-ofa-exh-exhibitions \\
\hline & & ac-ofa-prt-other partners \\
\hline & & ac-ofa-rc-referral from other customers \\
\hline & & ac-ofa-ts-trade shows \\
\hline & & ac-ofa-recl-repeat clients \\
\hline & Online access (ona) & ac-ona-blgs-personal blogs \\
\hline & & ac-ona-eml-email \\
\hline & & ac-ona-rc-referrals from other customers \\
\hline & & ac-ona-sn-social networks \\
\hline & & ac-ona-web-websites \\
\hline & & ac-ona-YouTube \\
\hline & $\begin{array}{l}\text { What convinces } \\
\text { customers to sign in } \\
\text { (wcc) }\end{array}$ & $\begin{array}{l}\text { Fast email response to customer queries } \\
\text { (ac-wcc-frcq-fast email response to } \\
\text { customer queries) }\end{array}$ \\
\hline & & $\begin{array}{l}\text { Good reputation (ac-wcc-gr-good } \\
\text { reputation) }\end{array}$ \\
\hline & & Quality service (ac-wcc-qs-quality service) \\
\hline & & $\begin{array}{l}\text { Provision of adequate information to } \\
\text { make decision (ac-wcc-pai-provision of } \\
\text { adequate information to make decision) }\end{array}$ \\
\hline & & Low cost (ac-wcc-lc-low cost) \\
\hline Access to information (ai) & $\begin{array}{l}\text { Means of access to } \\
\text { general information } \\
\text { (mai) }\end{array}$ & Websites (ai-mai-web-websites) \\
\hline & & $\begin{array}{l}\text { Social networks (Linkedln, Facebook, } \\
\text { Twitter) (ai-mai-sn-social networks) }\end{array}$ \\
\hline & & Brochures (ai-mai-broc-brochure) \\
\hline & & $\begin{array}{l}\text { Exhibitions and trade shows (face-to-face) } \\
\text { (ai-mai-exh-Exhibitions and trade shows) }\end{array}$ \\
\hline
\end{tabular}




\begin{tabular}{|c|c|c|}
\hline & & Newspapers (ai-mai-pm-newspapers) \\
\hline & $\begin{array}{l}\text { Positive effects of } \\
\text { access to information } \\
\text { (peai) }\end{array}$ & Open access (ai-peai-oa-open access) \\
\hline & & $\begin{array}{l}\text { Increased customers (ai-peai-ic-increased } \\
\text { customers) }\end{array}$ \\
\hline \multirow[t]{7}{*}{ Classification (cls) } & $\begin{array}{l}\text { Forms of branding } \\
\text { (fob) }\end{array}$ & $\begin{array}{l}\text { Online branding (cls-fob-onb-online } \\
\text { branding) }\end{array}$ \\
\hline & & $\begin{array}{l}\text { Offline branding (cls-fob-offb-offline } \\
\text { branding) }\end{array}$ \\
\hline & $\begin{array}{l}\text { Types of certifications } \\
\text { (toc) }\end{array}$ & Fair-trade (cls-toc-ft-fair-trade) \\
\hline & & $\begin{array}{l}\text { Rain-forest Alliance (cls-toc-rfa-Rainforest } \\
\text { Alliance) }\end{array}$ \\
\hline & & $\begin{array}{l}\text { Ethical tea partnership (cls-toc-etp-ethical } \\
\text { tea partnership) }\end{array}$ \\
\hline & $\begin{array}{l}\text { Effects of certifications } \\
\text { (eoc) }\end{array}$ & Better prices (cls-eoc-bp-better prices) \\
\hline & & $\begin{array}{l}\text { Ready customers for commodity (cls-eoc- } \\
\text { rcc-ready customers for commodity) }\end{array}$ \\
\hline \multirow[t]{7}{*}{ Online presence (op) } & Strategies (str) & Websites (op-str-web-websites) \\
\hline & & $\begin{array}{l}\text { Social media and social networks (op-str- } \\
\text { sm-social networks) }\end{array}$ \\
\hline & & $\begin{array}{l}\text { Online advertisements (op-str-oa-online } \\
\text { advertisements) }\end{array}$ \\
\hline & & $\begin{array}{l}\text { Web presence on third party sites or } \\
\text { platforms like (op-str-tpw-web presence } \\
\text { on third party sites) }\end{array}$ \\
\hline & $\begin{array}{l}\text { Effects of online } \\
\text { presence (eop) }\end{array}$ & $\begin{array}{l}\text { Enhanced visibility (op-eop-ev-enhanced } \\
\text { visibility) }\end{array}$ \\
\hline & & $\begin{array}{l}\text { Reduced cost of marketing (op-str-rcm- } \\
\text { reduced cost of marketing) }\end{array}$ \\
\hline & & Others (op-str-oth-others) \\
\hline \multirow[t]{7}{*}{ Costs (cos) } & Start-up costs (suc) & High (cos-suc-hi-high) \\
\hline & & Moderate (cos-suc-mod-moderate) \\
\hline & & Low (cos-suc-low) \\
\hline & $\begin{array}{l}\text { Impact of Internet on } \\
\text { operational costs (ioc) }\end{array}$ & $\begin{array}{l}\text { Radically reduce (cos-ioc-rr-radically } \\
\text { reduce) }\end{array}$ \\
\hline & & Reduce (cos-ioc-red-reduce) \\
\hline & & No change (cos-ioc-nc-no change) \\
\hline & & Increase cost (cos-ioc-ic-increase cost) \\
\hline
\end{tabular}




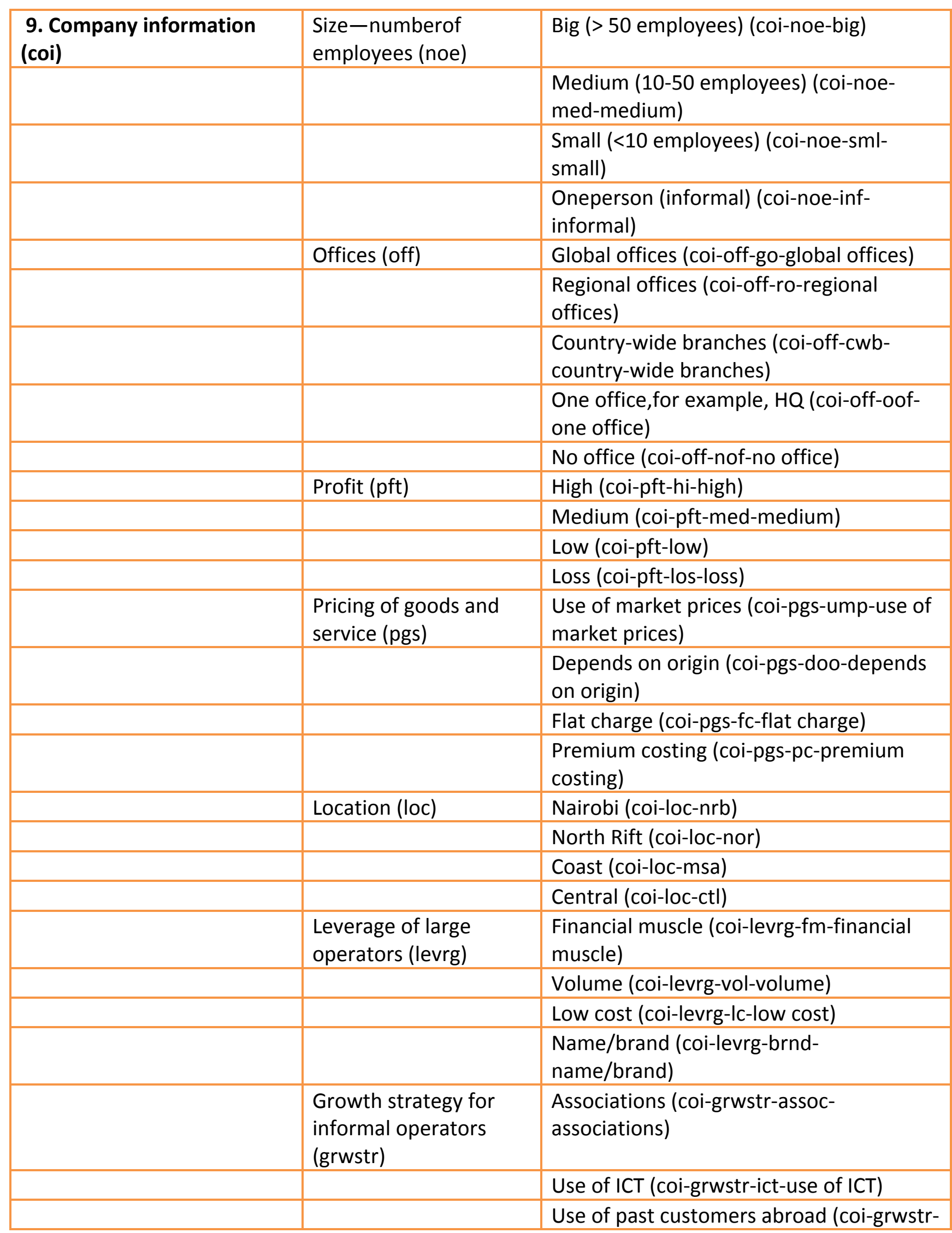




\begin{tabular}{|c|c|c|}
\hline & & prcust-use of past customers abroad) \\
\hline \multirow[t]{9}{*}{ 10. Payment (pmt) } & $\begin{array}{l}\text { Electronic payment } \\
\text { methods (epm) }\end{array}$ & M-PESA (pmt-epm-mpsa-MPESA) \\
\hline & & $\begin{array}{l}\text { Electronic banking billboard /bank } \\
\text { transfers (pmt-epm-ebb-electronic } \\
\text { banking billboard) }\end{array}$ \\
\hline & & PayPal (pmt-epm-pay-PayPal) \\
\hline & & PesaPal(pmt-epm-pesa-PesaPal() \\
\hline & & Credit card(pmt-epm-cc-credit card) \\
\hline & Challenges (chll) & $\begin{array}{l}\text { High transaction cost (pmt-chll-htc-high } \\
\text { transaction cost) }\end{array}$ \\
\hline & & $\begin{array}{l}\text { Lack of infrastructure (pmt-chll-infr-lack } \\
\text { of infrastructure) }\end{array}$ \\
\hline & & Trust issues (pmt-chll-trs-trust issues) \\
\hline & & $\begin{array}{l}\text { Lack of electronic payment skills (pmt- } \\
\text { chll-skil-lack of electronic payment skills) }\end{array}$ \\
\hline \multirow[t]{6}{*}{ 11. Human resources (hr) } & $\begin{array}{l}\text { Capacity building } \\
\text { strategies (cbs) }\end{array}$ & $\begin{array}{l}\text { Recruitment for jobs (hr-cbs-rfj- } \\
\text { recruitment for jobs) }\end{array}$ \\
\hline & & $\begin{array}{l}\text { External training (hr-cbs-et-external } \\
\text { training) }\end{array}$ \\
\hline & & $\begin{array}{l}\text { In-house training in the firm (hr-cbs-iht- } \\
\text { in-house training in the firm) }\end{array}$ \\
\hline & Challenges (chll) & $\begin{array}{l}\text { Skills shortages (hr-chll-ss-skills } \\
\text { shortages) }\end{array}$ \\
\hline & & $\begin{array}{l}\text { High cost of training (hr-chll-hct-high cost } \\
\text { of training) }\end{array}$ \\
\hline & & $\begin{array}{l}\text { High mobility of skilled staff (hr-chll- } \\
\text { hmss-high mobility of skilled staff) }\end{array}$ \\
\hline \multirow{3}{*}{$\begin{array}{l}\text { 12. Research and } \\
\text { development (res) }\end{array}$} & Strategies (str) & Innovation (res-str-inno-innovation) \\
\hline & & $\begin{array}{l}\text { Company policy and programs for } \mathrm{R} \text { and } \\
\mathrm{D} \text { (res-str-pol-company policy and } \\
\text { programs for research and development) }\end{array}$ \\
\hline & & $\begin{array}{l}\text { Curiosity, playing around, experimenting } \\
\text { (res-str-exp-curiosity, playing around, } \\
\text { experimenting) }\end{array}$ \\
\hline \multirow[t]{2}{*}{ 14. Competition (cmp) } & $\begin{array}{l}\text { Sources of competition } \\
\text { (soc) }\end{array}$ & $\begin{array}{l}\text { Reduced barriers to entry (cmp-soc-rbe- } \\
\text { reduced barriers to entry) }\end{array}$ \\
\hline & & $\begin{array}{l}\text { Reduced cost of services/products (cmp- } \\
\text { soc-rcsp-reduced cost of } \\
\text { services/products) }\end{array}$ \\
\hline
\end{tabular}




\begin{tabular}{|c|c|c|}
\hline & & $\begin{array}{l}\text { Entry of new actors (cmp-soc-enp-entry } \\
\text { of new actors) }\end{array}$ \\
\hline & & $\begin{array}{l}\text { Privatization and liberalization (cmp-soc- } \\
\text { pl-privatization and liberalization) }\end{array}$ \\
\hline & & $\begin{array}{l}\text { Competing with another specific country } \\
\text { (cmp-soc-csc-competing with another } \\
\text { specific country) }\end{array}$ \\
\hline & & $\begin{array}{l}\text { Broadcasting, clients or consumers } \\
\text { shopping around too much(cmp-soc-bc- } \\
\text { broadcasting, clients or consumers } \\
\text { shopping around too much) }\end{array}$ \\
\hline & & $\begin{array}{l}\text { Market efficiency/free markets (cmp-soc- } \\
\text { me-market efficiency/free markets) }\end{array}$ \\
\hline & $\begin{array}{l}\text { Causes of barriers to } \\
\text { entry (cbe) }\end{array}$ & $\begin{array}{l}\text { High start-up cost (cmp-cbe-hsc-high start } \\
\text { up cost) }\end{array}$ \\
\hline & & $\begin{array}{l}\text { Domination by big actors (cmp-cbe-dbp- } \\
\text { domination by big actors) }\end{array}$ \\
\hline & & Others (cmp-cbe-oth-others) \\
\hline & $\begin{array}{l}\text { Causes of lowered } \\
\text { barriers to entry (clbe) }\end{array}$ & $\begin{array}{l}\text { Affordable Internet cost (cmp-clbe-aic- } \\
\text { affordable Internet cost) }\end{array}$ \\
\hline & & $\begin{array}{l}\text { Formation of associations to formalize } \\
\text { informal operators (cmp-clbe-fas- } \\
\text { formation of associations to formalize } \\
\text { informal operators) }\end{array}$ \\
\hline & & Others (cmp-clbe-oth-others) \\
\hline & Effects of ICT (eoi) & $\begin{array}{l}\text { Market growth (cmp-eoi-mg-market } \\
\text { growth) }\end{array}$ \\
\hline & & $\begin{array}{l}\text { Shrinking market (cmg-eoi-sm-shrinking } \\
\text { market) }\end{array}$ \\
\hline & & $\begin{array}{l}\text { No market growth (cmp-eoi-nmg-no } \\
\text { market growth) }\end{array}$ \\
\hline \multirow[t]{4}{*}{$\begin{array}{l}\text { 15. Intermediation and } \\
\text { disintermediation (intd) }\end{array}$} & $\begin{array}{l}\text { Forms of } \\
\text { exploitation by } \\
\text { intermediary (foe) }\end{array}$ & High costs (intd-foe-hc-high costs) \\
\hline & & $\begin{array}{l}\text { Minimal value addedness of intermediary } \\
\text { ( intd-foe-mvai-minimal value addedness } \\
\text { of intermediary) }\end{array}$ \\
\hline & & $\begin{array}{l}\text { Lack of competition (intd-foe-loc-lack of } \\
\text { competition) }\end{array}$ \\
\hline & $\begin{array}{l}\text { Effects of } \\
\text { intermediation (eoi) }\end{array}$ & $\begin{array}{l}\text { Actors cutting others off the chain (intd- } \\
\text { eoi-pcoc-actors cutting others off the }\end{array}$ \\
\hline
\end{tabular}




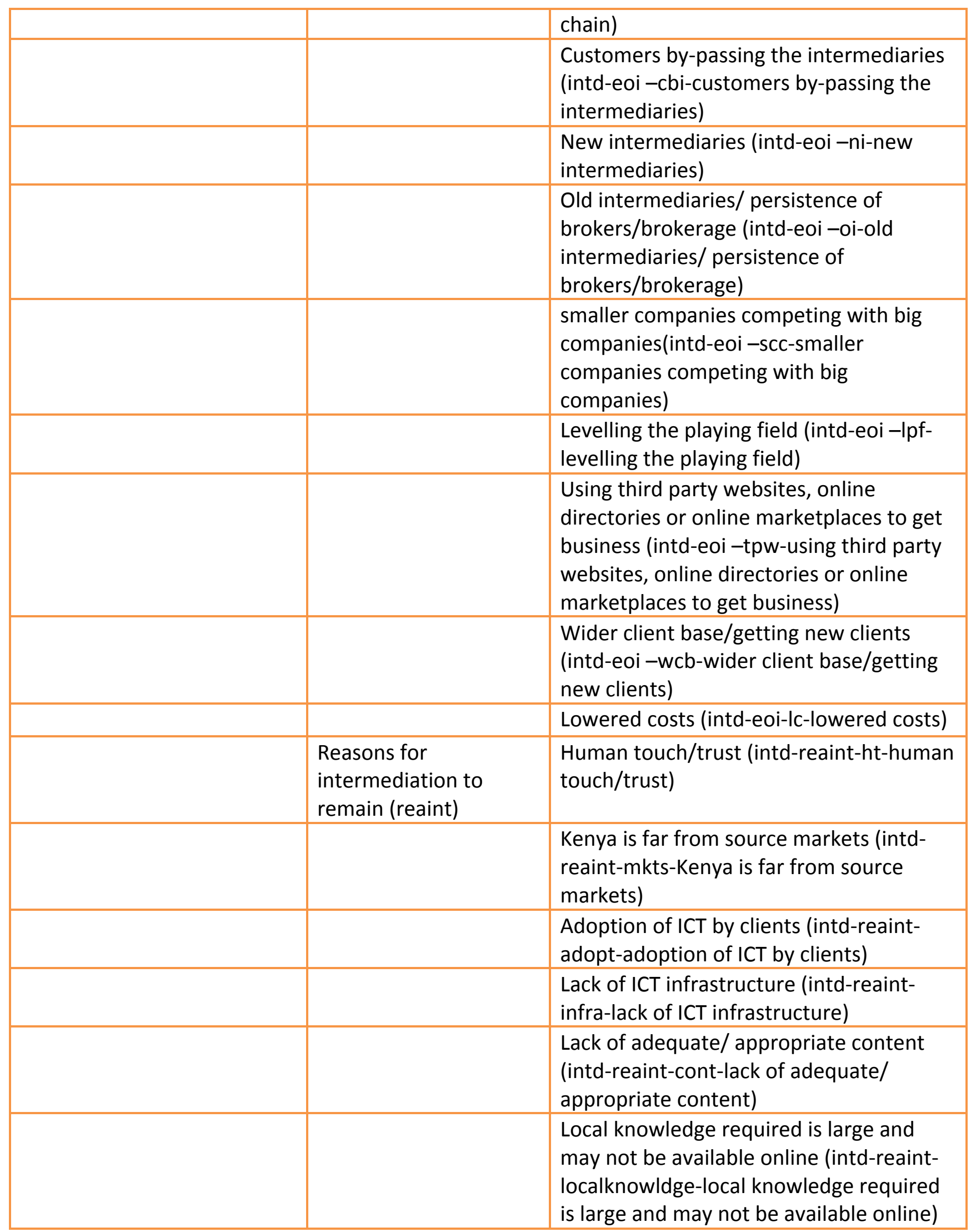




\begin{tabular}{|c|c|c|}
\hline 16. Relationships (rlt) & $\begin{array}{l}\text { Strategies for } \\
\text { formation of local } \\
\text { relationships (sflr) }\end{array}$ & $\begin{array}{l}\text { Face-to-face meetings or contacts (rlt- } \\
\text { sflr-ffm-face to face meetings or contacts) }\end{array}$ \\
\hline & & $\begin{array}{l}\text { Offline reputation or online reputation } \\
\text { (rlt-sflr-ofonr-offline reputation or online } \\
\text { reputation) }\end{array}$ \\
\hline & & $\begin{array}{l}\text { Private sector association and } \\
\text { coordination (rlt-sflr-psc-private sector } \\
\text { association and coordination) }\end{array}$ \\
\hline & & $\begin{array}{l}\text { Relationships and interactions between } \\
\text { businesses/referrals (rlt-sflr-ref- } \\
\text { relationships and interactions between } \\
\text { businesses/referrals) }\end{array}$ \\
\hline & & Sales team (rlt-sflr-st-sales team) \\
\hline & $\begin{array}{l}\text { Strategies for } \\
\text { formation of regional } \\
\text { and global } \\
\text { relationships (sfgr) }\end{array}$ & Diaspora (rlt-sfgr-dsp-diaspora) \\
\hline & & $\begin{array}{l}\text { Trade shows / trade fairs (rlt-sfgr-ts-trade } \\
\text { shows / trade fairs) }\end{array}$ \\
\hline & & $\begin{array}{l}\text { Partnerships with multinationals (rlt-sfgr- } \\
\text { pat-partnerships with multinationals) }\end{array}$ \\
\hline & & $\begin{array}{l}\text { Face-to-face meeting (rlt-sfgr-ffm-face to } \\
\text { face meeting-face to face meeting) }\end{array}$ \\
\hline & & Sales team (rlt-sfgr-st-sales team) \\
\hline & & $\begin{array}{l}\text { Overseas offices (rlt-sfgr-ovo-overseas } \\
\text { offices) }\end{array}$ \\
\hline & & $\begin{array}{l}\text { Representative offices (rlt-sfgr-ro- } \\
\text { representative office) }\end{array}$ \\
\hline & $\begin{array}{l}\text { Strategies to build trust } \\
\text { (sbt) }\end{array}$ & Physical visits (rlt-sbt-pv-physical visits) \\
\hline & & $\begin{array}{l}\text { Background checks (rlt-sbt-bc- } \\
\text { background checks) }\end{array}$ \\
\hline & & Referrals (rlt-sbt-ref-referrals) \\
\hline & $\begin{array}{l}\text { Challenges of } \\
\text { relationships (cor) }\end{array}$ & Trust (rlt-cor-trst-trust) \\
\hline & & Distance (rlt-cor-dist) \\
\hline & $\begin{array}{l}\text { Reason for relationship } \\
\text { (reason) }\end{array}$ & Client (rlt-reason-client) \\
\hline & & Supplier (rlt-reason-supplier) \\
\hline & & Outsourcing (rlt-reason-outsourcing) \\
\hline
\end{tabular}




\begin{tabular}{|c|c|c|}
\hline \multirow{5}{*}{$\begin{array}{l}\text { 17. Geography (local scale) } \\
\text { (gls) }\end{array}$} & Offline visibility (ov) & Office location (gls-ov-ol-office location) \\
\hline & & Advertising (gls l-ov-adv-advertising) \\
\hline & $\begin{array}{l}\text { Effects on geography } \\
\text { (eff) }\end{array}$ & Local spill-over (gls-eff-Iso-local spill-over) \\
\hline & & Urbanization (gls-eff-urb-urbanization) \\
\hline & & $\begin{array}{l}\text { Perceptions of local exclusion or } \\
\text { disconnects. (gls-eff-ple-perceptions of } \\
\text { local exclusion or disconnects) }\end{array}$ \\
\hline \multirow[t]{9}{*}{$\begin{array}{l}\text { 18. Geography (global and } \\
\text { regional scale)(grs) }\end{array}$} & $\begin{array}{l}\text { Effects on } \\
\text { geography(eff) }\end{array}$ & $\begin{array}{l}\text { Ideas about closeness or distance (grs-eff- } \\
\text { iad-ideas about closeness or distance) }\end{array}$ \\
\hline & & $\begin{array}{l}\text { Regional integration or East African } \\
\text { community (grs-eff-eac-regional } \\
\text { integration or East African community) }\end{array}$ \\
\hline & & $\begin{array}{l}\text { Scaling up into new areas (grs-eff-sna- } \\
\text { scaling up into new areas) }\end{array}$ \\
\hline & & $\begin{array}{l}\text { Locations of sellers and changing location } \\
\text { of sellers (grs-eff-los-locations of sellers } \\
\text { and changing location of sellers) }\end{array}$ \\
\hline & & $\begin{array}{l}\text { Globalization and mention of the word } \\
\text { "global" or "worldwide" (grs-eff-glo- } \\
\text { globalization and mention of the word } \\
\text { "global" or "worldwide") }\end{array}$ \\
\hline & & $\begin{array}{l}\text { Reconfiguring space/distance (grs-eff-rs- } \\
\text { reconfiguring space/distance) }\end{array}$ \\
\hline & $\begin{array}{l}\text { Location of customers } \\
\text { (loc) }\end{array}$ & Global (geo-loc-global) \\
\hline & & Regional (geo-loc-regional) \\
\hline & & Local (geo-loc-local) \\
\hline \multirow[t]{9}{*}{$\begin{array}{l}\text { 19. Historical comparisons } \\
\text { (his) }\end{array}$} & $\begin{array}{l}\text { Types of Internet } \\
\text { access (tia) }\end{array}$ & Dial Up (his-tia-du-dial up) \\
\hline & & VSAT (his-tia-vsat) \\
\hline & & Wireless (his-tia-wl-wireless) \\
\hline & & Radio (his-tia-rd-radio) \\
\hline & $\begin{array}{l}\text { Forms of } \\
\text { communication }(\mathrm{fc})\end{array}$ & Fax (his-fc-fax) \\
\hline & & Courier (his-fc-crr-courier) \\
\hline & & Post office (his-fc-po-post office) \\
\hline & & $\begin{array}{l}\text { Walkie Talkies (radio calls) (his-fc-rc-radio } \\
\text { calls) }\end{array}$ \\
\hline & Cost of Service (cs) & Travel Costs (his-cs-tc-travel costs) \\
\hline
\end{tabular}




\begin{tabular}{|c|c|c|}
\hline & & $\begin{array}{l}\text { Operation costs (his-cs-oc-operation } \\
\text { costs) }\end{array}$ \\
\hline & & Cost of Internet(his-cs-ci-cost of internet) \\
\hline \multirow[t]{18}{*}{ 20. Policies (pol) } & $\begin{array}{l}\text { Strategies to improve } \\
\text { sector (str) }\end{array}$ & $\begin{array}{l}\text { Economic growth (pol-str-eg-economic } \\
\text { growth) }\end{array}$ \\
\hline & & $\begin{array}{l}\text { Government policies (pol-str-gp- } \\
\text { government policies) }\end{array}$ \\
\hline & & $\begin{array}{l}\text { Vision } 2020 \text { and Vision } 2030 \text { (pol-str-vs- } \\
\text { Vision 2030) }\end{array}$ \\
\hline & & $\begin{array}{l}\text { Education policy/education in } \\
\text { schools/universities (pol-str-ep-education } \\
\text { policy) }\end{array}$ \\
\hline & & $\begin{array}{l}\text { National representation and national } \\
\text { branding (pol-str-nr-national } \\
\text { representation and national branding) }\end{array}$ \\
\hline & $\begin{array}{l}\text { Politics and elections } \\
\text { (ele) }\end{array}$ & $\begin{array}{l}\text { Positive effects (pol-ele-pe-positive } \\
\text { effects) }\end{array}$ \\
\hline & & $\begin{array}{l}\text { Negative effects(pol-ele-ne-negative } \\
\text { effects) }\end{array}$ \\
\hline & $\begin{array}{l}\text { Relationships or } \\
\text { interactions (rel) }\end{array}$ & $\begin{array}{l}\text { Relationships with suppliers? (pol-rel-rws- } \\
\text { relationships with suppliers) }\end{array}$ \\
\hline & & $\begin{array}{l}\text { Relationships with customers?? (pol-rel- } \\
\text { rwc-relationships with customers) }\end{array}$ \\
\hline & $\begin{array}{l}\text { Relationship with } \\
\text { government (relgov) }\end{array}$ & $\begin{array}{l}\text { Not supportive (pol-relgov-notsupp-not } \\
\text { supportive) }\end{array}$ \\
\hline & & Neutral (pol-relgov_neut-neutral) \\
\hline & & $\begin{array}{l}\text { Highly supportive (pol-relgov-hisupp- } \\
\text { highly supportive) }\end{array}$ \\
\hline & $\begin{array}{l}\text { Corruption/ favoritism } \\
\text { (corr) }\end{array}$ & High (pol-corr-hi-high) \\
\hline & & Medium (pol-corr-med-medium) \\
\hline & & Low (pol-corr-low) \\
\hline & Policy effects (pef) & $\begin{array}{l}\text { Positive, give strategic direction (pol-pef- } \\
\text { pos-positive, give strategic direction) }\end{array}$ \\
\hline & & Neutral (pol-pef-neu-neutral) \\
\hline & & $\begin{array}{l}\text { No policy, no direction (pol-pef-nodi-no } \\
\text { policy, no direction) }\end{array}$ \\
\hline \multirow[t]{3}{*}{$\begin{array}{l}\text { 21. Public discourse analysis } \\
\text { (pda) }\end{array}$} & $\begin{array}{l}\text { Hoped effects of } \\
\text { connectivity (hec) }\end{array}$ & Better Speeds (pda-hec-better speeds) \\
\hline & & $\begin{array}{l}\text { Economic growth (pda-hec economic } \\
\text { growth) }\end{array}$ \\
\hline & & Reduced Internet cost (pda-hec-reduced \\
\hline
\end{tabular}




\begin{tabular}{|l|l|}
\hline & \\
\hline & Internet costs) \\
\hline & Security Risk (pda-hec-security risk) \\
\hline
\end{tabular}




\section{Annex 2: Code Reliability Calculations}

\section{The Process of Calculating Inter-Coder Reliability}

A transcript was randomly selected.

The transcript was coded by each of the two coders coded separately and independently. Then a matrix was formed with codes as columns and transcript lines as rows. For each coder, a score of 1 was made if the code was present in a transcript line and with a 0 if the code was not present. This process was repeated for all codes and all the transcript lines.

A summary contingency table was formed as shown in the table below:

\section{Summary Data for Calculating Kappa Reliability Measure}

\begin{tabular}{|l|l|l|l|l|}
\hline & \multicolumn{3}{|l|}{ Coder 1 } & \\
\hline & & 1 (yes, present) & 2 (no, absent) & Total \\
\hline \multirow{2}{*}{ Coder 2} & 1(yes, present) & P11 & P12 & P1 \\
\cline { 2 - 5 } & 2(no, absent) & P21 & P22 & P2 \\
\hline & Total & P1 & P2 & \\
\hline
\end{tabular}

Key:

P11 - Number of times coder 1 and coder 2 tagged the same transcript line with the same code

P22 - Number of times both coders decided that a code does not apply to a given line of transcript

P21 - Number of times rater 1 tagged a line of transcript with a code but coder 2 did not P12 - Number of times rater 2 tagged a line of transcript with a code but coder 1 did not

The Kappa measure was calculated as

$\kappa=\frac{p_{o}-p_{e}}{1-p_{e}}$

where $p_{o}=p_{11}+p_{22}$

and $\quad p_{e}=p_{.1} p_{1}+p_{.2} p_{2} p_{e}=p_{.1} p_{1}+p_{.2} p_{2}$

In this case, the Kappa measure was calculated to determine agreement among the coders in i) identifying appropriate codes for a line of transcript and ii) agreement among the coders in identifying the theme from the concept map for the study that was manifested in a particular line of transcript.

For codes: 
The contingency table for codes was:

\begin{tabular}{|l|l|l|l|l|}
\hline & & \multicolumn{2}{|l|}{ Coder 1 } & \\
\hline & & $\begin{array}{l}1 \text { (yes, } \\
\text { present) }\end{array}$ & 2 (no, absent) & Total \\
\hline \multirow{2}{*}{ Coder 2 } & 1 (yes, present) & 5 & 62 & 67 \\
\cline { 2 - 5 } & 2 (no, absent) & 29 & 2164 & 2193 \\
\hline & Total & 34 & 2226 & 2260 \\
\hline
\end{tabular}

$K=0.37$

For code themes (using code stems):

\begin{tabular}{|l|l|l|l|l|}
\hline & & \multicolumn{2}{|l|}{ Coder 1 } & \\
\hline & & $\begin{array}{l}1 \text { (yes, } \\
\text { present) }\end{array}$ & 2 (no, absent) & Total \\
\hline \multirow{2}{*}{ Coder $\mathbf{2}$} & 1(yes, present) & 8 & 35 & 67 \\
\cline { 2 - 5 } & 2(no, absent) & 18 & 1020 & 1038 \\
\hline & Total & 26 & 1055 & 1081 \\
\hline
\end{tabular}

$\mathrm{K}=0.42$

The scale for agreement used to interpret the Kappa measure is as follows:

Poor agreement $=$ Less than 0.20

Fair agreement $=0.21$ to 0.40

Moderate agreement $=0.41$ to 0.60

Good agreement $=0.61$ to 0.80

Very good agreement $=0.81$ to 1.00

The Kappa measures for the codes, that is, 0.37 indicated fair agreement among the 2 coders. The Kappa measure for the themes was higher at 0.42 indicating moderate agreement. This is expected because there are many codes which stem from one theme and, therefore, chances of tallying are higher. But the measures for both the codes and themes were not good and, therefore, further refinement of the codes or improvement of the coding process was required.

The coding team discussed differences in coding. This resulted in new codes being introduced, some codes being merged, or codes being split. The coders' understanding of the coding process was also expected to improve since they shared reasons they coded some transcript lines as they did, thus increasing chances of convergence in their coding.

The two coders repeated coding using a new transcript which was selected randomly. Each coder coded the new transcript independently. 
Once again, the Kappa measure was calculated to determine agreement among the coders in i) identifying appropriate codes for a line of transcript and ii) agreement among the coders in identifying the theme from the concept map for the study that was manifested in a particular line of transcript.

For codes:

The contingency table for codes was:

\begin{tabular}{|l|l|l|l|l|}
\hline & & \multicolumn{2}{|l|}{ Coder 1 } & \\
\hline & & $\begin{array}{l}1 \text { (yes, } \\
\text { present) }\end{array}$ & 2 (no, absent) & Total \\
\hline \multirow{2}{*}{ Coder 2 } & 1 (yes, present) & 19 & 28 & 67 \\
\cline { 2 - 5 } & 2 (no, absent) & 8 & 425 & 433 \\
\hline & Total & 27 & 453 & 480 \\
\hline
\end{tabular}

$K=0.58$

For code stems (themes):

\begin{tabular}{|l|l|l|l|l|}
\hline & & \multicolumn{2}{|l|}{ Coder 1 } & \\
\hline & & $\begin{array}{l}1 \text { (yes, } \\
\text { present) }\end{array}$ & 2 (no, absent) & Total \\
\hline \multirow{2}{*}{ Coder $\mathbf{2}$} & 1(yes, present) & 16 & 7 & 67 \\
\cline { 2 - 5 } & 2(no, absent) & 2 & 239 & 241 \\
\hline & Total & 18 & 246 & 264 \\
\hline
\end{tabular}

$K=0.799(0.80)$

There was an improvement in agreement from the first round of coding to the next one. In terms of how coding had been done among the two coders (codes), inter-coder agreement increased from 0.37 to 0.58 . 0.58 indicates that the agreement had improved from fair to moderate.

The agreement between the coders in terms of identifying the themes manifesting in a particular line of transcript also improved from 0.42 to 0.80 . The new level of agreement of 0.80 indicates that agreement had improved from moderate to good.

The two coders again discussed their coding. In cases of disagreement, each coder indicated why coding had been done the way it was done. This led to a further refinement of the codes. The new set of codes was used to code the remaining transcripts. 
PARTICIPANTS IN THE TEA SECTOR

\begin{tabular}{|l|l|l|}
\hline & Organization & Category \\
\hline 1 & Kikuyu Highlands Tea Company & Packer \\
\hline 2 & Sasini Tea & Producer \\
\hline 3 & Knowledge Specialist and Value Chain Analyst & Value chain analyst \\
\hline 4 & Kenya Tea Development Agency & Producer \\
\hline 5 & Tea Board of Kenya & Tea association \\
\hline 6 & Nandi Tea Estates & Producer \\
\hline 7 & Eastern Produce Kenya Limited & Producer \\
\hline 8 & Prestine Solutions Limited & Tea solution provider \\
\hline 9 & James Finlay Mombasa & Buyer \\
\hline 10 & Cargill Kenya & Buyer and Warehouse operator \\
\hline 11 & Centreline Tea Brokers & Broker \\
\hline 12 & Consolidated Mombasa Limited & Warehouse operator \\
\hline 13 & East Africa Tea Trade Association (EATTA) & Tea association \\
\hline 14 & Siginon Group Limited & Transporter \\
\hline 15 & Chai Trading Company Limited & Buyer and warehouse operator \\
\hline 16 & Imperial Teas EPZ Limited & Buyer \\
\hline 17 & Venus Tea Brokers Limited & Broker \\
\hline 18 & Gokal Beverages Limited & Buyer \\
\hline 19 & Ngorongo Tea Factory & Producer \\
\hline 20 & KETEPA - Kenya Tea Packers & Packer \\
\hline 21 & Nyayo Tea Zones Development Corporation & Producer \\
\hline 22 & Karirana Tea Estates & Producer \\
\hline 23 & Home Comforts Tea & Packer \\
\hline 24 & James Finlay Kericho & Producer \\
\hline 25 & Kabianga Tea Factory & Producer \\
\hline 26 & Kapchebet Tea Factory & Producer \\
\hline 27 & Kapkatet Tea Factory & Producer \\
\hline 28 & Litein Tea Factory & Producer \\
\hline 29 & Kenya Tea Growers Association & Tea association \\
\hline 30 & Momul Tea Factory & Producer \\
\hline 31 & Unilever Tea Kenya & Producer \\
\hline 32 & Fintea Growers Cooperative Union Limited & Tea cooperative \\
\hline 33 & Ragati Tea Factory & Producer \\
\hline 34 & Gitugi Tea Factory & Producer \\
\hline 35 & Iriaini Tea Factory and Regional Office & Producer \\
\hline 36 & Kimunye Tea Factory & Producer \\
\hline 37 & Mungania Tea Factory & Producer \\
\hline 38 & Kinoro Tea Factory & Producer \\
\hline 39 & Imenti Tea Factory & Producer \\
\hline 40 & Coffee Auction & \\
\hline & & \\
\hline
\end{tabular}


PARTICIPANTS IN THE TOURISM SECTOR

\begin{tabular}{|c|c|c|}
\hline & Organization & Category \\
\hline 1. & Helinass Safaris & Tour operator \\
\hline 2. & Eco Adventures Limited & Tour operator \\
\hline 3. & Grand Edition Tours & Tour operator \\
\hline 4. & Incentive Travels & Travel agent \\
\hline 5. & Victoria Safaris & Tour operator \\
\hline 6. & Asili Adventures Limited & Tour operator \\
\hline 7. & Zaruma Safaris & Tour operator \\
\hline 8. & Leisure \& Travels & Travel agent \\
\hline 9. & Rickshaw Travels & Travel agent \\
\hline 10. & African Travel Hub & Travel agent \\
\hline 11. & Kilaguni Serena Safari Lodge & Hotel \\
\hline 12. & Tsavo West National Park & National park \\
\hline 13. & Twiga Tours & Tour operator \\
\hline 14. & Serena Hotels & Hotel \\
\hline 15. & Sarova Panafric & Hotel \\
\hline 16. & Timeless Tours \& Travels & Travel agent \\
\hline 17. & KWS Malindi Marine Park & National park \\
\hline 18. & Boat Operator & Beach operator \\
\hline 19. & Umoja Tours & Beach operator \\
\hline 20. & Boat Operator & Beach operator \\
\hline 21. & Lion In The Sun & Hotel \\
\hline 22. & Private Safaris EA & Travel agent \\
\hline 23. & Topcats Safaris & Tour operator \\
\hline 24. & Gametrackers (K) Limited & Tour operator \\
\hline 25. & Acacia Holidays & Tour operator \\
\hline 26. & Panari Hotel & Hotel \\
\hline 27. & $\begin{array}{l}\text { Kenya Association of Hotelkeepers and } \\
\text { Caterers (KAHC) }\end{array}$ & Tourism association \\
\hline 28. & Kenya Tourism Federation & Tourism association \\
\hline 29. & Palbina Tours \& Travels Limited & Travel agent \\
\hline 30. & Kenya Association Of Tour Operators & Tourism association \\
\hline 31. & Kobo Safaris & Travel agent \\
\hline 32. & Ecotourism Kenya & Tourism association \\
\hline 33. & Kenya Association of Women in Tourism & Tourism association \\
\hline 34. & Fountain Safaris & Tour operator \\
\hline 35. & Big Time Safaris & Tour operator \\
\hline 36. & Wote Safaris & Car hire/ taxi \\
\hline 37. & Universal Cabs & Car hire/ taxi \\
\hline 38. & Virgin Tours & Car hire/ taxi \\
\hline 39. & Jay Cab Services & Car hire/ taxi \\
\hline
\end{tabular}


